\title{
Um Simulador para o Sistema Visual Humano Usando Ray Tracing
}

\author{
Rogério Eduardo da Silva
}

Trientador: Prof. Dr. Luis Gustavo Nonato

Dissertação apresentada ao Instituto de Ciências Matemáticas e de Computação - ICMC-USP, como parte dos requisitos para obtenção do título de Mestre em Ciências de Computação e Matemática Computacional.

USP - São Carlos

Março/2001 
A Comissão Julgadoria:

Prof. Dr. Luis Gustavo Nonato

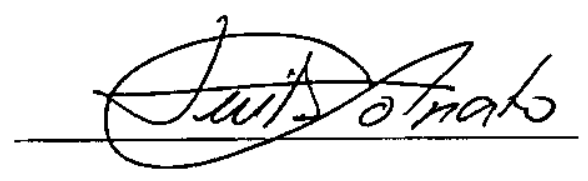

Profa. Dra. Rosane Minghim

Rosane Ningfion

Prof. Dr. Jarbas Caiado| de Castro Neto 


\section{Agradecimentos}

Gostaria de expressar meus sinceros agradecimentos aos meus pais pelo incentivo durante todas as etapas da minha vida, porém principalmente nesta, que por ser a mais recente tem especial importância na minha vida acadêmica. Aos demais familiares e amigos com quais sempre pude contar a qualquer momento.

Um agradecimento especial para Scheila, que me acompanha e apóia já a muito tempo, mas principalmente durante esta etapa extremamente difícil. Obrigado pelo carinho, amizade e paciência.

Ao meu orientador $b$ Prof. Dr. Luis Gustavo que tornou possível a realização deste trabalho. À Prof. Dra. Rosane que muito contribuiu, principalmente na fase inicial do meu curso, sem falar no apoio e amizade por ela demonstrado além dos assuntos acadêmicos. Aos demais professores do grupo: Prof. Castelo, Prof. Maria Cristina, Prof. Norberto, Prof. João os quais, através de críticas e sugestões contribuíram com esta pesquisa.

À CNPq pelo fundamental apoio financeiro.

A todos os meus cólegas Alex, Helton, Alexandre, Bruno, Veridiana, Igor, Marcelo e Dani, pela amizade que me proporcionaram, esperando que esta permaneça mesmo separados pela distância.

Aos demais que mesmo não citados, auxiliaram direta ou indiretamente na realização deste trabalho.

"A mais longa jornada começa com o primeiro passo." 


\section{Resumo}

Este trabalho descreye a criação e implementação de uma ferramenta para sinuulação do sistema visual hutnano. Tal ferramenta se baseia na nıodelagem triclimensional dos principais componentes que são responsáveis pela visão humana. A fim de modelar o caminho dos raios de luz dentro do olho utiliza-se uma técrica de computaçãa gráfica chamada ray-tracing.

O modelo proposto neste trabalho é capaz de sinnular a visão a partir de dados reais de olhos humanos, os quais são obtidos de mediçõ̃es oftalmológicas. Conno consequência disso, alguns distúrbios visuais comı miopia e hipermetropia podem ser simulados e seus efcitos sobre o sistenı visual analisados.

Os resultados obtidos dessas sinulações são apresentados e o uso da ferranıcıta enı oftalmologia é discutido. 


\section{Abstract}

This work describes the creation and implementation of a tool for simulating the human visual system. This tool is based on the modeling of the main threc-dimensional structures that are responsible for the human vision. In order to model the path of the light beam into the eye we make use of a computational technique called ray-tracing.

The model proposed in this work is able to simulate the vision from real liuman data, which can be obtained from ophthalmological measurements. As a consequence, some vision disturbs such as myopia and hypermetropia can be simulated and their effects over the visual system analyzed.

The results obtained from the simulations are presented and the use of this tool in ophthalmology is discussed. 


\section{Sumário}

1 O Olho Humanb 3

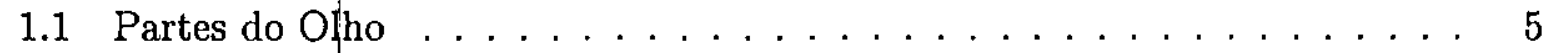

1.1 .1 A Cónnca . . . . . . . . . . . . . . . . 6

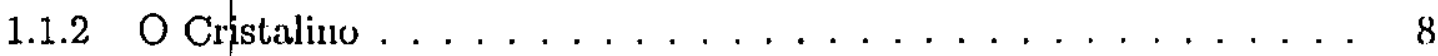

1.2 Ametropias da Visão . . . . . . . . . . . . . . . . . . . . . . . 8

1.3 Acuidade Visual . . . . . . . . . . . . . . . . . . . . . . 10

1.3.1 Critérios para Medida da Acuidade Visual . . . . . . . . . . . 12

1.3.2 Fatores que influenciam a Acuidade Visual . . . . . . . . . . 13

2 Ray-Tracing 15

2.1 Da Fotografia à Síntese de Innagens Realistas . . . . . . . . . . . . . . . 15

2.2 O Modelo de uma Câmera de Orifício . . . . . . . . . . . . . . . . 16

2.3 Algoritmo Ray-Tracing . . . . . . . . . . . . . . . . . . . . 17

2.3 .1 Pixels e Raios . . . . . . . . . . . . . . . . . . . . 18

2.3 .2 Traçado de Raios . . . . . . . . . . . . . . . . . . . . 18

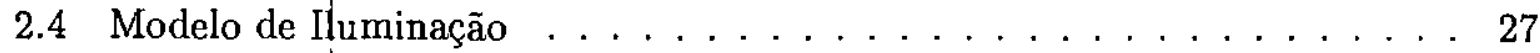

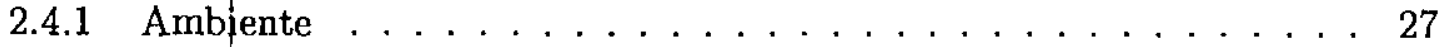

2.4 .2 Reflexão . . . . . . . . . . . . . . . . . . 28

2.4 .3 Modelo de Iluminação Local . . . . . . . . . . . . . . . . . . 31

2.4 .4 Modelo de Iluminação Global . . . . . . . . . . . . . . . . 31

2.5 Modelagem de Objetos e Superfícies . . . . . . . . . . . . . . . . 34

3 Modelagem dos Componentes envolvidos na Simulaçāo 36

3.1 O Olho . . . . . . . . . . . . . . . . . . . . 37

3.2 A Retina . . . . . . . . . . . . . . . . . . 38

3.2 .1 Multí-Resolução . . . . . . . . . . . . . . . . . . . 39

3.3 o Cristalino . . . . . . . . . . . . . . . . . . . . . 42

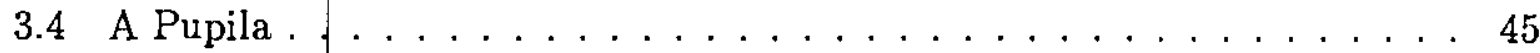

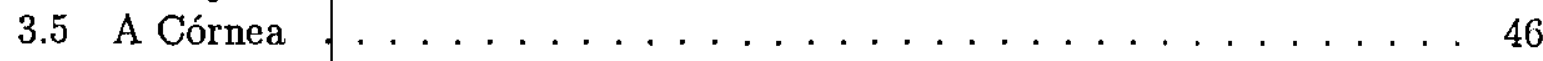

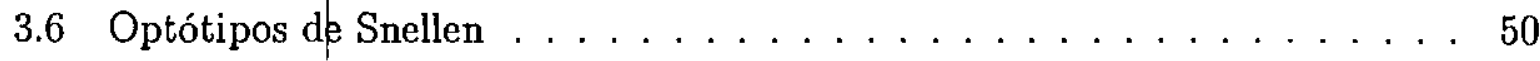


4 Simulador do Sistema Visual Humano 52

4.1 A Simulaçäo . . . . . . . . . . . . . . . . . . 52

4.1.1 Backwarl Ray-Tracing ................. 56

4.1.2 Forward Ray-Tracing . . . . . . . . . . . . . . 65

4.2 Os Módulos . . . . . . . . . . . . . . . . . 67

5 Conclusões e Trabalhos Futuros $\quad 70$ 


\section{Lista de Figuras}

1.1 Olho Humand e seus Componentes . . . . . . . . . . . . . . . 3

1.2 Geometria do Olho (Adaptada de [Car96]) . . . . . . . . . . . . 4

1.3 Caminho da tuz no Olho . . . . . . . . . . . . . . . 5

1.4 Camadas da Córnea (Retirada de [Car96]) . . . . . . . . . . . . . . 7

1.5 Acomodação do Cristalino (Adaptada de $[$ Gra80]) $\ldots \ldots \ldots \ldots$

1.6 Ametropias da Visão (Retirada de [Car96]) . . . . . . . . . . . . . . . . . 9

1.7 Padrões gerados por um olho astigmata (Retirada de [Car96]) . . . . . . 10

1.8 Anéis utilizados pela ferramenta para a definição de ametropias visuais (Adaptada de [Ven96]) . . . . . . . . . . . . . . . . . . . . . 12

1.9 Elemento da Tabela de Snellen (Retirada de [Alv94]) $\ldots \ldots \ldots$

2.1 Modelo da Cámera de Orifício . . . . . . . . . . . . . . 16

2.2 Funcionalidade do Orifício (Retirada de [Gla91]) . . . . . . . . . . 17

2.3 Câmera de Orifício Modificada (Retirada de [Gla91]) . . . . . . . . . 18

2.4 Alternativas para o Ray-Tracing - (a) Forward Ray-Tracing (b) Backward Ray-Tracing (Adaptada de [Wel93]) . . . . . . . . . . . . . . . . 19

2.5 Cálculo de Intersecções . . . . . . . . . . . . . . . . . . . . 21

2.6 Teorema da Curva de Jordan . . . . . . . . . . . . . . . . . . 22

2.7 Geometria da Reflexão (Adaptada de [Gla91]) . . . . . . . . . . . . 23

2.8 Efeito causado pelo fenômeno da refração (Retirada de [Gla91]) . . . . . 24

2.9 Geometria da Refração (Adaptada de [Gla91]) . . . . . . . . . . . 25

2.10 Árvore do Ray-Tracing . . . . . . . . . . . . . . . . . . . . 27

2.11 Reflexão Difusa (Adaptada de [Fol90]) . . . . . . . . . . . . 28

2.12 Diferentes coeficientes de difusão $K_{d}=0.4,0.55,0.7,0.85$ e 1.0 (Retirada de $[$ Fol90]) . . . . . . . . . . . . . . . . . . . 29

2.13 Exemplo de reflexão especular. Todas as esferas possuem $K_{a}=0.1$ e $K_{d}=$ 0.45 . Da esquerda para a direita temos $n=3.0,5.0,10.0,27.0$ e 200.0. De cima para baxo temos $K_{s}=0.1,0.25$ e 0.5. (Retirada de [Fol90]) $\ldots \ldots 30$

2.14 (a)Transparêtcias sem refração (b) Transparências com refração. . . . . . . 33

2.15 Função de Mapeamento de Textura (Retirada de [Gla91]) . . . . . . . . . 34

2.16 Esferas com diferentes resol uções apresentadas em fio de arame . . . . . . 35

2.17 Operações Booleanas - (a) Objetos Originais, (b) União, (c) Interseç̧ão, (d) A - B, (e) B - A (Retirada de $[$ Fol90]) . . . . . . . . . . 35 


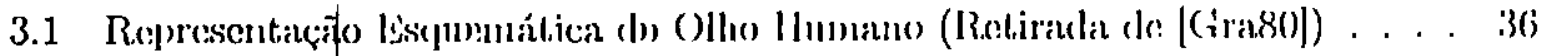

3.2 Moclelo Tridinensional dos componentes do ()lho . . . . . . . . . . . . . 37

3.3 Esquema dos componentes do Olho Teórico . . . . . . . . . . . . . . . 38

3.4 Processo de Refinamentos Sucessivos para a criação da mallıa da retina . . 39

3.5 Rofinanuento de ım políg(no . . . . . . . . . . . . . . . . . 39

3.6 Regiöes da unulti-resoluçĩo . . . . . . . . . . . . . . . . . 41

3.7 Divisöes de un polígono . . . . . . . . . . . . . . . . . . . . 4]

3.8 A sirperfício lo coristalino . . . . . . . . . . . . . . . . 42

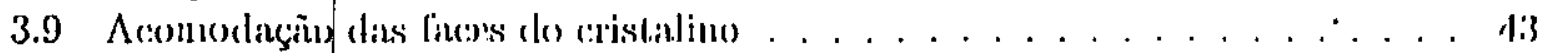

3.10 Cúlculo do centro da face do cristalino . . . . . . . . . . . . . . . . . . 14

3.11 Processo de acomodação to cristalino em relação à clistâncin . . . . . . . . 45

3.12 Matriz de pontos gerata por mun topografia de círnen . . . . . . . . . 48

3.13 Orclenação da nualtá poligonal para a cólnca . . . . . . . . . . . . . . . 19

3.14 Elemento da Tabela de Sirellen[Alv94] . . . . . . . . . . . . . . . . 50

3.15 Processo de criação de un optótipo . . . . . . . . . . . . . . . 51

4.1 Traçado de Raios - (a) Forward Ray-Tracing (b) Backward Ray-Tracing . . 55

4.2 (a) Resultado da $1^{a}$ simulação (b) Resultado da $2^{a}$ simulação . . . . . . . . 59

4.3 (a) Resultado da $3^{a}$ simulação (b) Resultado da $4^{a}$ simulação . . . . . . . . 59

4.4 (a) Resultado da $5^{a}$ simulação (b) Resultado da $6^{a}$ simulação . . . . . . . . 60

4.5 Resultado da $7^{a}$ simulação . . . . . . . . . . . . . . . . . . 60

4.6 Ampliação ihdesejável da imagern resultante em simulações com a pupila aberta ................................ 61

4.7 (a) Resultado da $1^{a}$ simulação (b) Resultado da $2^{a}$ sinulaçãa . . . . . . . . 62

4.8 (a) Resultado da $3^{a}$ simulação (b) Resultado da $4^{a}$ simulação . . . . . . . . . 63

4.9 (a) Resultado da $5^{a}$ simulação (b) Resultado da $6^{a}$ simulação . . . . . . . . . 63

4.10 (a) Resultado da $7^{a}$ simulação (b) Resultado da $8^{a}$ simulação . . . . . . . . 64

4.11 Exemplo de córnea com ceratocone . . . . . . . . . . . . . . . . 64

4.12 Resultados obtidos - a) Astigmatismo b) Ceratocone . . . . . . . . . . . 65

4.13 Círculo imaginário para traçado de raios a partir dos optótipos . . . . . . . 66

4.14 Resultado obtido por simulação usando Forward Ray-Tracing . . . . . . . . . 67

4.15 Definição da classe CEyeModel . . . . . . . . . . . . . . . . 68

4.16 Pipeline de yisualização usando biblioteca VTK . . . . . . . . . . . . . . 69

5.1 Simulações de lentes corretivas . . . . . . . . . . . . . . . 71

A.1 Cálculo otimizado de interseç̧ões da luz com uma malha poligonal . . . . . 73

A.2 Interpolação trilinear das normais em um polígono . . . . . . . . . . . . . 74

A.3 Coordenadas baricêntricas de um ponto em um triângulo . . . . . . . . . . 74 


\section{Introduçãc}

Uma das áreas da ciência que mais evoluiu nas últimas décadas foi a medicina, devido principalmente aos avanços tecnológicos e científicos proporcionados pelo homem. Através da invenção de novas técnicas para auxiliar diagnósticos, eles se tornaram mais rápidos, fáceis e precisos, deixando-os assim mais confiáveis. O homem desenvolveu a tomografia computadorizada, a ressonância magnética, a medicina nuclear, e tantas outras técnicas importantes.

Uma ferramenta valiosa para os médicos no auxílio a diagnósticos é a computação. $\mathrm{O}$ uso do computador em consultórios médicos agilizou muitas das tarefas que antes ou eram extremamente demoradas e complicadas, ou simplesmente eram impossíveis de serem feitas. Foi através desse novo recurso que a medicina deu um grande salto na qualidade de seus serviços. É graças à informática e suas técnicas que os médicos hoje podem detectar certos tipos de doenças (como o câncer, por exemplo [Hoh96]).

Este trabalho trata de um avanço em uma área específica da medicina: a oftalmologia, que estuda e trata as doenças relacionadas com a visão e com problemas oculares.

Um dos principais problemas enfrentados em oftalmologia é o diagnóstico das chamadas ametropias ${ }^{1}$ da visão, como miopia, hipermetropia e astigmatismo. Hoje em dia, esse diagnóstico é feito através de um teste de capacidade visual chamado de Teste de Acuidade Visual, onde o médico questiona o paciente sobre "o que ele consegue ver". Porém esse teste é bastante impreciso devido à subjetividade das respostas fornecidas. Seria interessante para médicos e também para estudantes de medicina, tornar possível a execução de tal teste atłavés do computador, ou, pelo menos, simular o funcionamento ótico do olho do paciente sob exame, de maneira que os resultados obtidos fossem mais confiáveis.

A proposta deste trabalho foi elaborar uma ferramenta capaz de representar, através de técnicas de computaçāo gráfica e visualização científica, os principais componentes óticos de um olho e, a partir daí, simular o seu funcionamento ótico. Para isso, utilizou-se dentre outras coisas, uma técnica de computação gráfica denominada Ray-Tracing (descrita no capítulo 2) que traça o caminho que os raios de luz percorrem desde a córnea até a retina, formando uma imagem. Dada uma imagem no mundo real, o simulador forma a imagem vista pelo olho, seja ele amétrope (com defeitos na visão) ou normal. Acredita-se que o estudo dessa ferramenta seja um importante passo inicial para a elaboração de uma

\footnotetext{
${ }^{1}$ Defeitos da visão devido a problemas decorrentes em um ou mais componentes do olho.
} 
ferramenta capaz de auxiliar em diagnósticos oftalmológicos.

A idéia deste trabalho surgiu da colaboração entre o grupo de computação gráfica e processamento de imagens do ICMC - USP e o grupo de ótica do Instituto de Física de São Carlos - USP.

O capítulo 1 desta monografia apresenta o olho humano e seus principais componentes, seu funcionamento ótico e as principais ametropias visuais. Será abordado ainda um tópico sobre acuidade visual com a descrição de como é realizado o teste e quais resultados são esperados.

É apresentado, no capítulo 2, uma breve introdução sobre a técnica Ray-Tracing a qual foi a base para a realização deste trabalho.

Em seguida, o capítulo 3 apresenta a modelagem do olho em seus diversos componentes. Optou-se por modelar apenas os seguintes componentes: córnea, pupila, cristalino e retina (pelos motivos a serem apresentados no decorrer do capítulo).

No capítulo 4 será abordada a simulação do funcionamento ótico do olho humano, através da utilização da técnica Ray-Tracing, onde são apresentados os resultados obtidos pela pesquisa.

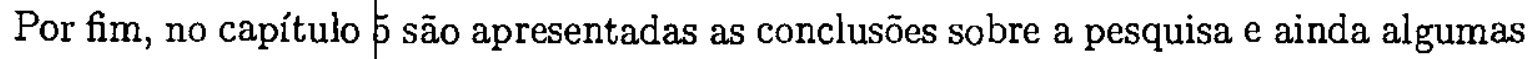
sugestões para futuros trabalhos relacionados com o mesmo tema. 


\section{Capítulo 1}

\section{O Olho Humano}

A visão pode ser consıderada um dos principais sentidos do ser humano. Ela é responsável pela maior parte das informações que uma pessoa adquire. O processo de receber estímulos visuais (luz) e convertê-los em imagens coerentes é uma das tarefas mais custosas para o cérebro humano.

O estudo do olho e seus componentes (ver Figura 1.1) é essencial para que se possa compreender seu funcionamento e, assim, permitir sua simulação computacional. O início deste capítulo descreve cada uma das estruturas principais do olho. Essas descriçōes permitirão sua modelagem matemática e a criação de um sistema ótico virtual capaz de simular a ótica (descrita na seção 1.3) de um olho.

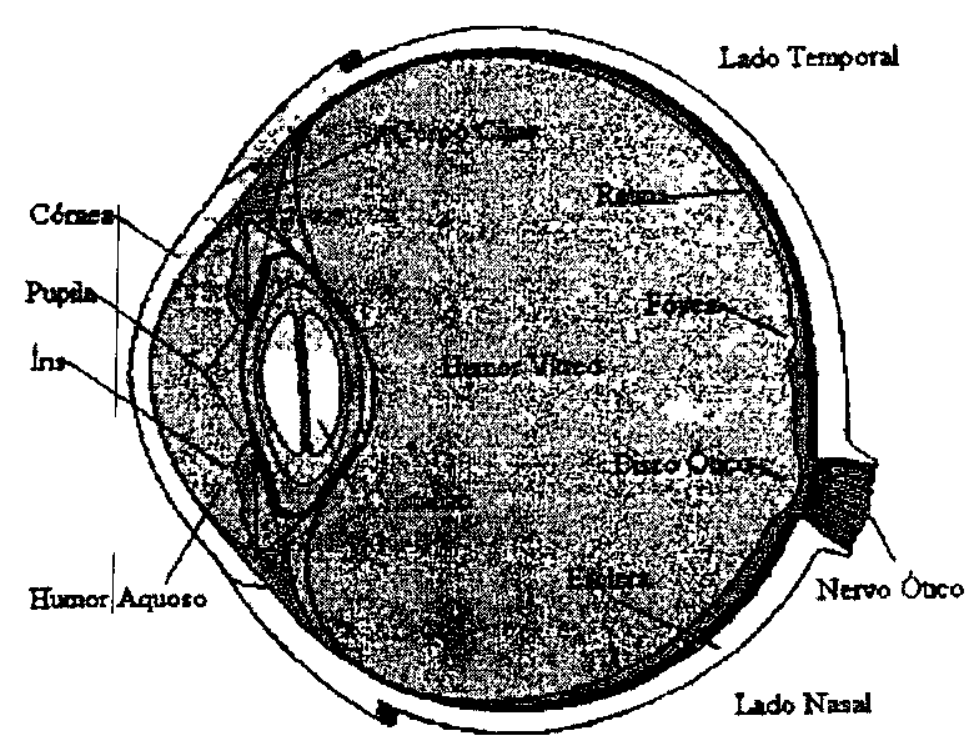

Figura 1.1: Olho Humano e seus Componentes 
O olho tem um funciфnamento semelhante a uma máquina fotográfica. Ele é composto por um sistema de lentes, um sistema de diafragma variável e a retina (que age como um filme colorido) [Car96].

Apesar de nenhum órgão no corpo humano possuir uma forma geométrica bem definida, é bastante usual a representação do globo ocular como uma esfera de raio 12 $\mathrm{mm}$ (chamada de Esclera), acoplada anteriormente a outra de raio $8 \mathrm{~mm}$ (chamada de Córnea).

A figura 1.2 ilustra que, na verdade, um olho é um pouco achatado na sua parte posterior, e que os centros das duas esferas citadas anteriormente distam $5 \mathrm{~mm}$ entre si. A região que une a córnea com a esclera é chamada de limbus.

A representação utilizada para a modelagem do olho durante a simulação será melhor descrita no capítulo 3.

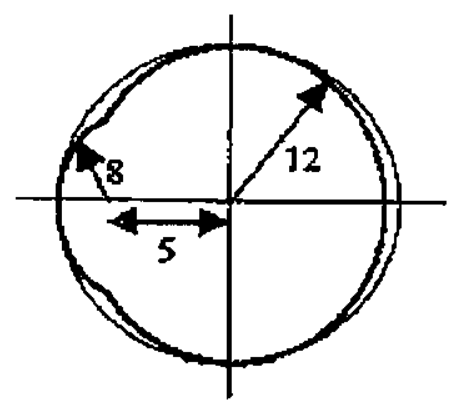

Figura 1.2: Geometria do Olho (Adaptada de [Car96])

Podemos dividir o globo ocular em dois pólos: Anterior e Posterior. Cada um possui um certo conjunto de estruturas óticas, que serão descritas na próxima seção. As principais estruturas oculares que fazem parte do pólo anterior são (figura 1.1) [Gra80]:

- Córnea

- Humor Aquoso

- Íris

- Pupila

- Cristalino

Já o pólo posterior é composto basicamente por:

- Humor Vítreo

- Retina 


\section{- Fóvea}

Vale ressaltar que essas estruturas não são as únicas encontradas em um globo ocular. São apenas as estruturas óticas principais, responsáveis diretas pelo funcionamento do olho (captação da luz ambiente para geração de imagens), que é o interesse deste trabalho.

\subsection{Partes do Olho}

A seguir serão descritas, segundo [Car96], as principais partes de um globo ocular, na ordem em que elas são percorridas pelos raios de luz que atingem o olho.

A primeira estrutura a receber os raios de luz do ambiente é a córnea, um conjunto de camadas de tecido, claras e transparentes que são responsáveis por $75 \%$ de todo poder de refração da luz no olho. A refração da luz ocorre na córnea por dois motivos: a curvatura da superfície e a diferença dos índices de refração do ar $(\cong 1.00)$ e da córnea $(\cong 1.37)$. A figura 1.3 mostra o camịh ho dos raios de luz, dentro do olho, desde a córnea até a retina.

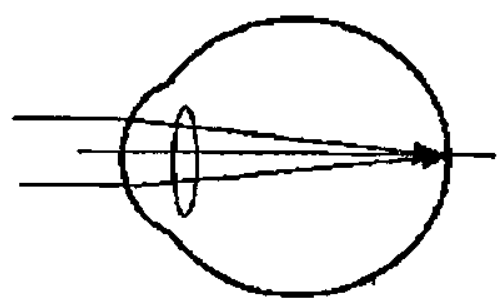

Figura 1.3: Caminho da Luz no Olho

Logo atrás da córnea, existe uma substância líquida e clara que tem a função de manter

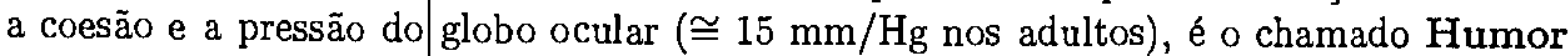
Aquoso. Uma característica importante do humor aquoso é que seu índice de refração é praticamente igual ao índice de refração da córnea, não produzindo, portanto, desvio significativo do caminho da luz no olho, podendo até ser considerado desprezível. Outra função importante do humor aquoso é a de nutrir a córnea e o cristalino.

A próxima estrutura ocular é a íris que nada mais é do que um conjunto de músculos ciliares responsáveis pela abertura (e fechamento) da pupila.

A pupila é justamente a abertura do olho por onde entra a luz. Seu diâmetro é controlado pela íris e pode variar de 1.5 a $8 \mathrm{~mm}$. Esse processo de abertura e fechamento da pupila é dado principalmente em função da quantidade de luz do ambiente, embora outros fatores interfiram em seu funcionamento. Pode levar até 5 segundos para que a pupila se feche completamente e até 5 minutos para que se abra por completo.

A seguir vem o cristalino, que é uma estrutura muito importante no olho. Ele age como uma lente natural que tem a capacidade de alterar sua distância focal de acordo 
com a necessidade. Devido a essa capacidade, ele consegue alterar também o seu poder de refração, e, portanto, é de responsabilidade dele controlar a focalização dos raios de luz na retina (regiāo do olho onde se forma a imagem). Em ótica são consideradas duas situações distintas para a focalização do olho: pontos próximos (distância menor que 6 metros) e pontọs no infinito (distẩncia maior ou igual a 6 metros). Ao processo do cristalino se adaptar a essas situações dá-se o nome de acomodação.

Conforme pode ser visto na figura 1.1, o próximo componente do olho é o Humor Vítreo, que é uma substância parecida com o humor aquoso e tem a mesma função: controlar a pressão e a coesão do globo ocular. Analogamente também, seu poder de refração pode ser considerado desprezível devido a seu índice de refração ser muito parecido ao do cristalino.

Finalmente a luz atinge a retina, que é a região na parte posterior do olho responsável pela captação e conversão dos estímulos luminosos em impulsos elétricos, os quais serão transmitidos através do pervo ótico até o cérebro. Lá, esses impulsos serão interpretados, e será formada a imagem da visão. Na retina existem dois tipos de células chamadas de fotorreceptores: os cones e os bastonetes ${ }^{1}$, que são responsáveis por captar os fótons da Iuz, produzindo uma reação fotoquímica, transformando-os em estímulos visuais. Um fóton infravermelho não possui energia suficiente para iniciar a reação e portanto não é detectado pelo olho. Já um fóton ultravioleta possui energia suficiente mas é absorvido antes de atingir a retina. Isso explica a faixa de radiação eletromagnética visível ao ser humano.

Segundo [Lim90], os cones são estruturas menos sensíveis à luz do que os bastonetes, sendo, por esse motivo, mais utilizados para a visão diurna. Outra função dos cones é a captação das cores. Existem, na retina, três tipos diferentes de cones, cada um com sensibilidade para uma cor específica (vermelho, verde ou azul). Os bastonetes são responsáveis pela captação de luz de baixa intensidade (são bem mais sensíveis que os cones) e, por isso, são eles que captam a luz noturna. Como à noite a intensidade de luz ambiente diminui consideravelmente, não há Iuminosidade suficiente para excitar os cones, por esse motivo é que se reduz a capacidade de percepção de cores em ambientes pouco iluminados.

A concentração dos cones é máxima em uma pequena depressão circular de aproximadamente $0.3 \mathrm{~mm}$ na região central da retina chamada de fóvea. É nessa região que o globo ocular tentará incidir os raios de luz. Na fóvea não existem bastonetes. Portanto, à noite, um objeto focalizado nessa estrutura não é percebido pelo olho.

\subsubsection{A Córnee}

Por ser essa uma das prumcipais partes do olho a ser estudada (pelos motivos a serem expostos na seção 1.2), descreveremos a córnea detalhadamente segundo [Gra80].

A córnea é uma membrana que recobre a parte anterior do olho e tem uma espessura

\footnotetext{
${ }^{1}$ Existem aproximadamęte 7 milhões de cones e cerca de 120 milhões de bastonetes na retina [Lim90]
} 
de 0.4 a $0.7 \mathrm{~mm}$ no póld anterior e aumenta em direção à periferia. Ela é composta por várias camadas:

Epitélio é a camada mais externa da córnea com uma espessura de $45 \mu \mathrm{m}$ no pólo e $39 \mu \mathrm{m}$ na periferia e é responsável pela sua "aparência suave". Está constantemente sendo recoberta por uma fina camada de lágrima a cada piscar. A função da lágrima é preencher pequenas imperfeições na superfície da córnea, além de irrigá-la, pois sem oxigenação ela perde a característica de transparência;

Lâmina Anterior também chamada de Membrana de Bowman. É formada por fibras muito bem empacotadas, conferindo-a uma espessura de $16 \mu m$ no ápice e $9 \mu m$ na periferia;

Estroma constitui a maior parte da córnea ( $90 \%$ de sua espessura) e é composto por 50 lâminas sobrepostas e por células chamadas de keratócitos;

Lâmina Posterior ou Membrana de Descemet é muito similar à membrana de Bowman. Possui uma espessura de $7 \mu m$ no ápice e $11 \mu m$ na periferia (em pessoas adultas). Essa espessura varia conforme a idade do indivíduo, podendo chegar a $20 \mu \mathrm{m}$ na velhice;

Endotélio é a camada mais posterior da córnea, com uma espessura de $6 \mu \mathrm{m}$ e tem a importante funçã $\phi$ de bombear para fora o humor aquoso absorvido pela córnea, evitando com isso que ela se torne opaca.

A figura 1.4 mostra uma seção transversal de uma córnea e suas diversas camadas.

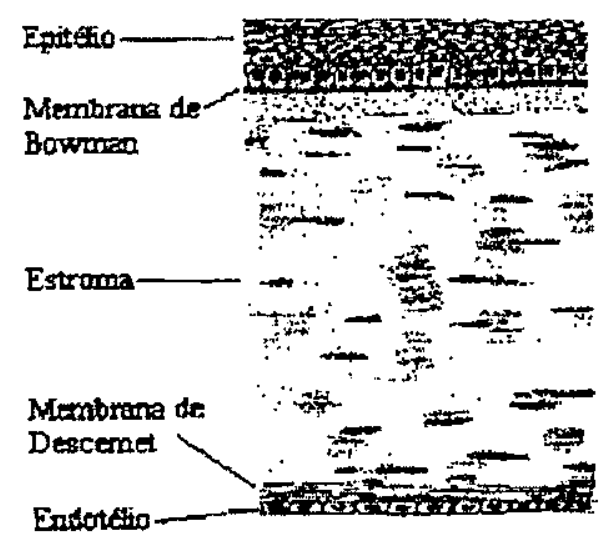

Figura 1.4: Camadas da Córnea (Retirada de [Car96]) 


\subsubsection{O Cristalino}

Conforme já foi citado, o cristalino é uma lente natural localizada logo após o humor aquoso, que tem a responsabilidade de focalizar os raios de luz sobre a retina, através da sua própria acomodação. A figura 1.5 ilustra a lente acomodada (linha pontilhada) e não acomodada (linha cheia). Quando o cristalino está acomodado, seu poder de refração é máximo.

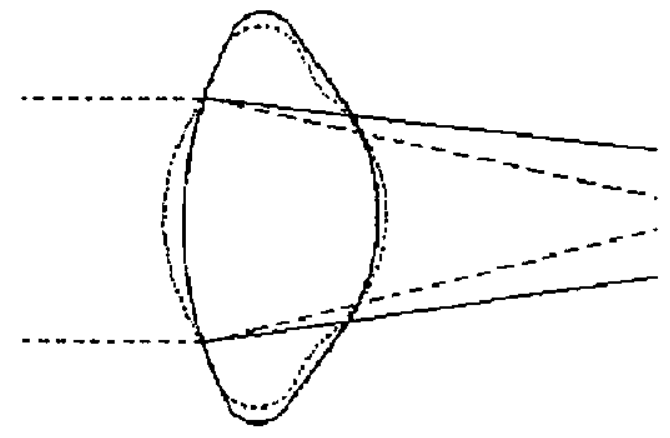

Figura 1.5: Acomodação do Cristalino (Adaptada de [Gra80])

Essa lente se desenvolve durante toda a vida do indivíduo e suas dimensōes crescem através da superposição de novas camadas sobre as mais antigas (da mesma forma que os anéis de uma árvore), formando uma estrutura estratificada como uma cebola. Em um recém-nascido, o cristalino mede $3.5 \mathrm{~mm}$ de espessura e $6 \mathrm{~mm}$ de diâmetro (no equador) sendo mais esférica do que em um indivíduo adulto ( 4 por $9 \mathrm{~mm}$ ) ou, na velhice ( 4.5 por $9.5 \mathrm{~mm})$.

A concentração de água em uma lente adulta é considerada baixa para um tecido orgânico (66\%) e essa taxa decresce com a idade. Além de água, é encontrada na lente uma certa quantidade de minerais como potássio, sódio, adenosina trifosfato (ATP), e proteínas. O equilíbrio entre essas substâncias e a água é o que garante a capacidade de transparência à lente. A lente pode se tornar opaca (catarata) [Gra80] por diversos motivos tais como: idade, doenças (como a diabetes mellitus), ação de radiações ionizantes, radiação infravermęlha, frio, deficiências alimentares, substâncias tóxicas ou algum trauma.

\subsection{Ametropias da Visão}

Toda vez que os elementos oculares não funcionam harmoniosamente, percebemos algum tipo de ametropia visual. Se um olho não possui problemas referentes à visão dizemos se tratar de um olho emétrope ou normal, ou seja, os raios que atingirem a córnea serão projetados diretamente sobre a retina, conforme pode ser visto na figura 1.6(a). 


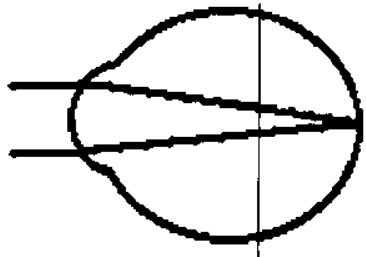

(A)

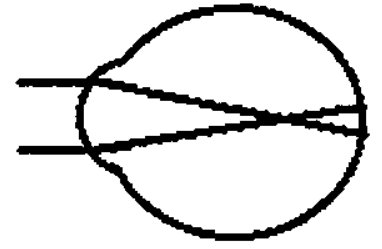

(B)

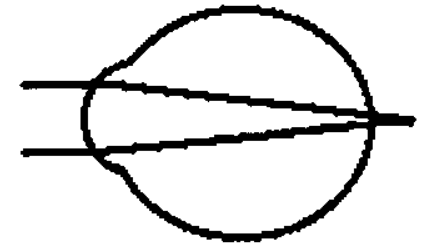

(C)

Figura 1.6: Ametropias da Visão (Retirada de [Car96])

O caminho percorrido pelos raios de luz ao atingirem o olho é o seguinte: primeiramente, os raios atingem a córnea onde, devido à sua curvatura e seu índice de refração, sofrem uma alteração em seu percurso, sendo convergidos para o interior do globo ocular. A seguir, a luz atravessa o humor aquoso que, por ter um índice de refração muito próximo ao da córnea, não produz refração significativa. A próxima estrutura ocular a ser atingida é a pupila, que é a abertura do olho, ou seja, os raios de luz que não a atingirem serão bloqueados e não contribuirão para a formação da imagem da visão. A "pequena"parcela dos raios de luz que entraram no olho, atingem o cristalino, que é a lente que tentará focalizar a luz na retina alterando seu poder de refração através da mudança do seu raio de curvatura. A luz ainda atravessa o humor vítreo que, analogamente ao humor aquoso, não contribui para o poder de refração ocular; e finalmente atinge a retina, onde os fotorreceptores captam seus naios formando a imagem que será enviada ao cérebro através do nervo ótico.

Um olho é tido como amétrope quando apresenta algum tipo de defeito da visão, ou seja, por algum motivo, o ponto remoto ${ }^{2}$ está localizado fora da retina, conforme pode ser visto nas figuras 1.6 (b) e (c).

A miopia ocorre quahdo os raios de luz convergem antes de atingirem a retina (figura 1.6 (b)) devido ao fato de que o globo ocular é mais alongado que o normal, gerando imagens borradas, e sendo necessário "trazer os objetos" para uma distância finita $(<6$ metros).

A hipermetropia é justamente o oposto. Quando um olho é excessivamente curto (figura 1.6 (c)), o ponto remoto localiza-se após a retina, sendo necessário "afastar os objetos" para um ponto infinito $(\geq 6 \mathrm{~m})$.

O astigmatismo é um defeito da visão causado por erro de curvatura, de centralização, ou de índice de refração [Car96]. O astigmatismo de curvatura é causado pela não esfericidade da córnea ou do cristalino, sendo mais comum na córnea (grau mais intenso). Devido a esse erro de curvatura, raios de luz que atingirem a córnea em uma região de baixa curvatura irão focalizar em um ponto mais próximo do que aqueles que tocarem uma regiāo de alta curvatura. Disso resulta que o olho astigmata irá formar padrōes de

\footnotetext{
${ }^{2}$ Ponto de localização do pbjeto para um dado olho em repouso onde a imagem se forma na retina
} 
visão dos quais será escolhido (pelo olho) aquele mais simétrico possivel que representa o círculo de menor confusão, o qual será mantido sobre a retina. A figura 1.7 ilustra os padrōes visuais gerados por um olho astigmata.

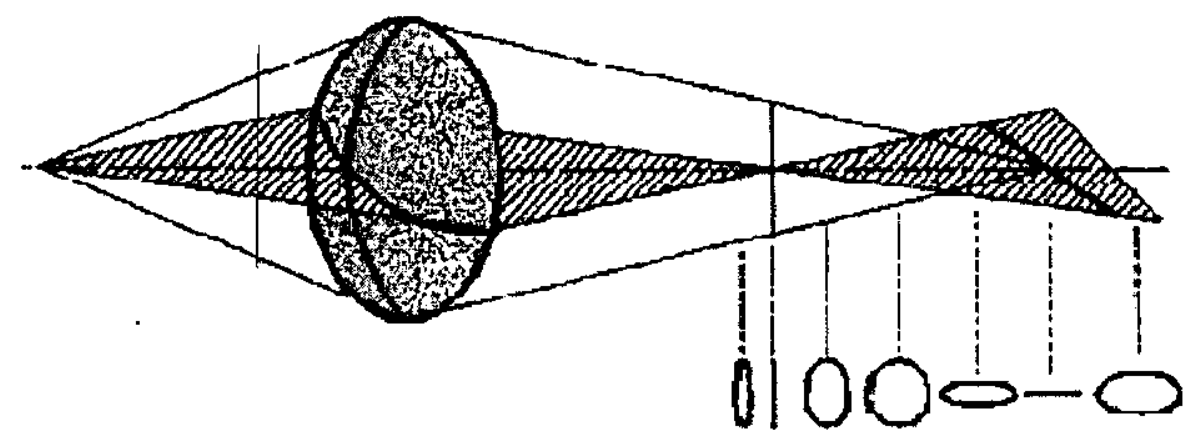

Figura 1.7: Padróes gerados por um olho astigmata (Retirada de [Car96])

A correção das ametropias é feita através de lentes colocadas na frente do olho, com o intuito de efetuar pequenas correções no caminho do raio de luz, de maneira que quando esse raio atravessar o olho amétrope essa variação será suficiente para minimizar, ou até, em alguns casos, corrigir o defeito da visão. Esse conceito já é conhecido do homem deste o século XIV [Gra80] sendo que, no século XVII, foi descoberto o princípio do uso de lentes de contato, que por motivos técnicos só foram realmente utilizadas há algumas poucas décadas atrás.

\subsection{Acuidade Visual}

Acuidade visual é a capacidade que o olho humano tem de distinguir entre dois pontos próximos entre si, ou seja, o quão detalhada é a imagem formada na retina. Em um olho emétrope, somente a natureza ondulatória da luz pode determinar a nitidez dos detalhes.

De fato, objetos cujo diâmetro é menor que 1 minuto de grau $\left(1^{\prime}\right)$ parecerão (na retina) como simples pontos; a menor dimensão angular percebida pelo olho é aproximadamente dessa ordem de grandeza. Obviamente, defeitos inerentes à visão, como os mencionados acima, irão contribuir significativamente para a diminuição da acuidade visual.

Para médicos oftalmologistas, a maneira atual de medição da acuidade visual de um paciente é através de um teste que o questiona sobre símbolos (frequentemente letras) projetados em um anteparo, de maneira que, de acordo com as respostas dadas, pode-se determinar o menor ângulo de visão daquele olho ${ }^{3}$. Esse tipo de teste já vem sendo usado há muitos anos [Ven94] e apresenta alguns inconvenientes, como a baixa precisão dos

\footnotetext{
${ }^{3} \mathrm{E}$ importante salientar que um mesmo paciente pode ter acuidades visuais diferentes nos dois olhos
} 
resultados devido à subjetividade das respostas dadas pelo paciente, e ainda o problema do teste requerer um espaço livre em torno de 7 metros para sua realização.

Uma ferramenta capaz de simular o caminho percorrido pelos raios de luz dentro do olho, até formarem uma imagem na retina, auxiliaria na compreensão das causas que levam um olho a ter problemas de acuidade visual. Através dela, seria possível manipular parâmetros do olho (como a abertura da pupila ou a acomodação do cristalino) e produzir simulaçōes que resultariam em imagens da visão. Assim, seria possível estudar a relação entre o problema em uma dada estrutura e a capacidade de acuidade visual do olho. Essa foi a motivação pała a realização desta pesquisa. Numa próxima etapa, anexou-se informaçōes reais de olhos para, com isso, produzir resultados que refletissem a realidade de um paciente. Uma outra motivação para o desenvolvimento de tal ferramenta, é que ela permitiria a realização de testes de acuidade visual em pacientes que apresentem algum tipo de dificuldade para a realização do teste convencional, como deficientes mentais, crianças, pessoas com alta sensibilidade à luz, etc.

Infelizmente os resultados obtidos pela pesquisa, indicam que simular a ótica do olho humano não é uma tarefa tão simples como possa parecer em um primeiro momento. Existem diversos fatores a considerar, sendo um dos principais o fato de que a quantidade de raios de luz e fotorreceptores na retina pode tornar o processo computacionalmente inviável. Apesar disso, diversos resultados satisfatórios foram obtidos (os quais serão apresentados no decorrer deste trabalho).

Uma ferramenta para a deteç̧ão automática de defeitos da visão (miopia, hipermetropia e astigmatismo) foi desenvolvida por profissionais da USP de São Carlos/SP e de Ribeiräo Preto/SP e é melhor descrita em [Ven94, Ven96], sendo um importante ponto de referência para esta pesquisa. Essa ferramenta possui um sistema capaz de medir os três tipos de ametropias mencionadas anteriormente de forma objetiva e automática em cerca de 3,5 segundos. Ela se baseia na projeção de seis anéis (em três meridianos distintos: $120^{\circ}, 240^{\circ}$ e $360^{\circ}$ ) (ver Figura 1.8) sobre o olho e a posterior captação e análise da imagem refletida na retina. Os anéis se deslocarão de posição de acordo com a ametropia visual percebida no olho sob análise. Se o olho for míope, os anéis se aproximarão. Se o olho for hipermétrope, ocorrerá um distanciamento entre cada par de anéis. Em um olho astigmata, a quantidade que cada par de anéis (pertencentes a um mesmo meridiano) se afasta ou se aproxima, é diferente para cada um dos meridianos.

A deteç̧ão das ametropias consiste da projeção dos anéis no olho e a captação da imagem refletida através de uma câmera CCD. A imagem resultante é então analisada, através de técnicas de pfocessamento de imagens. O resultado é a medição das distâncias dos centros dos anéis, em cada meridiano, permitindo assim o diagnóstico.

Acredita-se que a utilização de técnicas de simulação do funcionamento ótico do olho humano possa ser uma alternativa promissora como auxílio aos medidores automáticos de ametropias visuais pфis permitiriam quantificar a confiabilidade dos resultados obtidos nas medições. 


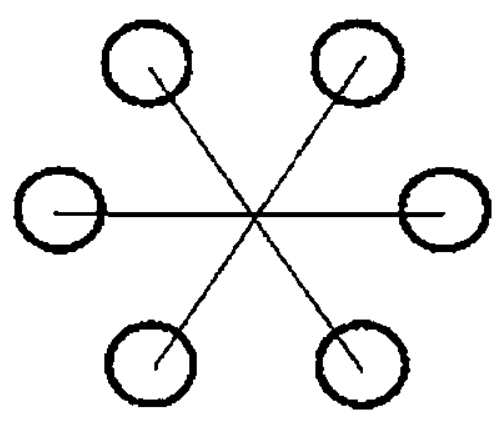

Figura 1.8: Anéis utilizałłos pela ferramenta para a definição de ametropias visuais (Adaptada de [Ven96])

\subsubsection{Critérios para Medida da Acuidade Visual}

Segundo [Alv94] exister alguns critérios importantes a serem considerados durante a execução do teste de acuidade visual. Esses são apresentados a seguir.

\section{Mínimo Visível}

"Corresponde à melhor acuidade visual na percepşão da menor superfície, cuja luminosidade é diferente do fundo sobre o qual ela se apresenta". Em outras palavras, representa a capacidade de percepcão do brilho ou contraste de um objeto.

De uma maneira geral, superfícies que apresentem contraste inferior a $1 \%$ (em relação ao fundo) não são suficientemente brilhantes e portanto não são percebidas pelo olho.

\section{Mínimo Separável}

Esse é o critério principal utilizado para a medição da acuidade visual de um olho devido ao fato de se tentar medir o mínimo legivel. Esse critério é baseado nos estudos de Helmholtz que sugeriu o valor de 1 minuto de grau (1') como sendo a acuidade visual normal. A partir daí, em 1862, Snellen, um jovem assistente de uma clínica, estudou e criou uma tabela composta por letras (optótipos) de diferentes tamanhos, que representavam um ângulo visual de cinco minutos (5'), onde cada letra é composta por elementos de $\frac{1}{5}$ desse tamanho, conforme pode ser visto na figura 1.9 abaixo.

Nessa tabela, as letras de mesmo tamanho eram dispostas em linhas com números que indicavam a distância que subentendia um ângulo de cinco minutos. Medir, então, a acuidade visual consiste de uma fração onde o numerador representa a distância da realização do exame e o denominador representa a distância em que aquele optótipo subentende um ângulo de 5'. 


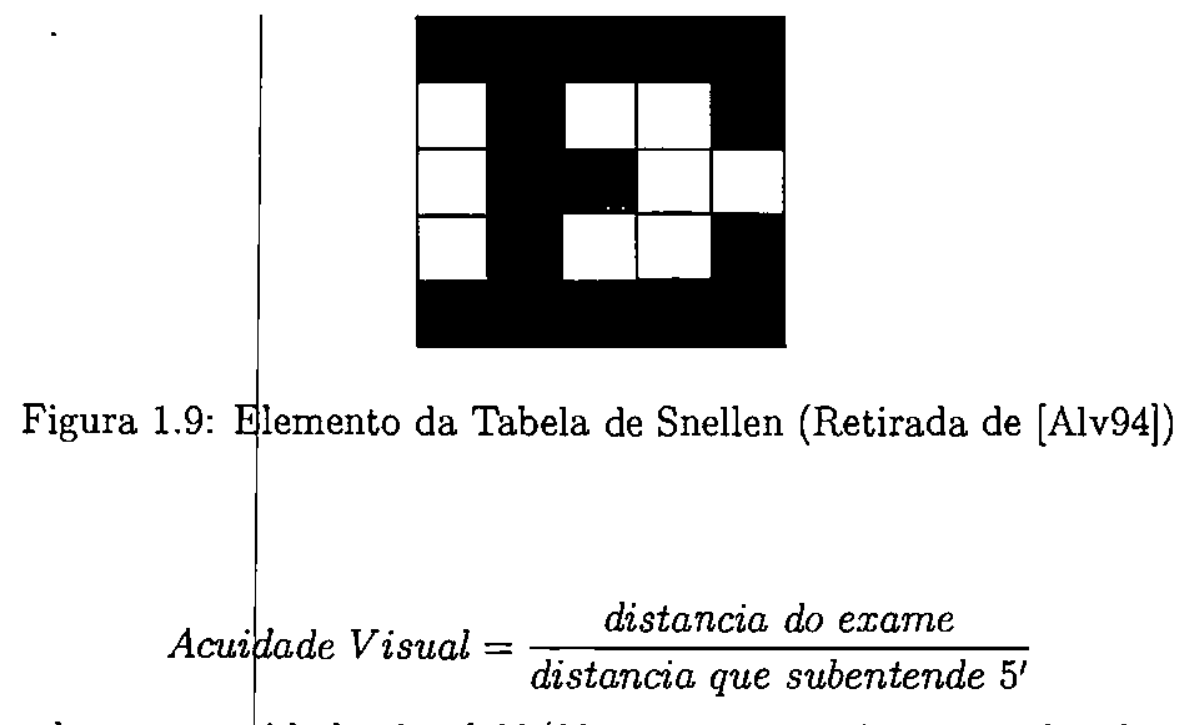

Desse modo, uma acuidade visual $20 / 20$ representa a visão considerada normal, pois significa que um paciente situado a 20 pés, consegue distinguir o optótipo que subentende um ângulo de 5', a 20 pés. Outro exemplo: a acuidade visual 0.5 (ou 10/20) representa um olho que, para conseguir ler um optótipo que subentende $5^{\prime}$ a 20 pés, precisa estar situado a apenas 10 pés de distância do local do teste.

O tamanho dos optótipos correspondentes a diferentes acuidades visuais, pode ser determinado por:

$$
H=14,6 \cdot \frac{D}{V}
$$

onde $H$ é a altura do optótipo (em milímetros), $D$ é a distância de apresentação do optótipo (em metros), Vé o valor da acuidade visual (em décimos) e a constante 14,6 representa a tangente de 5 ' multiplicada por 10.000 para compensar a utilização de milímetros e décimos nas demais componentes.

\section{Ângulo Visual}

"É o ângulo formado pelo objeto, no ponto nodat do olho". A equação que converte a marcação de Snellen em minutos é descrita na equação (Eq. 1.3):

$$
\text { angulo visual }(\min )=\frac{1}{\text { marcacao de Snellen }}
$$

portanto $20 / 20$ corresponde a 1 minuto de grau, 20/40 a 2 minutos e assim por diante.

\subsubsection{Fatores que influenciam a Acuidade Visual}

Existem alguns fatores que influenciam os resultados dos testes de acuidade visual:

\footnotetext{
${ }^{4}$ Ponto que representa uma simplificação do sistema ótico do olho.
} 
- Ambliopia é um defeito da visão que se caracteriza por identificar melhor as letras se estas estiverem separadas;

- A acuidade visual yaria de acordo com a idade do paciente, decrescendo gradativamente a partir dos 60 anos;

- O diâmetro da pupila pode aumentar ou diminuir os defeitos da ótica ocular e os inconvenientes da natureza ondulatória da luz;

- As letras de Snellen (optótipos) não são igualmente legíveis. A letra B é a mais difícil enquanto que a letra $L$ é a de mais fácil reconhecimento;

- A iluminação influencia diretamente no resultado da acuidade visual: quanto maior a iluminação no ambiente do teste, menores serão os optótipos reconhecidos por um paciente.

Neste capítulo foram descritas cada uma das estruturas principais que compõem o olho humano. O objetivo de se estudar tais estruturas é que, para permitir uma simulação que se identifique com a realidade, se faz necessária a compreensão do problema real (relação entre ametropias visuais e acuidade visual, e o caminho da luz dentro do olho).

No próximo capítulo será descrita a técnica utilizada para a simulação da interação dos raios de luz com os diversos componentes do olho humano. Essa técnica é chamada Ray-Tracing e se baseia|no princípio do funcionamento de uma máquina fotográfica. 


\section{Capítulo 2}

\section{Ray-Tracing}

Neste capítulo serão discutidas técnicas de geração de imagens foto-realistas através da simulação do princípio ótico da fotografia, ou seja, o rastreio de raios de luz provenientes de fontes luminosas que atingem um filme fotográfico, registrando assim, uma imagem.

O estudo dessa técnica é importante para o trabalho pois acredita-se que rastrear o caminho de raios de luz é uma boa alternativa para a simulação do funcionamento ótico do olho humano.

A seção 2.1 trata de um breve histórico da síntese de imagens, desde a invenção da fotografia no final do séqulo passado. Essa discussão se aprofunda na seção 2.2, onde será visto um modelo de representação de uma máquina fotográfica simplificada (a câmera de orifício). O princípio de funcionamento dessa câmera será a base para o estudo da seção 2.3, na qual será visto o algoritmo Ray-Tracing. Completando este capítulo temos, na seção 2.4 , o conceito sobre modelo de iluminação e ainda, na seção 2.5 , vemos técnicas de modelagem de objetos eq superfícies.

\subsection{Da Fotografia à Síntese de Imagens Realistas}

Desde o inicio da humanidade, o homem procurou maneiras de representar o mundo a seu redor, como se observa nas gravuras rupestres. De lá pra cá, ele vem descobrindo e criando formas mais eficientes e sofisticadas de se representar imagens, que por sua vez devem representar informações bem mais complexas.

Foi em meados do século XIX que o princípio básico da fotografia foi inventado ${ }^{1}$, e foi através desse invento que o homem conseguiu criar imagens do mundo com uma qualidade até então nunca experimentada.

Com o advento do computador e posteriormente da computação gráfica, o homem experimentou uma nova forma de criação e representação de imagens. Por algum tempo, os profissionais da computação gráfica imaginavam uma maneira de gerar, computacionalmente, imagens com uma qualidade que imitasse as fotografias. O ponto de partida

\footnotetext{
${ }^{1} \mathrm{~A}$ fotografia foi inventada em 1839 pelo francês Louis-Jacques-Mandé Daguerre (1787-1851) [Ass99]
} 
para a solução desse problema veio dos livros de física. Com o desenvolvimento de lentes, os físicos desenham, no papel, o caminho percorrido pelos raios de luz desde uma dada fonte, passando através das lentes e atingindo um anteparo. Esse processo de seguir o caminho dos raios de luz foi chamado de Ray-Tracing.

Como o princípio da fotografia também se baseia na luz, percebeu-se que simular a física ótica seria uma boa alternativa para a síntese de imagens com alto grau de realismo. A partir daí, as técnicas de geração de imagens foto-realistas mais populares passaram a se basear nessa idéia. Porém, na época (início dos anos 60), os computadores não tinham poder de processamento suficiente para a geração de imagens em tempo aceitável [Gla91]. Porém esse problema foi solucionado com o avanço da tecnologia dos computadores, que se tornaram mais potentes a um custo cada vez menor.

Hoje em dia, a técnica Ray-Tracing se tornou uma das mais populares e poderosas na síntese de imagens, apesar de não ter ainda atingido a qualidade considerada ideal por profissionais da área.

Para que se possa entender como funciona a técnica Ray-Tracing, é necessário estender o princípio ótico do funcionamento de uma máquina fotográfica [Weg92]. A idéia básica é "fotografar uma cena virtual"e gerar uma matriz de pontos que aproxima a imagem que seria representada em um filme fotográfico.

\subsection{Modelo de uma Câmera de rifício}

O algoritmo Ray-Tracing é baseado no funcionamento ótico da câmera de orifício, que nada mais é do que o princípio básico de como uma máquina fotográfica registra uma fotografia do mundo real.

A câmera de orifício [Gla91, Wel93] é um dispositivo extremamente simples. Ela é composta por uma caixa oca e escura onde, em uma das extremidades, temos um pequeno orifício com uma tampa removível. Na parte interna da extremidade oposta temos um filme fotográfico, que é uma superfície plana que tem a propriedade de registrar a "cor"do raio de luz que o atinge. A figura 2.1 ilustra os componentes básicos de uma câmera de orifício [Gla91].

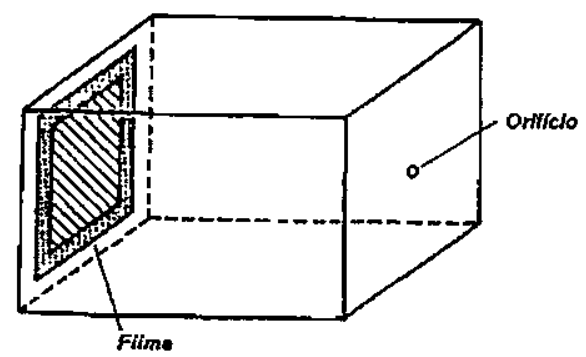

Figura 2.1: Modelo da Câmera de Orifício 
Para se registrar uma fotografia no filme, basta remover a tampa do orifício durante algum tempo. Nesse período, a luz ambiente entra na câmera e atinge o filme registrando a imagem. Depois, basta recolocar a tampa sobre o orifício e o processo está concluído.

O orifício é uma parte fundamental no processo, pois se tentássemos removê-lo e expor o filme fotográfico diretamente à luz ambiente, teríamos uma super-exposição de luz no filme, gerando, assim, uma fotografia saturada (totalmente branca). Portanto, o orifício é responsável por contrplar a quantidade de luz que entra na caixa. A figura 2.2 abaixo ilustra esse processo.

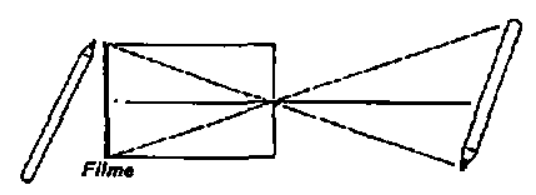

Figura 2.2: Funcionalidade do Orifício (Retirada de [Gla91])

\subsection{Algoritmb Ray-Tracing}

O princípio de funcionamento da câmera de orifício é utilizado na técnica Ray-Tracing. Para tal, algumas adaptações são necessárias:

- para o orifício temos um ponto de observação, ou seja, o ponto onde ocorre a convergência dos raios de luz que atingem a câmera;

- para o filme fotográfico temos um plano de projeção (representado através de uma matriz de pontos) que representa a tela do computador;

- para os raios de laz temos semi-retas orientadas;

- cada raio de luz é tratado como sendo monocromático;

- para a cena do mundo real, temos representações matemáticas ou geométricas de primitivas gráficas (esferas, cilindros, planos, etc.).

Outra modificação significativa está no fato de que, para efeito de simplificação de programação, o plano de projeção é deslocado para a frente do ponto de observação, conforme pode ser visto na figura 2.3 .

\footnotetext{
${ }^{2} \mathrm{~A}$ cor de um raio de luz é determinada pelo comprimento de onda predominante entre um conjunto de vários comprimentos de onda diferentes.
} 


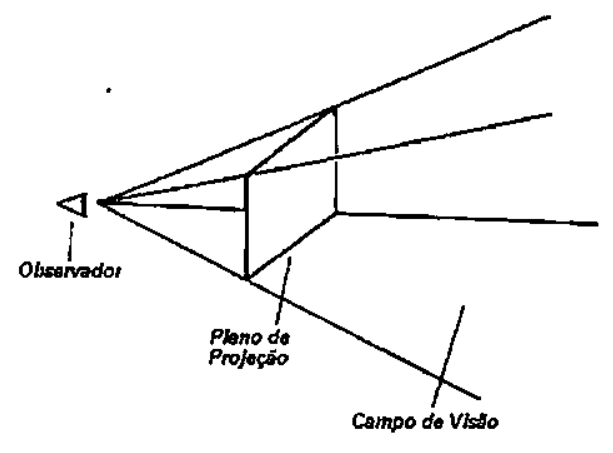

Figura 2.3: Câmera de Orifício Modificada (Retirada de [Gla91])

\subsubsection{Pixels e Raios}

Gerar uma imagem usando Ray-Tracing consiste basicamente em se determinar a cor de cada pixel do plano de projeção. Isso é feito através da realização dos seguintes passos:

1. Determinar o raio de luz proveniente da cena, que atinge cada um dos pixels que compõem o plano de projeção passando pelo ponto de observação;

2. Determinar, nos objetos que compõem a cena virtual, o ponto mais próximo ao observador no caminho de cada raio de luz;

3. Aplicar um model $\phi$ de iluminação (a ser descrito no decorrer deste texto) a cada um dos pontos determinados no item anterior;

4. Repetir o processo acima para considerar possíveis reflexões e refrações até que não haja mais interações de raios de luz com a cena virtual.

Cada uma dessas etapas é melhor descrita a seguir.

\subsubsection{Traçado de Raios}

A primeira etapa do algoritmo consiste do traçado de raios (Ray-Casting). Inicialmente "disparam-se"raios de luz, partindo do observador $(O)$, em direção a cada um dos pixels do plano de projeção $\left(P_{i}\right)$. Cada raio é determinado através de $\vec{R}=P_{i}-O$. A seguir, determina-se qual(is) objeto(s) da cena é(são) interceptado(s) pelo raio $\vec{R}$. Dentre os pontos de interseç̧ão obtidos, escolhe-se aquele mais próximo ao observador (ponto de visão).

Os raios de luz, conforme já foi apresentado na seção anterior, são representados através de uma reta. Na verdade, a representação utilizada é a equação paramétrica da reta, da forma: 


$$
\left\{\begin{array}{l}
X=P_{x}+V_{x} * t \\
Y=P_{y}+V_{y} * t \\
Z=P_{z}+V_{z} * t
\end{array}\right.
$$

onde:

$P_{x}, P_{y}, P_{z}$ são as coordenadas do ponto de origem da reta

$V_{x}, V_{y}, V_{z}$ são as coordenadas do vetor direção da reta

$t$ é o termo paramétrico da equação.

A partir disso, podemos determinar um raio de luz tendo o observador como ponto de origem e a direção variando em relação a cada um dos pixels do plano de projeção.

\section{Forward Ray Tracing e Backward Ray Tracing}

No mundo real, o fenômeno de propagação da luz segue o seguinte modelo: uma fonte emissora de luz (p. ex.: uma lâmpada ou o sol) emite raios de luz iluminando objetos que refletem esses raios em direçōes diversas. Uma certa quantidade desses raios atinge o olho do observador (ou o filme fotográfico), gerando assim a imagem final. A figura 2.4(a) ilustra esse fenômeno.

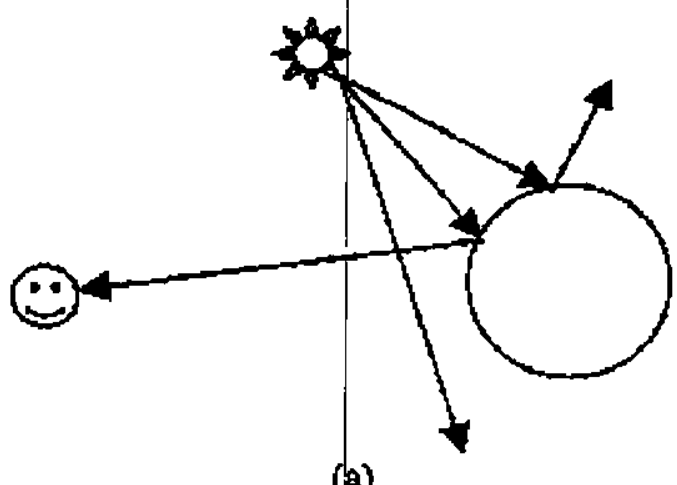

(a)

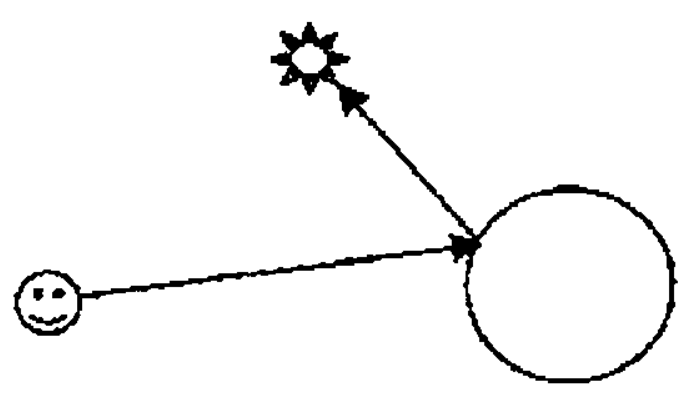

(b)

Figura 2.4: Alternativas para o Ray-Tracing - (a) Forward Ray-Tracing (b) Backward Ray-Tracing (Adaptada de [Wel93])

Em termos computacionais, usar essa alternativa é inviável devido ao fato que a quantidade de raios de luz que atinge o olho do observador é apenas uma "pequena"parcela do total de raios emitidos pela fonte. Sendo assim, o algoritmo estaria efetuando processamento desnecessário, elevando o tempo de renderização a um nível inaceitável.

Essa técnica de traçar raios partindo da fonte de luz em direção a cena, e então ao olho do observador, é chamada de Forward Ray Tracing. Devido aos problemas mencionados 
anteriormente, desenvolyeu-se uma nova alternativa para a técnica, que apesar de não representar fisicamente o fenômeno, em nada denigre a qualidade final da imagem.

A técnica Backward Ray Tracing trabalha no sentido inverso da anterior. Ao invés de considerar os raios de luz partindo da fonte de luz em direção à cena, considera-os partindo do ponto de observação. Com isso, os raios que, ao partirem da fonte de luz não sejam refletidos em direção ao plano de projeção, são automaticamente desconsiderados (Figura 2.4(b)), melhorando assim, o tempo de processamento de uma imagem, significativamente.

Em outras palavras, a técnica forward ray tracing trata o percurso que cada raio fará desde a fonte até o observador enquanto que na backward ray tracing, o foco está em se voltar pelo caminho percorrido pelo raio de luz desde o observador até a fonte.

Devido à sua melhor eficiência na geração de imagens sintéticas, a partir de agora, ao se mencionar a técnica Ray-Tracing, fica subentendido que se trata da alternativa backward ray tracing.

\section{Cálculo de Intersecçöes}

Uma vez determinadas as equações de cada raio de luz, o próximo passo é o cálculo das intersecções de cada raio com os objetos que compõem a cena virtual, e assim determinar qual é o ponto que está efetivamente sendo "visto" pelo observador.

O processo de se determinar a(s) interseção(ões) de um raio com um objeto qualquer nem sempre é uma tarefa trivial. Porém, muitas das primitivas gráficas podem ser representadas por equações, o que facilita a tarefa. É o que ocorre, por exemplo, com esferas (a mais simples das primitivas) e com os planos.

Nesses casos, determinar se houve intersecção entre um dado raio $\vec{R}$ e um objeto, se torna uma simples operação algébrica entre equações. Para ilustrar esse processo, vejamos um exemplo através de esferas.

Seja $E$ uma esfera de raio $r_{e}$ e centro em $\left(e_{x}, e_{y}, e_{z}\right)$ e ainda um raio de luz $R$ que partiu do observador $O$ posicionado em $\left(O_{x}, O_{y}, O_{z}\right)$ na direção do vetor $V\left(V_{x}, V_{y}, V_{z}\right)$, então teremos:

$$
\begin{aligned}
& E \mid=\left(X-e_{x}\right)^{2}+\left(Y-e_{y}\right)^{2}+\left(Z-e_{z}\right)^{2}-r_{e}^{2} \\
& R_{x}=O_{x}+V_{x} * t \\
& R_{y}=O_{y}+V_{y} * t \\
& R_{z}=O_{z}+V_{z} * t
\end{aligned}
$$

onde (Eq. 2.2) e (Eq. 2.3) representam as equações que definem a esfera $E$ e o raio de luz $R$ respectivamente. Determinar se existe alguma interseç̧ão entre esses elementos consiste em determinar se existe pontos comuns a ambos. Sendo assim, basta fazermos $E=R$ e teremos uma nova equação (Eq. 2.4) que tem como única incógnita o valor paramétrico $t$ : 


$$
\left(\left(O_{x}+V_{x} * t\right)-e_{x}\right)^{2}+\left(\left(O_{y}+V_{y} * t\right)-e_{y}\right)^{2}+\left(\left(O_{z}+V_{z} * t\right)-e_{z}\right)^{2}-r_{e}^{2}=0
$$

Resolvendo a equação anterior obtém-se um valor para o parâmetro $t$, e a partir desse valor é que se determina se houve ou não interseção de $E \operatorname{com} R:^{3}$

Se $t>0$ houve intersecção e $t$ representa a distância do observador $O$ da esfera $E$;

Se $t=0$ houve intersecção e o observador situa-se sobre a superfície da esfera;

Se $t<0$ não houve interseç̧ão ou não apresenta solução real.

Uma vez encontrado o valor de $t$ basta substituí-lo na equação (Eq. 2.3) e determinar as coordenadas exatas $\left(R_{x}, R_{y}, R_{z}\right)$ do ponto onde ocorreu a interseç̧ão.

Caso um mesmo raio de luz intercepte mais de um ponto (seja no mesmo objeto ou em objetos distintos) será considerado o menor dentre todos os valores encontrados para $t$, que é o ponto visível mais próximo ao observador, conforme é ilustrado na figura 2.5.

Uma vez determinadas as coordenadas do ponto visível de um raio de luz, a próxima etapa é a aplicação de um modelo de iluminação para a definição da cor com a qual será colorido o pixel correspondente no plano de projeção.

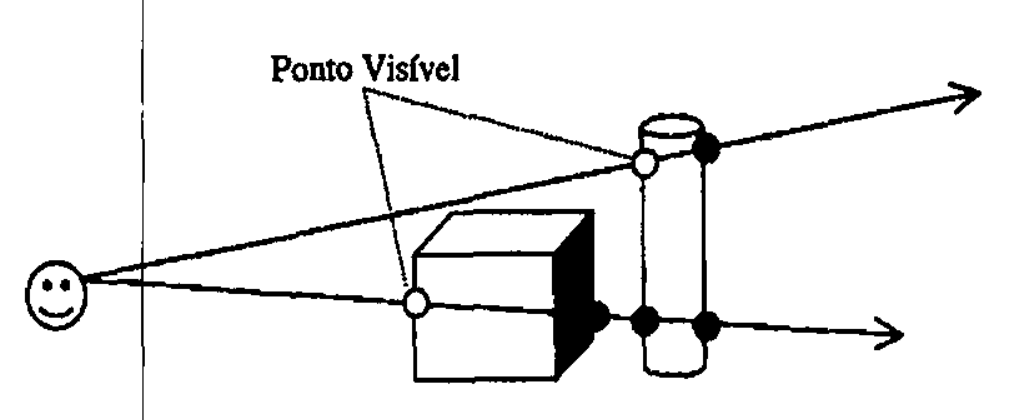

Figura 2.5: Cálculo de Intersecções

Os modelos de iluminação serão melhor descritos nas próximas seções.

Para o cálculo de interseções de raios de luz com qualquer outra primitiva geométrica, o processo é análogo. A partir das equações, encontra-se o termo paramétrico, e a partir deste, as coordenadas do ponto visível para, então aplicar um modelo de iluminação.

Caso o objeto não seja descrito por uma equação, o processo de se determinar interseç̧ões se torna um pouco mais complexo. Aproximar uma superfície por um conjunto de polígonos ${ }^{4}$ é uma alternativa bastante utilizada no caso de objetos complexos.

\footnotetext{
${ }^{3} \mathrm{O}$ raio $\mathrm{R}$, sempre que interceptar a esfera $\mathrm{E}$, o fará em dois pontos distintos, exceto quando $R$ for tangente a $E$. Nesse caso, uma única intersecção ocorrerá.

${ }^{4}$ Um polígono é descrito através de um conjunto de vértices ligados por arestas
} 
Para determinar se $4 \mathrm{~m}$ objeto poligonal foi interseptado por um raio de luz, basta verificar se pelo menos um dos polígonos que compõem esse objeto foi interceptado. O processo para se determinar intersecçōes com um polígono pode ser dividido em 2 passos:

1. A partir da equaşão do plano que passa pelos vértices que compõem o polígono, encontra-se o ponfo de interseção do raio com o plano (conforme já descrito nos parágrafos anteriores);

2. Verificar se o pontb encontrado é interno ao polígono correspondente.

Após essas duas etapas, considera-se um polígono como sendo interseptado por um raio se o ponto de intersecção com o plano do polígono for interno aos vértices daquele polígono. Para se determinar se um ponto é interno a um polígono, utiliza-se o Teorema da Curva de Jordan[Gla91] ou seja, disparando um raio (a partir do ponto a ser testado) em uma direção arbitrárła, determina-se o número de interseções desse raio com as arestas do polígono. O ponto é interno se o número de interseções for ímpar, caso contrário, é considerado externo. A figura 2.6 ilustra esse teorema (Adaptada de [Gla91]).

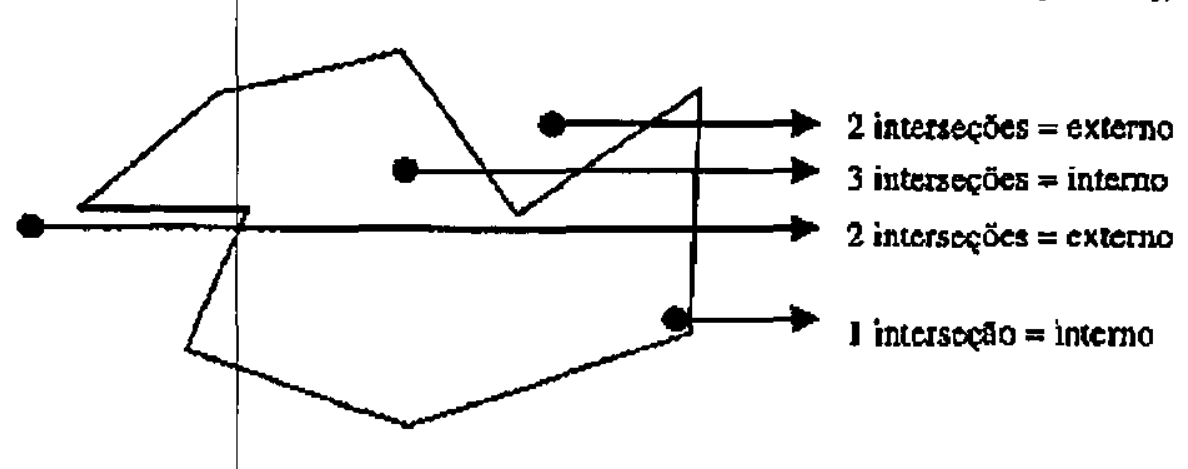

Figura 2.6: Teorema da Curva de Jordan

Até o presente momento, o algoritmo Ray-Tracing cuidou apenas da chamada iluminação local, ou seja, determinou a intensidade de luz no ponto visível, se baseando apenas na luz que atinge esse ponto. Porém, a superfície de um objeto é iluminada não somente pela iluminação local, nas também pela iluminação proveniente de reflexões e refrações da luz na superfície de outros objetos no ambiente.

A partir de agora estaremos preocupados em entender como tratar esses dois casos, e anexá-los ao modelo do algoritmo de traçado de raios.

\section{Reflexōes}

Ao olhar para uma superfície lisa e polida pode-se perceber imagens refletidas de outros objetos presentes no ambiente, como se estivéssemos olhando em um espelho. Esse fenômeno ocorre devido a reflexão dos raios de luz sobre a superfície. Quando um raio de 
luz atinge a superfície, ppde-se observar dois princípios básicos da ótica. Primeiro, o raio incidente, a normal à superfície no ponto e o raio refletido são co-planares. Isso significa que um é combinação linear dos outros dois. Além disso, o ângulo formado entre o raio incidente $(\vec{I})$ e a normal $(\vec{N})$ é o mesmo que entre a normal e o raio refletido $(\vec{R})$ (ver figura 2.7).

Matematicamente, a direção do raio refletido $\vec{R}$ é dada pela equação 2.5 :

$$
\vec{R}=\vec{I}-2(\vec{N} \cdot \vec{I}) \vec{N}
$$

onde:

$\vec{I}$ é o raio incidente

$\vec{N}$ é o vetor normal à superfície no ponto de reflexão

$\vec{R}$ é o raio refletido

e ainda, todos os vetores possuem módulo unitário $(|\vec{I}|=|\vec{R}|=|\vec{N}|=1)$.

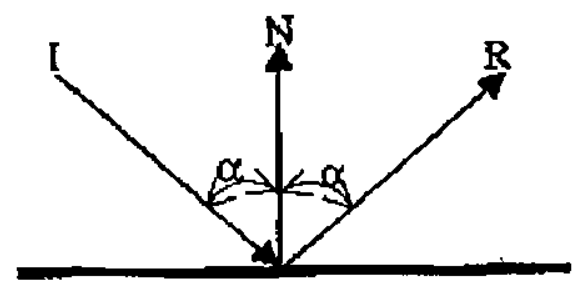

Figura 2.7: Geometria da Reflexão (Adaptada de [Gla91])

Uma vez determinada a direção do raio refletido $\vec{R}$, a próxima etapa consiste em continuar o traçado de raios (visto na seção 2.3.2), onde o ponto de observação é substituído pelo ponto de reflexão, e o vetor do raio de luz passa a ser o vetor do raio de luz refletido. A partir daí calcula-se todas as interseç̧ões para esse novo raio, determina-se o ponto mais próximo ao ponto de origem, e aplica-se um modelo de iluminação sobre ele. A cor resultante desse processo é a chamada componente de reflexão do ponto.

Quando se está determinando a cor de um dado ponto na superfície de um objeto, são levadas em consideração as características físicas do material que compõem essa superfície (coeficiente de difusão, especularidade, transparência, e outros). Portanto, a componente de reflexão de um ponto está diretamente ligada a esses parâmetros: se um ponto estiver sobre uma superfície com coeficiente de especularidade zero (superfície completamente opaca) significa que nenhum raio de luz é refletido especularmente a partir da superfície, e portanto esse cálculo é desnecessário.

Uma vez determinado o valor da componente de reflexão, o mesmo é composto com o valor previamente calculado pelo modelo de iluminação local (e também pela componente 
de refração, conforme será visto na próxima seção). O valor resultante dessa composição recebe o nome de modelo de iluminação global e é a cor que realmente será representada no plano de projeção para o pixel em questão.

A seguir veremos como determinar a componente de refração.

\section{Refrações}

O processo de cálculo da componente de refração é análogo ao cálculo da reflexão descrito acima. Primeiramente, define-se a direção do raio de luz transmitido (em relação à normal a superfície no ponto), e então aplica-se o modelo de iluminação para o novo vetor resultante.

O fenômeno da refrạ̧ão (também chamado de transmissão)[Gla91] ocorre quando uma determinada superfície, que foi atingida pelos raios de luz, tem a capacidade de permitir que esses raios atravessem a superfície. Um exemplo clássico de superfície que apresenta esta característica é o vidro.

Um fato importante a ressaltar, quando se fala de transmissão, é que não necessariamente os dois lados da superfície transmissora precisam ser iguais. Se imaginarmos um copo de vidro transparente cheio de água, teremos três superfícies que serão percorridas pela luz: o vidro, a água e o ar ao redor do copo. Um raio de luz que atravesse esse copo terá passado do ar para o vidro, depois do vidro para a água, então da água para o vidro, e finalmente do vidro para o ar.

Sempre que um fenômeno como esse ocorre (um raio de luz atravessar meios diferentes), a direção desse raid irá sofrer uma pequena distorção (em função das características do meio que está atravessando). É justamente esse fenômeno que explica porque, ao mergulharmos uma régua em um copo cheio de água, nós a veremos aparentemente "quebrada" (figura 2.8).

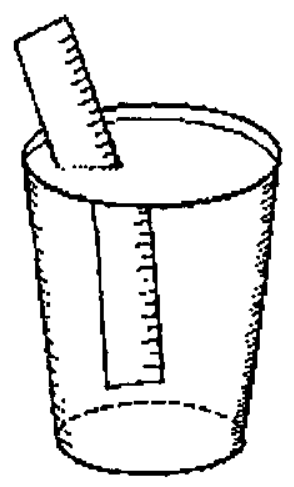

Figura 2.8: Efeito causado pelo fenômeno da refração (Retirada de [Gla91])

É importante salientar que essa distorção realizada pela luz ao atravessar um certo 
meio é determinada pelo índice de refração $0^{5}$ daquele meio. O que quantifica a distorção da luz é justamente a relação entre os índices de refração dos dois meios sendo atravessados e do ângulo de incidência dos raios de luz na superfície. A figura 2.9 ilustra a geometria do fenômeno da refração em uma superfície qualquer.

A relação entre o raio incidente $(\vec{I})$, a normal à superfície $(\vec{N})$ e o raio transmitido $(\vec{T})$ é baseada na Lei de Snell:

$$
\frac{\sin \alpha}{\sin \beta}=\frac{\eta_{\alpha}}{\eta_{\beta}}
$$

onde:

$\alpha$ ângulo de incidência da luz

$\beta$ ângulo de transmissão da luz

$\eta_{\alpha}$ índice de refração do meio 1

$\eta_{\beta}$ índice de refração do meio 2.

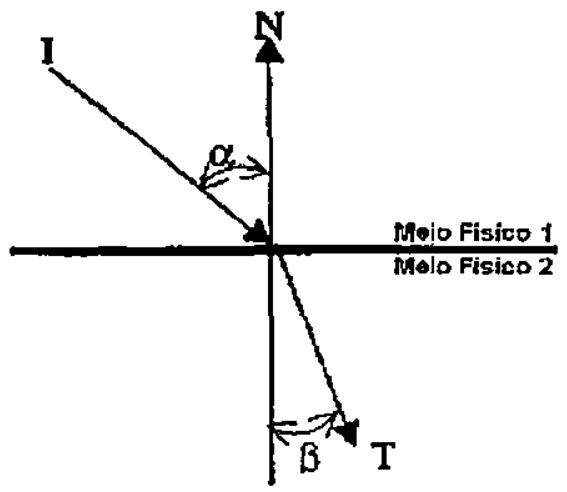

Figura 2.9: Geometria da Refração (Adaptada de [Gla91])

A seguir é mostrada uma tabela com os índices de refração de alguns meios físicos [Gla91]:

\footnotetext{
${ }^{5}$ Velocidade da luz em um determinado meio em comparação com a velocidade da luz no vácuo.
} 


\begin{tabular}{lr} 
Meio Físico & Indice de Refração \\
\hline Agua & 1.33 \\
Alcool Etílico & 1.36 \\
Ar $\left(1 \mathrm{~atm}, 20^{\circ} \mathrm{C}\right)$ & 1.00003 \\
Yidro ondulado & 1.52 \\
Yidro rígido & 1.66 \\
Cloreto de Sódio & 1.53 \\
\hline
\end{tabular}

Uma vez determinada a direção do raio de luz transmitido, é realizado processo semelhante ao que foi realizado para a reflexão, ou seja, aplica-se um modelo de iluminação ao ponto de observação, a partir do ponto atualmente sendo considerado pelo algoritmo, e compõem-se o resultado com a iluminação local e a componente de reflexão.

\section{Árvore Ray Tracing}

Uma vez definida a forma de cálculo das intersecções e das componentes de reflexão e refração, pode-se compreender melhor a idéia básica e completa do algoritmo Ray-Tracing. Primeiramente, é determinado, para cada raio de luz partindo do observador em direção a um pixel do plano de projeção, a intersecção mais próxima. A seguir, determinam-se as componentes de reflexão e refração (se necessário), e compõem-se todas.

Entretanto, cada vez que uma componente de reflexão (ou refração) estiver sendo calculada, novas interações (com outros objetos) podem ser realizadas, gerando assim uma árvore de raios que só terminaria quando já não houvessem mais interações da luz na cena virtual para um dado raio.

A figura 2.10 exemplifica essa árvore, onde cada aresta representa o "disparo"de um raio na cena (arestas grossas representam reflexões e finas as refrações). Na representação em árvore, as arestas à direita são as reflexões enquanto que à esquerda são as refrações ${ }^{6}$, e os vértices representam pontos de observação aos quais serão aplicados modelos de iluminação. Os raios sãb compostos até resultarem (na raiz da árvore) no valor da cor para o ponto sendo renderizado.

Assim que a árvore é gerada, torna-se relativamente simples determinar o valor da cor para o ponto em questãp. Percorrem-se todos os vértices da árvore compondo as cores, levando em consideração as características da superfície do objeto.

A seguir, será descrito um modelo de iluminação, que é uma técnica para a simulação (como o próprio nome sugere) da interação da luz com objetos em um ambiente tridimensional.

\footnotetext{
${ }^{6}$ Essa representação de árvore é meramente uma convenção, podendo ser adotada qualquer outra, desde que mantenha a distinçāo entre reflexões e refrações.
} 

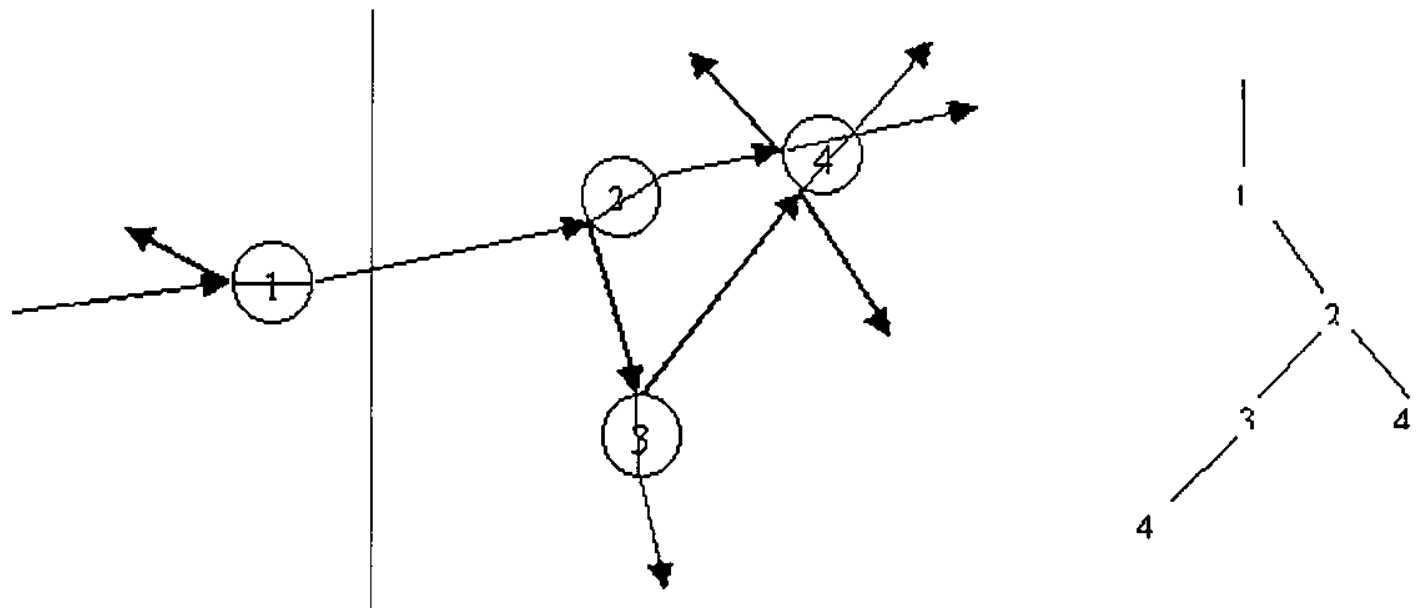

Figura 2.10: Árvore do Ray-Tracing

\subsection{Modelo de Iluminação}

A idéia básica de um modelo de iluminação[Fol90, Hea97, Gla91] é simular computacionalmente o fenômeno de propagação da energia luminosa em um ambiente tridimensional.

Conforme foi apresentado na seção 2.3, o algoritmo Ray-Tracing determina os pontos de uma cena tridimensional, que são visíveis a um observador. Associando essa idéia a um modelo de iluminação, pode-se determinar a cor de cada um desses pontos e com isso gerar uma imagem.

Devido à sua complexidade e elevado custo computacional, o modelo de iluminação aqui apresentado será baseado em uma série de aproximações que resultam em uma sensível melhora no desempenho do algoritmo, preservando ainda a qualidade final da imagem resultante.

O que torna um objeto visível é o fato dele refletir luz. Qualquer quantidade de luz incidente sobre uma superfície irá ser refletida, transmitida ou absorvida e transformada em calor pela mesma. Se porventura um objeto absorver toda a luz incidente sobre ele, esse será chamado de corpo negro e será invisivel.

A maneira como a luz se comporta na superfície de um objeto depende diretamente das características físicas do material do qual o objeto é composto. Uma superfície pode ser iluminada de três maneira diferentes: luz proveniente do ambiente, de reflexōes e de refraçōes.

A seguir estaremos discutindo detalhadamente cada uma dessas possibilidades.

\subsubsection{Ambiente}

O algoritmo Ray-Tracing se baseia na iluminação direta, isso significa que ele trata apenas os raios de luz que atingem diretamente a superfície do objeto. Porém, no mundo real, além de um objeto ser iluminado pela luz proveniente da fonte de luz primária (por 
exemplo, uma lâmpada) | ele também é iluminado por raios de luz provenientes de reflexões internas no ambiente em todas as direções.

Como determinar todos esses raios é muito custoso computacionalmente, é realizada uma aproximação para incluir no modelo de iluminação essa componente chamada de iluminação de ambiente. Matematicamente, é feito um acréscimo de uma constante (usualmente $30 \%$ da iluminação total). Sendo assim, para todos os pontos que não forem iluminados diretamente será considerada essa iluminação constante, evitando com isso, que o ponto seja considerado negro (sem iluminação).

A equação que representa essa componente é dada por:

$$
I_{A}=I_{L} \cdot K_{A}
$$

onde $I_{L}$ indica a intensidade da fonte de luz e $K_{A}$ representa o fator de iluminação do ambiente.

\subsubsection{Reflexão}

A reflexão da luz ocorre em qualquer objeto visível, porém a maneira e quantidade de luz que será refletida depende basicamente do material de que o objeto é feito. Existem dois tipos de reflexão: a difusa e a especular.

\section{Reflexão Difusa}

$\mathrm{Na}$ reflexão difusa, também conhecida como reflexão lambertiana, a luz se reflete em igual intensidade em todas as direções, sendo de menor intensidade que a luz incidente. A intensidade da reflexão difusa em uma superfície é proporcional ao ângulo $\theta$ formado entre o raio de luz e a normal à superfície (ver Figura 2.11(a)). Isso se deve ao fato de que a área $(\mathrm{dA})$ que o raio ilumina no objeto varia inversamente proporcional ao ângulo entre o mesmo e a normal, conforme pode ser visto na figura 2.11(b).

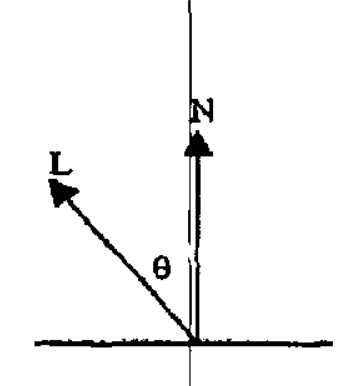

(a)

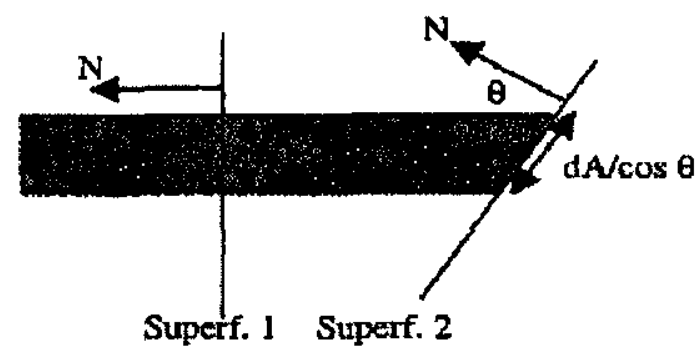

(b)

Figura 2.11: Reflexão Difusa (Adaptada de [Fol90])

A equação de Lambert para a reflexão difusa é dada por: 


$$
I_{D}=I_{L} \cdot K_{D} \cdot \cos \theta
$$

onde:

$I_{L}$ representa a intensidade da fonte de luz

$K_{D}$ representa a constante de difusão do material

$$
I_{D}=I_{L} \cdot K_{D} \cdot(\vec{N} \cdot \vec{L})
$$

onde $(\vec{N} \cdot \vec{L})$ representa o produto escalar entre o vetor normal e o raio de luz. Se adotarmos os vetores $\vec{L}$ e $\vec{N}$ como unitários $(|\vec{L}|=|\vec{N}|=1)$ então teremos $(\vec{N} \cdot \vec{L})=|\vec{N}| \cdot|\vec{L}| \cdot \cos \theta=$ $\cos \theta$.

Determinar a reflexão difusa significa, na realidade, determinar a cor da superfície de um objeto. Quanto mais difusamente um objeto reflete mais intensa será a cor do mesmo. A figura 2.12 mostra vârias esferas com diferentes constantes de difusão representando assim, diferentes intensidades de reflexão difusa.

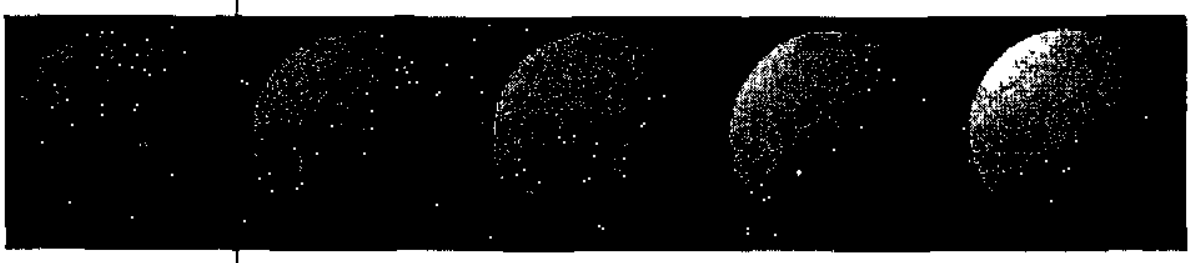

Figura 2.12: Diferentes coeficientes de difusão $K_{d}=0.4,0.55,0.7,0.85$ e 1.0 (Retirada de [Fol90])

Pelo fato do algoritmo Ray-Tracing trabalhar apenas com iluminação direta, regiões que não recebem luz direta simplesmente não são iluminadas e apresentam-se completamente escuras. Esse problema é amenizado se acrescentarmos a componente de iluminação ambiente. Assim a resultante de iluminação, até o momento, é dada por:

\section{Reflexão Especular}

$$
I=I_{A}+I_{D}=I_{L} \cdot K_{A}+I_{L} \cdot K_{D} \cdot(\vec{N} \cdot \vec{L})
$$

A reflexão especular é responsável pela "aparência brilhante"da superfície. Ela é governada pela equação de Fresnel[Ces95], que afirma que a reflexão especular é direcional. Idealmente, todo raio de luz será refletido com o mesmo ângulo de incidência (superfície perfeitamente espelhada). Porém a reflexão especular é percebida em maior intensidade na direção do observador. Por esse motivo é que ocorre o fenômeno chamado highlight 
(ponto luminoso), o qual pode ser concentrado ou esparso, dependendo das características do material.

O modelo empírico de Bui-Tuong Phong é muito utilizado devido a sua simplicidade, para a representação do fenômeno da reflexão especular. Ele é expresso pela seguinte equação:

$$
I_{S}=I_{L} \cdot W(i, \lambda) \cdot \cos ^{n} \alpha
$$

onde : $W(i, \lambda)$ é a razão entre a luz refletida especularmente e a luz incidente $i$ em função do comprimento de onde $\lambda ; n$ é a aproximação matemática para a concentração espacial da reflexão (highlight $)^{7}$ e $\alpha$ é o ângulo formado entre o raio de luz incidente $(\vec{I})$ e o raio refletido na superfície $(\vec{R})$ (ver Figura 2.7 ).

A figura 2.13 ilustra vários exemplos de esferas com diferentes coeficientes de especularidade, e também diferentes concentraçōes especulares (highlight). É importante salientar que a cor do highlight náo depende da cor do objeto e sim da cor da fonte de luz, já que se trata de uma reflexão perfeita.

Computacionalmente pode-se substituir a função $W(i, \lambda)$ por uma constante $K_{S}$, a qual terá o mesmo significado da função $W(i, \lambda)$, simplificando os cálculos necessários ao processamento sem perda significativa na qualidade da imagem resultante [Rog85].

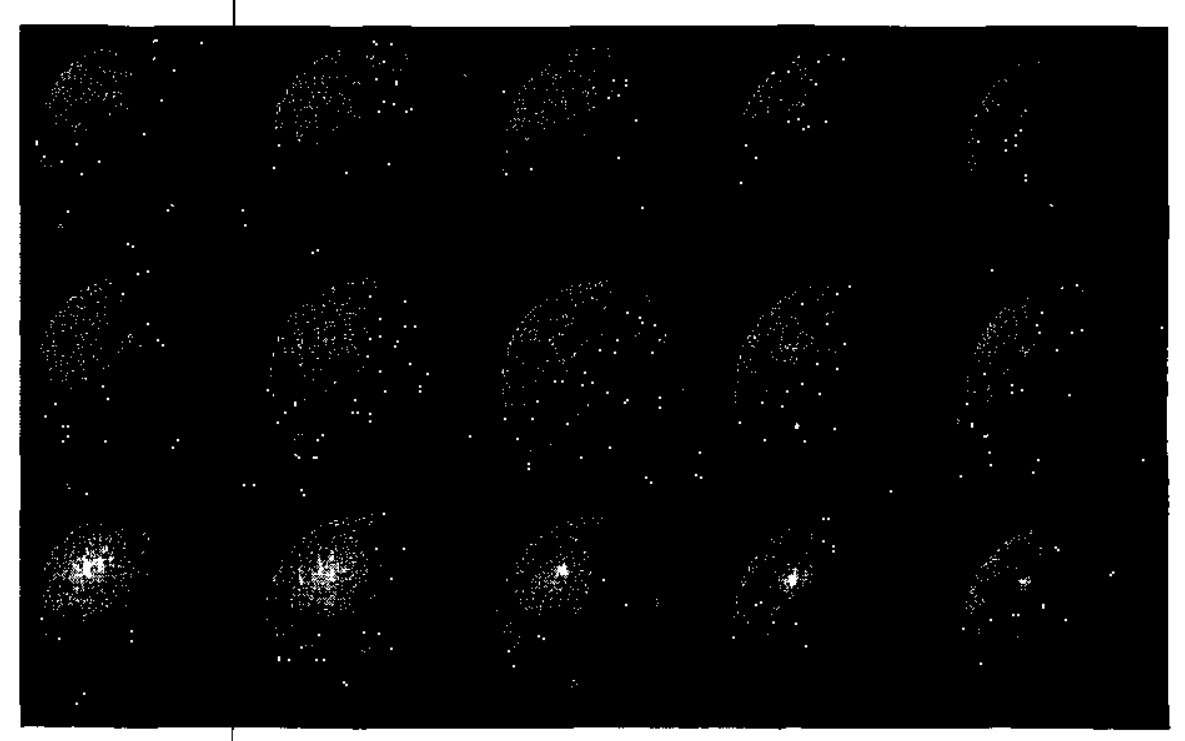

Figura 2.13: Exemplo de reflexão especular. Todas as esferas possuem $K_{a}=0.1$ e $K_{d}=$ 0.45 . Da esquerda para a direita temos $n=3.0,5.0,10.0,27.0$ e 200.0. De cima para baixo temos $K_{s}=0.1,0.25$ e 0.5. (Retirada de [Fol90])

\footnotetext{
${ }^{7}$ Valores pequenos para $n$ representam materiais opacos (pouco especulares) enquanto que valores grandes representam materiais altamente especulares como por exemplo, metais.
} 


\subsubsection{Modelo de Iluminação Local}

Um modelo de iluminaçâo local nada mais é do que um modelo de iluminação que considera apenas a luz direta sobre um ponto, sem levar em consideração a maioria dos efeitos óticos existentes no mundo real como sombras, espelhamentos, transparências, etc.

Conforme foi visto nas seções anteriores, é possível determinar valores aproximados para a intensidade de luz que um dado ponto está recebendo em um ambiente virtual através do cálculo das i uminações ambiente, difusa e especular. Através da composição desses valores determina-se o valor da cor do pixel a ser armazenado no plano de projeção.

A equação que compõem essas três componentes é a seguinte:

$$
I=I_{L} \cdot K_{A}+I_{L} \cdot\left(K_{D} \cdot \cos \theta+K_{S} \cdot \cos ^{n} \alpha\right)
$$

Um fator importante é que quando estamos falando em armazenar cores computacionalmente, estamos nos referindo ao sistema RGB (Red-Vermelho, Green-Verde e BlueAzul)[Fol90, Hea97] e que a equação 2.12 deve ser aplicada individualmente para cada uma das componentes R, G e B. Portanto, na realidade a equação do modelo de iluminação local fica:

$$
\begin{aligned}
& I_{R}=I_{L_{R}} \cdot K_{A}+I_{L_{R}} \cdot\left(K_{D_{R}} \cdot \cos \theta+K_{S} \cdot \cos ^{n} \alpha\right) \\
& I_{G}=I_{L_{G}} \cdot K_{A}+I_{L_{G}} \cdot\left(K_{D_{G}} \cdot \cos \theta+K_{S} \cdot \cos ^{n} \alpha\right) \\
& I_{B}=I_{L_{B}} \cdot K_{A}+I_{L_{B}} \cdot\left(K_{D_{B}} \cdot \cos \theta+K_{S} \cdot \cos ^{n} \alpha\right)
\end{aligned}
$$

Outra informação importante é que, caso haja mais de uma fontes de luz, o modelo será aplicado individualmente para cada uma e os resultados compostos para a produção de um valor resultante.

\subsubsection{Modelo de Iluminação Global}

Um modelo de iluminação global é uma extensão da idéia do modelo local. Nesse caso, são acrescidas caracterígticas inerentes a qualquer sistema físico de propagação da energia luminosa.

A partir de agora veremos como adicionar efeitos mais sofisticados e desejáveis ao modelo de iluminação, tais como: sombras, espelhamentos, transparências e mapeamento de texturas. Apesar de existirem várias outras características que podem ser anexadas a um modelo de iluminaçăo, aqui serão estudadas apenas as mais comuns. Maiores detalhes podem ser obtidos em [Fol90].

\section{Sombras}

Gerar sombras usando Ray-Tracing é um processo relativamente simples. Apesar do resultado não ser o ideal, ainda sim serve para ajudar na idéia de perspectiva da imagem, fornecendo uma noção de profundidade. 
No mundo real, uma região encontra-se na sombra se, entre ela e a fonte de luz, existirem objetos opacos ou translúcidos. Desta forma eles impedirão a passagem dos raios de luz, gerando uma área de escuridão. Sombras, porém, não podem ser consideradas como sendo regiões onde haja ausência de luz pois, apesar delas não receberem iluminação direta de fontes, ainda sim são iluminadas por reflexões da luz no ambiente. Isso explica porque uma sombra geralmente não é completamente escura.

Esse conceito confrohta diretamente com a idéia básica do algoritmo Ray-Tracing que trata apenas da iluminação direta, o que impede uma representação mais realista de sombras. Computacionalmente, sombras serão tratadas como regiões onde haja ausência de luminosidade e serão consideradas negras (intensidade de luz incidente igual a 0 ).

Sendo assim, determinar se um dado ponto na cena está ou não na sombra se torna um processo simples: basta definir se entre o ponto em questão e a fonte de luz existe algum outro objeto com características opacas. Isso é feito através de traçado de raios, conforme visto na seção 2.3.2. Tendo como origem o ponto ao qual está se aplicando o modelo de iluminação, "dispara-se"um raio em direção a fonte de luz e determina-se possíveis interseções com outros objetos. A partir daí, determinar se o ponto está na sombra é equivalente a saber se existem objetos opacos no caminho do raio, em caso afirmativo, este recebe intensidade de luz nula $\left(I_{L}=0\right)$. Se existirem intersecções com objetos transparentes, $\phi$ ponto está numa penumbra e recebe intensidade de luz igual à composição dos coeficientes de transparência dos objetos interceptados, e se não houverem interseç̧ões, o ponto é iluminado $\left(I_{L}=1\right)$.

Uma vez determinado o valor para $I_{L}$ basta substituí-lo no modelo local de iluminação (Eq. 2.13).

\section{Espelhos}

Definir uma superfície espelhada no Ray-Tracing, é um processo mais de traçado de raios do que de modelo de iluminação. A seção 2.3.2 mostrou como gerar raios que determinam as reflexões a partir de um dado ponto na cena. Para esse raio refletido, onde o ponto de origem é o ponto a ser iluminado, aplica-se o modelo de iluminação local e compōemse o resultado com o valor já calculado, no próprio ponto. $O$ valor do espelhamento é ponderado através de una constante $\left(K_{M}\right)$ que determina a característica de espelhamento da superfície.

Portanto o novo modelo de iluminação seria:

$$
I=I_{L} \cdot K_{A}+I_{L} \cdot\left(K_{D} \cdot \cos \theta+K_{S} \cdot \cos ^{n} \alpha\right)+I_{M} \cdot K_{M}
$$

onde $I_{M}$ representa o modelo local de iluminação aplicado ao ponto iluminado pelo raio refletido. 


\section{Transparências}

Assim como para os espelhos, determinar o valor para a transparência de uma superfície é feita através da aplicação do modelo local para o raio transmitido (seção 2.3.2) e anexando o resultado $\left(I_{T}\right)$ ao modelo anteriormente calculado, ponderado por uma constante de transparência $\left(K_{T}\right)$ :

$$
I=I_{L} \cdot K_{A}+I_{L} \cdot\left(K_{D} \cdot \cos \theta+K_{S} \cdot \cos ^{n} \alpha\right)+I_{M} \cdot K_{M}+I_{T} \cdot K_{T}
$$

A figura 2.14(a) ilustra uma superfície transparente onde não foi considerado o fenômeno da refração, ou seja, não há mudança no índice de refração entre diferentes meios e o raio de luz não sofreu desvio. Na figura 2.14(b) temos o exemplo oposto: transparência com refração da luz através do objeto (Adaptada de [Fol90]).

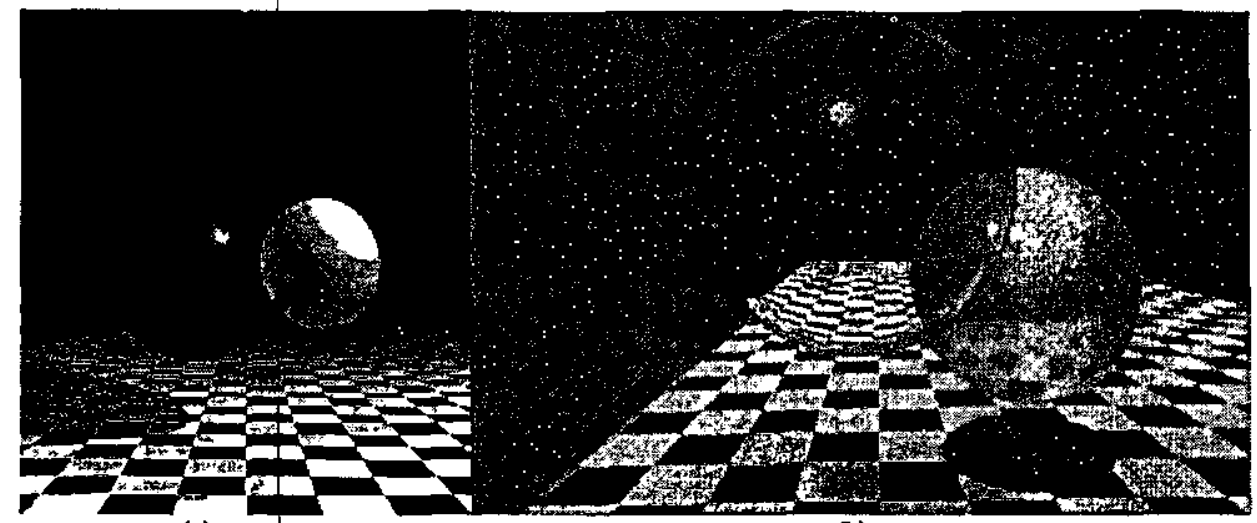

(a)

(b)

Figura 2.14: (a)Transparências sem refração (b) Transparências com refração.

\section{Texturas}

Até agora vimos como representar diversas características físicas de um modelo de iluminação permitindo criar imagens tridimensionais com bom grau de realismo. Porém, no mundo real as superfícies não são sempre lisas (como estão sendo representadas no modelo até agora). Elas podem apresentar aparências diversas tais como: rugosidade, granularidade, variação nas cores, entre tantas outras possibilidades. Para exemplificar, imagine como seria gerar uma laranja através de Ray-Tracing: como gerar uma superfície que apresente a aparência da casca da laranja? Ou então, como criar o piso quadriculado que é visto na figura 2.14 ?

A resposta para esse problema está na aplicação de uma textura sobre a superfície sendo renderizada. Uma textura é, via de regra, uma matriz de pontos gerados externamente ao algoritmo, ou através de um procedimento. Esses pontos são então aplicados ao modelo, representando a cor da superfície no ponto. Isso é feito através de uma função 
de mapeamento que associa pontos específicos da matriz (2D) ao ponto na superfície do objeto (3D). A figura 2.15 mostra como funciona uma função de mapeamento para uma esfera.

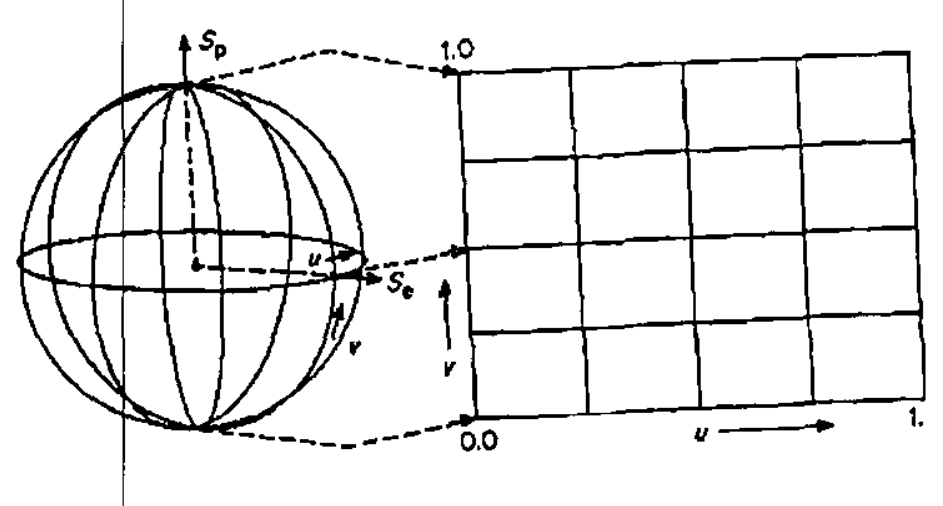

Figura 2.15: Função de Mapeamento de Textura (Retirada de [Gla91])

Além das características avançadas de iluminação já vistas, inúmeras outras podem ser anexadas a um modelo de iluminação global, como, por exemplo: atenuação da intensidade de luz em função da distância, névoa e movimento.

A seguir, serão descritas algumas das principais técnicas de modelagem de objetos e superfícies, sobre as quals podem ser aplicados os modelos de iluminação estudados.

\subsection{Modelagem de Objetos e Superfícies}

Definir os objetos que compõem a imagem que será gerada não é um processo trivial. Existem diversas técnicas que realizam essa tarefa com complexidades e resultados diferentes. Uma das formas mais simples para a definição da cena é através de equações paramétricas ou implícitas, tais como: esferas, elipsóides, planos, toróides, entre outros. Essa técnica se baseia na representação de uma superfície tridimensional que captura a estrutura do objeto. Entretanto, ela não consegue tratar de forma adequada a região interior aos objetos (objetos são apenas "cascas"e não sólidos).

Apesar dessa limitação, essa técnica satisfaz a necessidade de parte das aplicações que utilizam a técnica Ray-Tracing para gerar imagens tridimensionais foto-realistas.

Outra forma bastante utilizada e bem mais genérica que a primeira, é a aproximação de uma dada superfície por malha de polígonos. Essa técnica permite a representação de uma grande variedade de superfícies complexas sem a necessidade que seja definida uma equação para tal. No entanto, ela não é muito precisa devido ao fato de que a superfície é aproximada por polígonos planos. A quantidade de polígonos necessários para se representar uma dada superfície cresce proporcionalmente com a complexidade do objeto e com o grau de aproximação que se deseja obter. A figura 2.16 [Ces95] ilustra várias esferas representadas por essa técnica, com grau de aproximação diferenciados. 

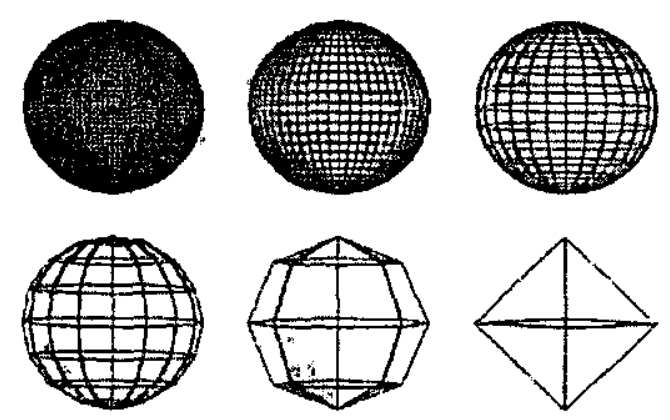

Figura 2.16: Esferas com diferentes resoluções apresentadas em fio de arame

Uma terceira maneira bastante útil para se representar objetos complexos é através de operações booleanas[Wel93] que consistem de operações lógicas realizadas sobre um conjunto de primitivas (ou objetos) para a criação de outro objeto. As operações booleanas mais comuns são a união, a interseç̧ão e a diferença (ver Figura 2.17).

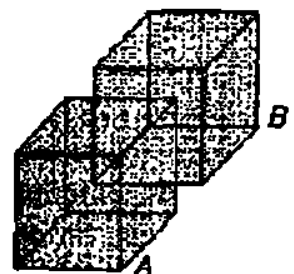

(a)

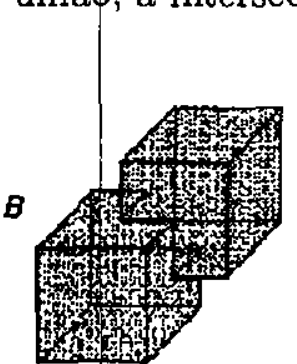

(b)

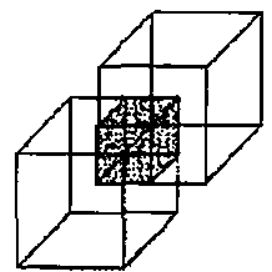

(c)

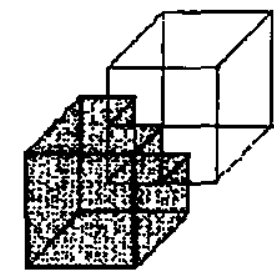

(d)

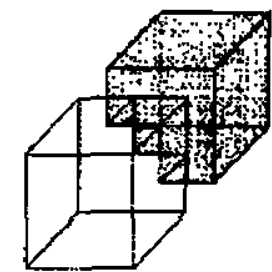

(a)

Figura 2.17: Operações Booleanas - (a) Objetos Originais, (b) União, (c) Intersecção, (d) A - B, (e) B - A (Retirada de [Fol90])

As técnicas apresentadas neste capítulo deverão ser, em parte, utilizadas para simular a geração de imagens na retina de um olho virtual.

A seguir, estudaremos a modelagem dos componentes básicos do olho humano utilizados durante a simulação de seu funcionamento ótico. A simulação propriamente dita será discutida no capítulo 4 


\section{Capítulo 3}

\section{Modelagem dos Componentes envolvidos na Simulação}

Neste capítulo é apresentada a modelagem dos componentes do olho que serão utilizados durante a simulação. Na primeira seção discute-se a maneira como foi modelado o olho humano e, a seguir, seus principais componentes. Por fim, na seção 3.6, os optótipos de Snellen.

O olho humano é uma estrutura bastante complexa e pode apresentar grandes variações, de indivíduo para indivíduo, em relação ao tamanho e forma de seus componentes. Por esse motivo, a criação de um modelo do olho é feita a partir de dados médios de cada componente. A figura 3.1 mostra o modelo do olho, proposto por H.V. Helmholtz, que serviu de base para esta pesquisa.

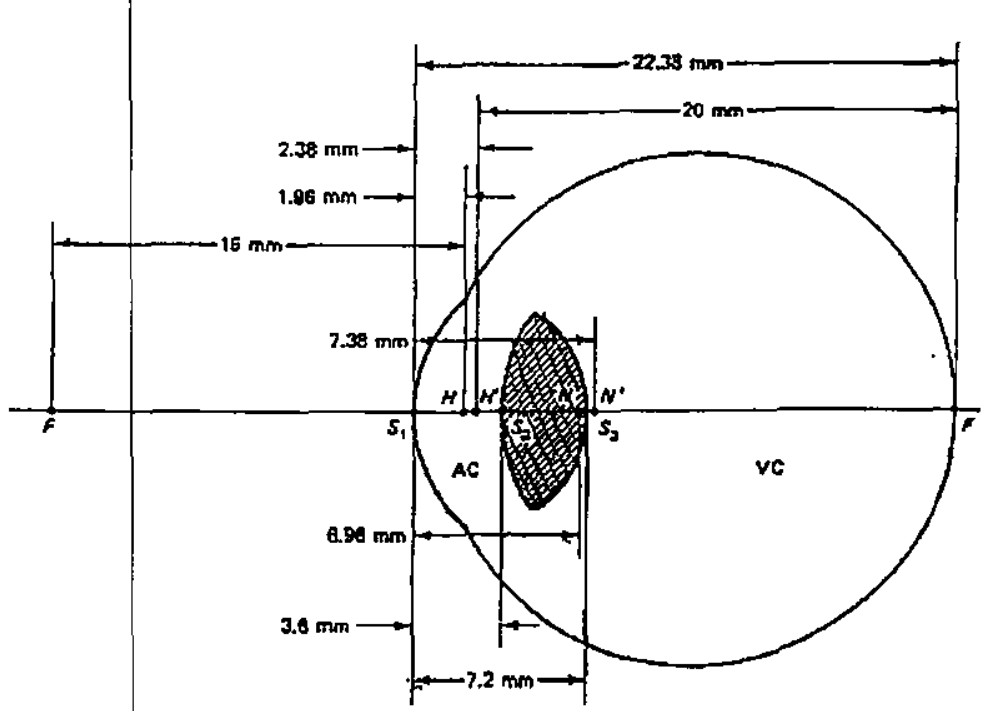

Figura 3.1: Representação Esquemática do Olho Humano (Retirada de [Gra80]) 
A maneira como tai\$ componentes foram utilizados pela ferramenta durante a simulação será descrita em detalhes no capítulo 4 .

\subsection{O Olho}

Inicialmente trata-se da modelagem do globo ocular, ou seja, as estruturas consideradas pelo modelo matemático e a forma de representação utilizada para cada uma.

Tentar simular todos os componentes do olho seria uma tarefa inviável computacionalmente, bem como desnecessária. Isso se deve ao fato de que apenas alguns poucos componentes do olho são efetivamente responsáveis pelo seu funcionamento ótico.

Pode-se simplificar o funcionamento do olho para apenas quatro componentes principais: a córnea que é responsável pela maior parte do poder de refração da luz no olho e é onde se percebe a maioria das ametropias visuais (ver seção 1.2); a pupila que é o orifício responsável pelo controle da quantidade de luz que entra no olho, bem como do controle da profundidade de foco da imagem. A próxima estrutura importante percorrida pela luz, no olho, é o cristalino, uma lente natural capaz de mudar seu raio de curvatura e permitir com isso a conreta focalização dos raios de luz na retina. Por fim, a retina que é a parte posterior do olho responsável pela captação dos raios de luz e sua conversão em estímulos luminosos, os quais são enviados ao cérebro para a criação da imagem da visão. A figura 3.2 ilustra o modelo proposto.

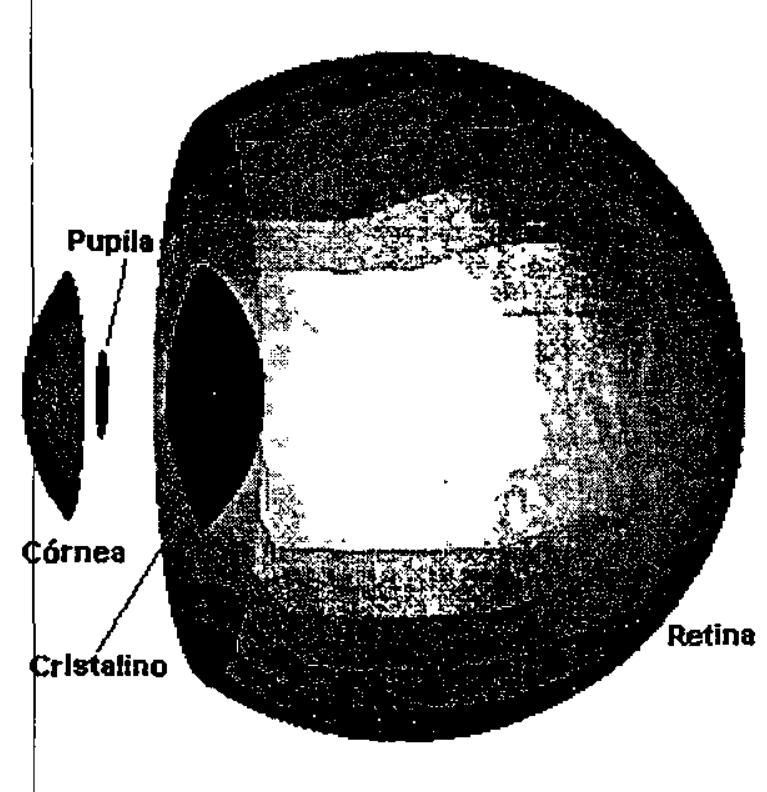

Figura 3.2: Modelo Tridimensional dos componentes do Olho

O capítulo 2 mostrou que realizar uma simulação utilizando Ray-Tracing não é uma tarefa trivial computacionalmente. Devido a isso, toda e qualquer otimização que possa 
ser feita sem que isso répresente perda significativa nos resultados finais da simulação é sempre desejável. Motivo pelo qual optou-se por simular apenas os componentes citados anteriormente, ignorando-se os demais. Como será visto no próximo capítulo, esses componentes são suficientes para produzir resultados satisfatórios.

A figura 3.3 mostra as distâncias entre os componentes modelados (em $\mathrm{mm}$ ).

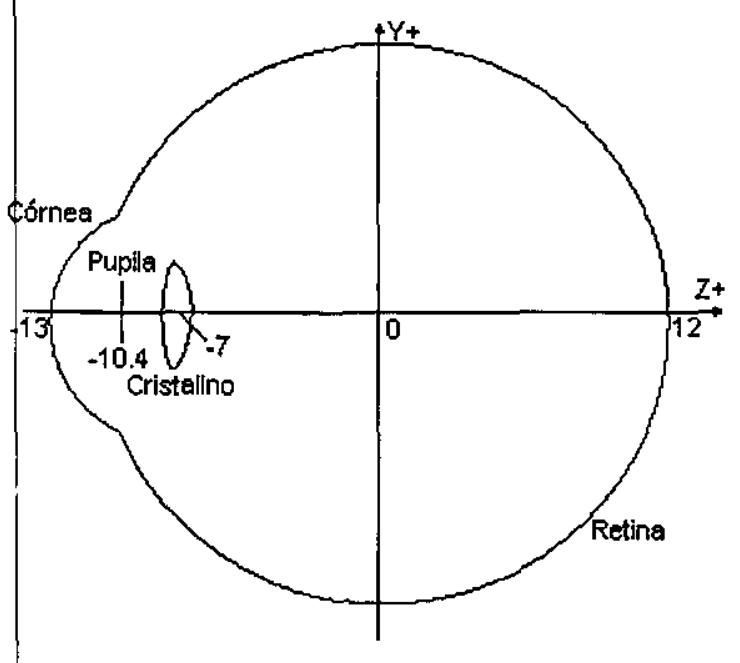

Figura 3.3: Esquema dos componentes do Olho Teórico

A seguir, discute-se separadamente cada um dos componentes tratados pela ferramenta de simulação.

\section{$3.2 \quad$ A Retina}

Conforme foi apresentado na seção 1.1, a retina é a parte posterior da esclera e é composta por um conjunto muito grande de células fotorreceptoras. Essas células são responsáveis pela captação da luz e o envio dos estímulos luminosos ao cérebro através do nervo ótico.

Computacionalmente, a representação adotada para a retina foi a de uma malha de polígonos triangulares de maneira que, os vértices desses polígonos representem os fotorreceptores.

O processo de criação dessa malha é realizado através de refinamentos sucessivos a partir de uma malha inicial grosseiramente refinada (Figura 3.4(a)). Para cada polígono da malha, divide-se suas arestas ao meio, gerando três novos vértices os quais são reposicionados sobre a superfície da esfera. Quatro novos polígonos são criados a partir desses novos vértices, conforme é ilustrado na figura 3.5. As figuras 3.4(b) e (c) ilustram exemplos de malhas resultantes de diferentes refinamentos.

Devido a grande quantidade de fotorreceptores presentes na retina humana (acima de 120 milhões segundo [Lim90]), se faz necessário um refinamento bastante grande. Mo- 

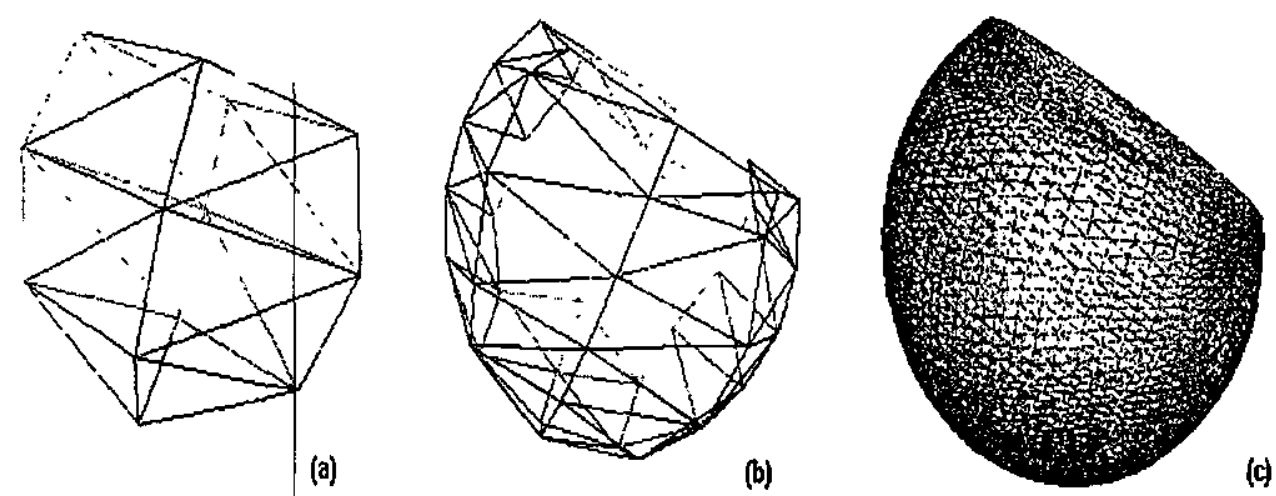

Figura 3.4: Processo de Refinamentos Sucessivos para a criação da malha da retina

delar tal quantidade de vértices em uma malha tornaria o processo computacionalmente inviável. Desse modo, optou-se por criar um modelo simplificado do olho onde os polígonos ficam mais concentrados (refinados) na região mais próxima à fóvea (parte posterior da retina) e diminuem de densidade na região periférica da retina (multi-resolução).

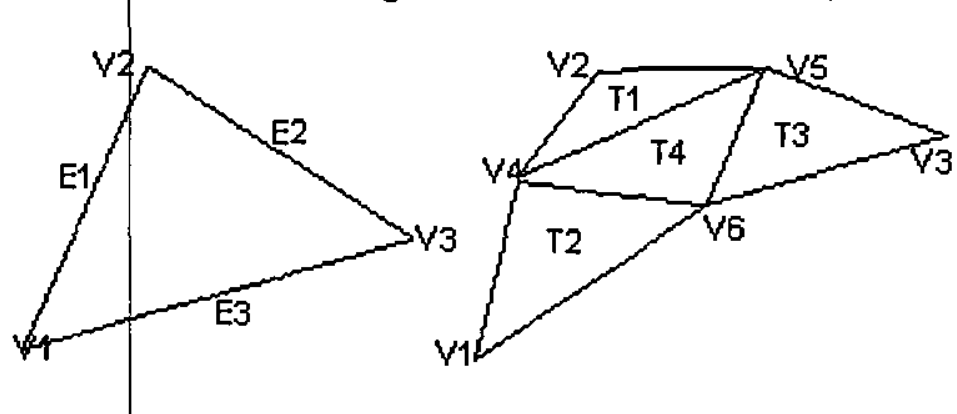

Figura 3.5: Refinamento de um polígono

Essa aproximação condiz com a realidade pois percebe-se que a maior parte da luz inciden te no olho atinge a região próxima à fóvea. Apenas uma pequena parcela dos raios de luz atinge as demais regiões da retina formando o que chamamos de visão periférica. Sendo assim, tal artifício não representou perda significativa nos resultados obtidos nas simulações.

O processo de criação desta malha é descrito a seguir.

\subsubsection{Multi-Resolução}

O processo de criação da malha poligonal consiste basicamente na utilização de refinamentos sucessivos a partir de uma malha inicial pouco refinada. Subdivide-se cada polígono que compõem a malha qriginal, tantas vezes quanto necessário, até se obter um grau de 
refinamento satisfatório. O número de vezes que a malha inicial sofre refinamentos diz qual será a densidade dos polígonos resultantes.

No caso da malha ufilizada na pesquisa, utilizou-se triângulos como o polígono base. A idéia do refinamento de um triângulo é conceitualmente simples (Figura 3.5):

1. Divide-se cada aresta do triângulo inicial ao meio encontrando assim, três novos vértices para a malha $\left(V_{4}, V_{5}, V_{6}\right)$;

2. Eliminam-se as arestas $\left(E_{1}, E_{2}, E_{3}\right)$ existentes para o triângulo atual;

3. Criam-se quatro novos triângulos $\left(T_{1}, T_{2}, T_{3}, T_{4}\right)$ a partir dos 6 vértices resultantes com suas respectiyas novas arestas.

No caso da retina, a malha resultante tem a forma esférica. Sendo assim, os 3 novos pontos gerados em cada triângulo serão deslocados a partir do centro em direção à superfície da esfera. A divisão das arestas e deslocamento dos novos vértices é feito da seguinte forma:

1. Determinam-se dois vetores $\left(\vec{V}_{1}\right.$ e $\left.\vec{V}_{2}\right)$ a partir do centro da esfera em direção aos vértices de cada aresta;

2. Somam-se esses dois vetores $\left(\vec{V}_{1}\right.$ e $\left.\vec{V}_{2}\right)$. O vetor resultante $\vec{M}$ passa pelo ponto médio da aresta;

3. Multiplica-se o vetor normalizado $\vec{M}$, pelo raio da esfera desejada;

4. O resultado são as coordenadas do ponto na superfície da esfera.

Para se produzir a malha com multi-resolução deve-se dividir a malha inicial (não refinada) em diferentes regiões. No caso da retina, optou-se por dividir a malha em três regiōes distintas ${ }^{1}$ (com diferentes graus de refinamento) conforme a figura 3.6 ilustra.

O refinamento por região utilizado durante as simulações é o seguinte ${ }^{2}$ :

- região 1: 3 divisões.

- região 2: 4 divisōes.

- região 3: 9 divisões (fundo do olho).

Para se realizar o processo começa-se pela região menos refinada (dividindo-se todos os polígonos da malha). A seguir, refina-se as regiōes 2 e 3 (em sequência). Para tal, se faz necessário percorrer a lista de polígonos definindo a qual região cada polígono pertence.

\footnotetext{
${ }^{1}$ As fronteiras foram posicionadas em -9.0, 10.0 e $11.75 \mathrm{~mm}$ no eixo $O_{z}$

${ }^{2}$ Valores escolhidos em funç̧ão da memória disponível
} 


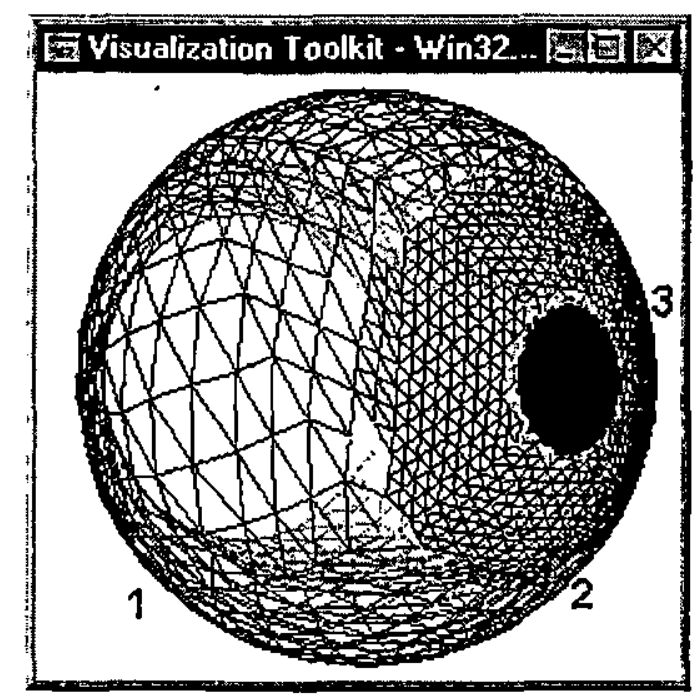

Figura 3.6: Regiōes da multi-resolução

Um polígono será considerado como pertencendo à região 2 se todos os seus vértices não pertencerem à região 1. O mesmo aplica-se aos polígonos da região 3 .

Um problema inerente a esse processo pode ser percebidos nas fronteiras entre as regiões. Entre dois níveis de refinamento existem polígonos com mais de 3 vértices como na figura 3.7(a). Tais polígonos dificultam a manutenção da estrutura de dados. A solução encontrada foi dividir o triângulo vizinho em dois (Figura 3.7 (b)) de maneira a manter a topologia da malha consistente.

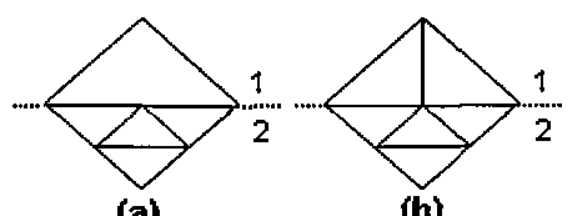

(a)

(b)

Figura 3.7: Divisões de um polígono

Para se determinar os polígonos que necessitam ser adaptados basta verificar a vizinhança (polígonos que compartilham uma aresta) de um polígono de fronteira. Se o seu vizinho pertencer a outfa região, este deve ser dividido pela aresta compartilhada.

A próxima seção discute a forma de modelagem do cristalino, a lente natural do olho. 


\subsection{O Cristalino}

O cristalino é uma lente natural do olho que tem a capacidade de mudar seu raio de curvatura para com isso. mudar o seu poder de refração e garantir a focalização da luz na retina.

Em termos de modelagem para a ferramenta de simulação, optou-se por uma representação através da equação implícita das superfícies do cristalino, como será visto a seguir. A figura 3.8 ilustra essas superfícies.

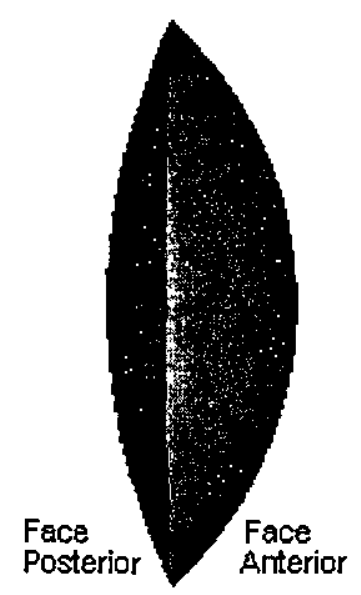

F'igura 3.8: A superfície do cristalino

Para representar o cristalino como duas calotas esféricas de raios diferentes é necessário definir os parâmetros de tais superfícies de forma precisa.

A equação implícita da esfera é dada por :

$$
E=\left(X-e_{x}\right)^{2}+\left(Y-e_{y}\right)^{2}+\left(Z-e_{z}\right)^{2}-r_{e}^{2}
$$

onde $\left(e_{x}, e_{y}, e_{z}\right)$ representa as coordenadas do centro da esfera e $r_{e}$ representa seu raio. Os valores das coordenadas utilizadas na simulação foram retirados do modelo de Helmholtz, o qual é ilustrado na figura 3.1.

O modelo matemático do cristalino é adaptativo com a distância de focalização, isto é, os parâmetros referentes ao raio de curvatura de cada superfície, bem como a posição do centro de cada uma, muda em função da distância (em relação ao olho) do objeto sendo focalizado.

Segundo o modelo proposto por Gullstrand [Gra80], o cristalino apresenta os seguintes valores médios para sua acomodação: 


\begin{tabular}{l|cc} 
& Ponto Remoto $(\geq 6.0 \mathrm{~m})$ & Ponto Próximo $(\leq 0.3 \mathrm{~m})$ \\
\hline Índice de Refração & 1.40 & 1.42 \\
\hline Raio de Curvatur & & \\
Sup. Anterior & 10.0 & 5.33 \\
Sup. Posterior & 6.0 & 5.33 \\
\hline
\end{tabular}

Baseado nesses valores, criou-se um modelo automático de acomodação do cristalino. A figura 3.9 abaixo ilustra uma variação linear do raio de curvatura de cada face do cristalino separadamente, em relação à variação da distância do objeto sendo focalizado.
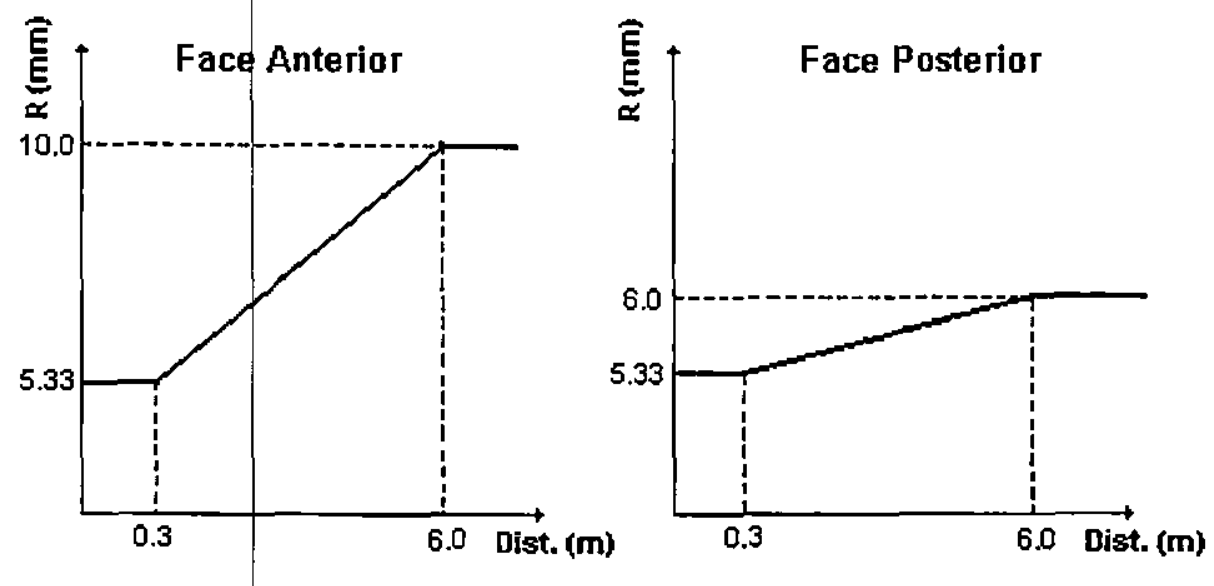

Figura 3.9: Acomodação das faces do cristalino

Embora a acomodadão não seja realmente linear, como na figura 3.9, ela varia muito de indivíduo para individuo, dificultando a criaçāo de um modelo preciso. Desta forma, optou-se pela conduta linear para a acomodação do cristalino por razões de simplicidade e pela falta de dados reais que guiassem nossa modelagem.

Para se determinar o valor do raio de curvatura de uma face do cristalino utilizou-se a função linear apresentada na equação 3.2 .

$$
Y=m \cdot\left(X-X_{0}\right)-Y_{0}
$$

onde $X$ representa a distância do olho ao objeto sendo focalizado, $Y$ representa o raio de curvatura da superfície, $\left(X_{0}, Y_{0}\right)$ é o ponto inicial da reta (conforme a figura 3.9) e $m$ é a inclinação da reta dada por:

$$
m=\frac{\Delta_{y}}{\Delta_{x}}=\frac{Y-Y_{0}}{X-X_{0}}
$$

Através das equações 3.2 e 3.3 é possivel determinar o valor do raio de curvatura para uma distância $D$ qualquer. Criou-se um modelo para cada uma das superfícies do cristalino, apresentadas na equação 3.4 : 


$$
\begin{aligned}
& \left(R_{a}-10.0\right)=\frac{10.0-5.33}{6.0-0.3} \cdot(D-6.0) \\
& \left(R_{p}-6.0\right)=\frac{6.0-5.33}{6.0-0.3} \cdot(D-6.0)
\end{aligned}
$$

sendo $R_{a}$ o raio de curvatura da face anterior e $R_{p}$ o raio de curvatura da face posterior. Resolvendo a equação 3,4 temos:

$$
\begin{aligned}
& R_{a}=0.83 \cdot(D-6.0)+10.0 \\
& R_{p}=0.12 \cdot(D-6.0)+6.0
\end{aligned}
$$

Portanto, a partir da equação 3.5 é possível se determinar o raio das faces do cristalino a qualquer distância de focalização do objeto.

Porém, um problema geométrico ocorre aqui, se o centro de curvatura de cada face permanecer fixo, com a variação dos raios, as dimensōes da superfície (largura $4.0 \mathrm{~mm}$ e altura $9.0 \mathrm{~mm}$ ) também seriam alteradas. Sendo assim, se fez necessário também, a criação de um modelo de variação dos centros de curvatura em função da mesma distância $D$ para, com isso, mantẹr as proporções desejadas para a superfície resultante.

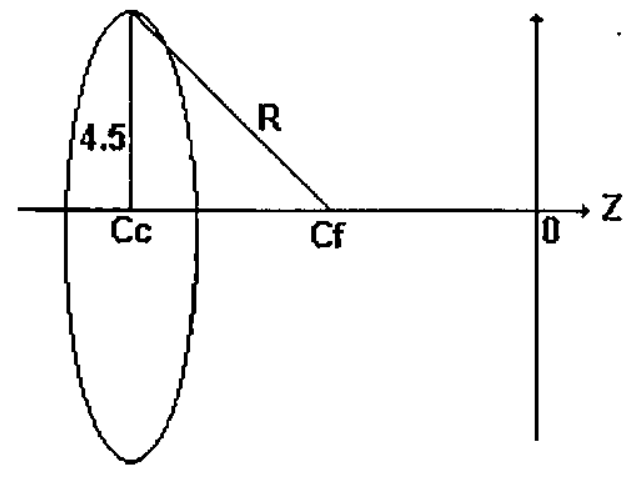

Figura 3.10: Cálculo do centro da face do cristalino

Conforme a figura 3.10, o centro de cada uma das faces do cristalino, varia linearmente com o raio da face. Para determinarmos a posição exata do centro de curvatura, basta calcular a distância entre $C_{c}$ (centro do cristalino) e $C_{f}$ (centro da face). A equação que resolve este problema é dada em 3.6.

$$
C_{f}=C_{c}-\sqrt{R_{f}^{2}-4.5^{2}}
$$

onde $R_{f}$ é o raio de curvatura da face e a constante 4.5 representa a metade da altura da superfície do cristalino (Figura 3.10).

De posse das equações 3.5 e 3.6 já é possível a construção do modelo automático de acomodação do cristalino em função da distância de focalização. Esses parâmetros são passados para a equaçā 3.1 , a partir da qual é realizada a simulação.

A figura 3.11 ilustra a superfície do cristalino variando em função da distância. 


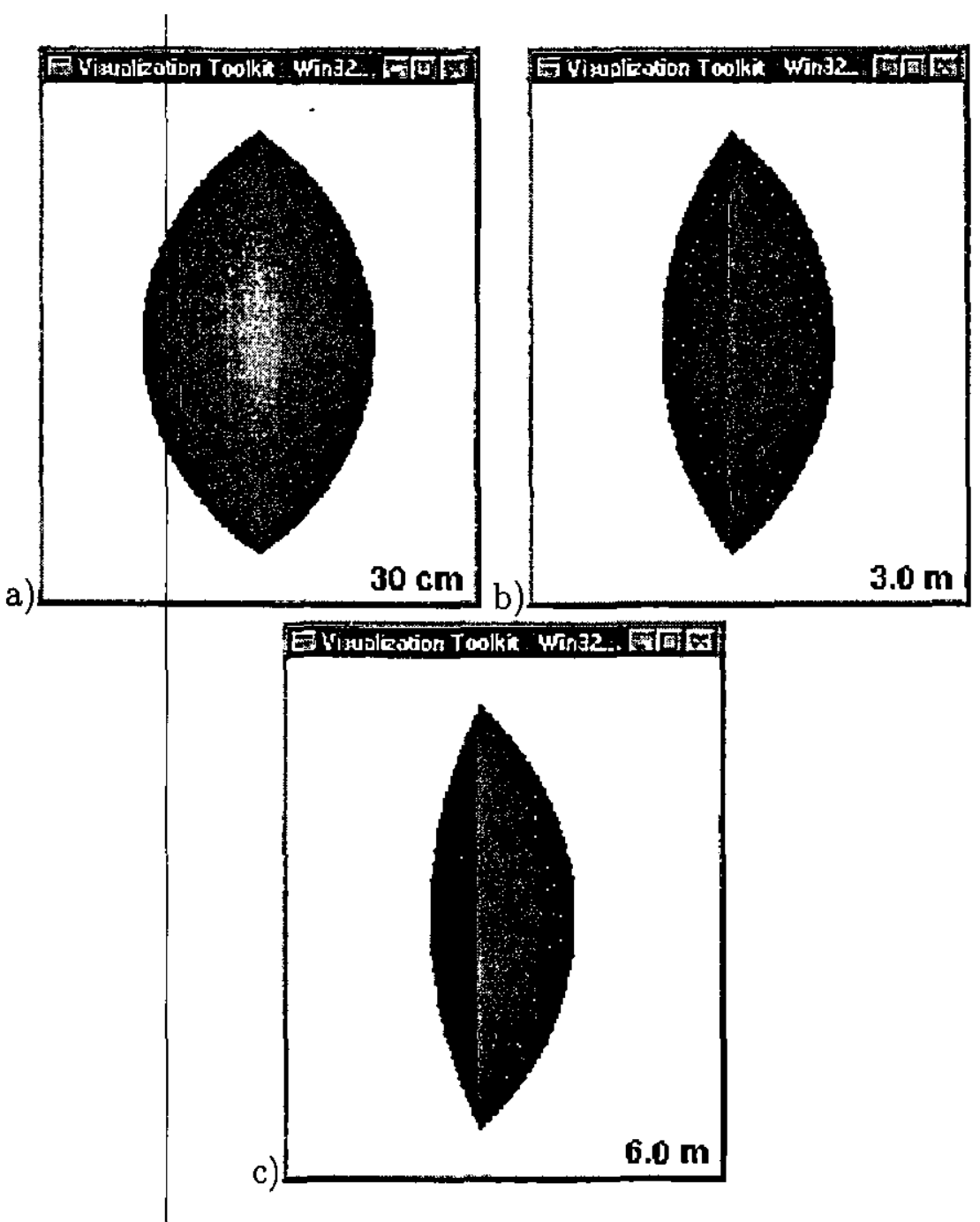

Figura 3.11: Processo de acomodação do cristalino em relação à distância

O próximo componente a ser estudado é a pupila, que é a abertura de entrada da luz no olho.

\subsection{A Pupila}

Por ser a porta de entrada da luz no olho, a pupila foi escolhida como ponto de partida para a simulação. De modelagem extremamente simples, a pupila é a origem de todos os raios de luz utilizados na simulação (maiores detalhes no capítulo 4).

A pupila é representada no modelo como sendo um círculo de raio $R$ (abertura pupi$\operatorname{lar})^{3}$.

\footnotetext{
${ }^{3} \mathrm{~A}$ abertura pupilar pode variar entre 0.75 e $4.0 \mathrm{~mm}$ [Gra80]
} 
Durante a simulação, é necessário informar ao modelo, quantos raios de luz devem ser "disparados"no ambiente. Esse processo é definido através de dois parâmetros, os quais são fundamentais para a discretizaçāo dos pontos na superfície da pupila: número de anéis e resolução de um anel. O primeiro parâmetro informa em quantos sub-círculos concêntricos deverá ser dividida a pupila, enquanto que, o segundo parâmetro informa quantas divisões deverá ter cada sub-círculo.

O cálculo da discrețização é feito ponto a ponto, a partir de coordenadas polares do círculo:

$$
\begin{aligned}
& X=C_{x}+\text { Raio } \cdot \cos \theta \\
& Y=C_{y}+\text { Raio } \cdot \sin \theta \\
& Z=C_{z}
\end{aligned}
$$

onde $\left(C_{x}, C_{y}, C_{z}\right)$ sāo as coordenadas do centro do círculo e $\theta$ varia entre $[0,2 \pi]$.

Assim, as coordenadas de um ponto na pupila são dadas pelas equações 3.8 e 3.9:

$$
\begin{gathered}
P_{x}=C_{x}+R_{a} \cdot \cos \theta \\
P_{y}=C_{y}+R_{a} \cdot \sin \theta \\
P_{z}=C_{z} \\
R_{a}=\frac{R_{p}}{\text { RingResolution }} \cdot \text { RingsProcessed }
\end{gathered}
$$

onde $R_{a}$ representa o raio do anel (sub-círculo) sendo discretizado; $R_{p}$ representa a abertura pupilar; RingResolution é a quantidade de anéis utilizados na discretização e RingsProcessed representa a quantidade de anéis já discretizados no processo (varia entre $0 \mathrm{e}$ RingResolution).

Uma vez definidas as coordenadas de um ponto na pupila, essa informação é passada ao simulador que inicia o disparo de raios a partir daquele ponto em direção à córnea. Esse processo se repete até que todos os pontos da pupila tenham sido processados. $O$ disparo de um raio $(\vec{V})$ é determinado pela equação 3.10 abaixo:

$$
\vec{V}=P_{c r n}-P_{p}
$$

onde $P_{c r n}$ são as coordenadas de um ponto discretizado na direção da córnea e indica a direção do raio disparado e $P_{p}$ representa as coordenadas do ponto discretizado sobre a pupila.

A próxima seção descreverá a modelagem da córnea.

\subsection{A Córnea}

Em termos óticos, a cơnnea é a estrutura principal do olho humano. Ela é responsável por $75 \%$ de todo poder de refração do olho e os principais problemas inerentes à visão ocorrem aqui. 
A modelagem dessa estrutura foi feita, para efeito de estudo, de duas formas distintas: equação implícita da esfera e malha poligonal da superfície de córneas de olhos reais.

Primeiramente, discutiremos a modelagem da córnea através da equação implícita da esfera. Analogamente ao cristalino, a córnea "implícita"necessita apenas dos parâmetros do raio e do centro para sua simulação. Esses dados foram obtidos a partir da bibliografia de apoio ([Gra80, Car96, Ped87, San93]) e compostos para se criar o modelo utilizado na pesquisa. A partir de agora, o modelo aqui proposto será denominado olho teórico.

O processo matemático de simulação da luz através de uma esfera já foi discutido na seção 2.3.2, sendo assim, compreender como essa técnica foi aplicada para a córnea implícita se torna uma tarefa simples:

- Para cada raio disparado a partir da pupila, calculam-se as interseções com a esfera;

- Serão encontrados dois pontos de interseção;

- Escolhe-se o ponto de interseção que gerar um termo paramétrico positivo ${ }^{4}$.

- Para esse ponto, calcula-se o vetor normal e o raio refratado pela superfície.

- Prossegue-se com a simulação (melhor descrita no capítulo 4).

A córnea modelada a partir de uma esfera produz (conforme o capítulo 4 irá mostrar) resultados próximos ao que se espera para um olho emétrope (que não apresenta ametropias da visão). A seguir, trata-se a forma como foi modelada a córnea real, obtida a partir de dados fornecidos por pesquisadores do grupo de ótica oftálmica do Instituto de Física (IFSC) da USP de São Carlos.

Os dados fornecidos são chamados de topografia de córnea. Entende-se por topografia de córnea, o conjunto de diversas curvaturas nas diversas regiōes da córnea humana. A medição da curvatura das regiões da córnea é feita através de um videoceratógrafo ou topógrafo de córnea. Esse aparelho funciona da seguinte maneira: primeiramente, ilumina-se a superfície do olho com anéis concêntricos de luz. Esses anéis irão refletir na superfície da córnea e a imagem resultante dessa reflexão é captada por uma câmera (ou máquina fotográfica).

Uma vez obtida a imagem dos anéis sobre o olho, através de técnicas de processamento de imagens [Gon93, Fil99] obtêm-se o valor da curvatura em diversos pontos da superfície da córnea [Car96] (discretização).

O resultado de uma topografia de córnea é usualmente apresentado como uma matriz em coordenadas cilíndricas(figura 3.12) e cada ponto amostrado é do tipo $(r, \rho, z)$ onde:

r representa a distâncią do ponto em relação ao centro dos anéis;

$\rho$ significa o ângulo radial sendo amostrado $\left(0^{\circ}\right.$ até $\left.360^{\circ}\right)$

$\mathbf{z}$ indica a elevação da córnea no ponto. 


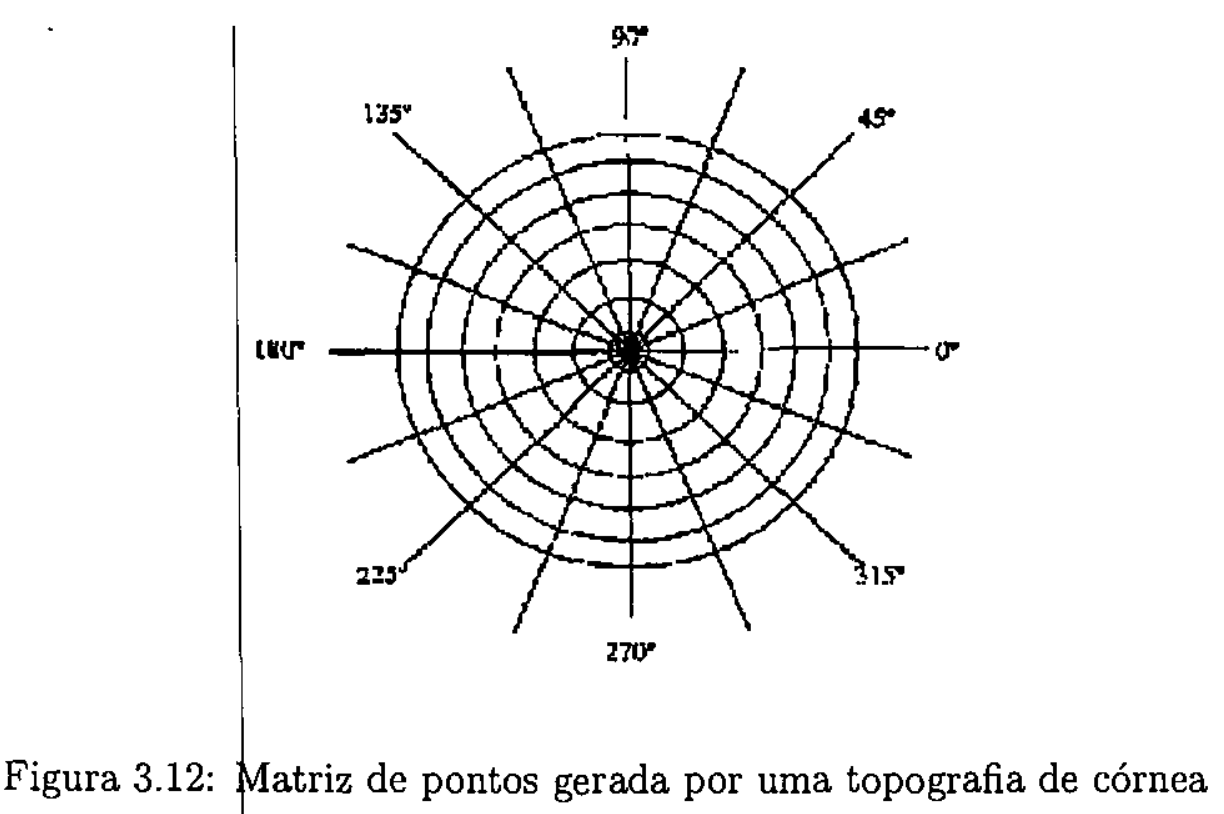

Outro conceito importante em topografia de córnea é o de dioptria. Pode-se entender dioptria como sendo o poder de refração de uma região da córnea, ou seja, o quanto a luz irá ser desviada em sua trajetória ao atravessar a córnea naquele ponto.

O cálculo da dioptria é dado por:

$$
D=\frac{\eta_{c}-\eta_{a r}}{r}
$$

onde:

D Dioptria (Poder de Refração)

$\eta_{c}$ índice de refraçāo da córnea $(\cong 1.37)$

$\eta_{a r}$ índice de refração d $\phi$ ar $(\cong 1.00)$

r raio de curvatura da córnea

Vale salientar que essa relação entre o raio de curvatura e o poder de refração se baseia em uma série de simplificações, e que portanto pode variar de um instrumento para outro.

Os dados da topografia de córnea são passados na forma de duas matrizes ${ }^{5}$ (360 raios $\mathrm{x} 17$ anéis) sendo que a primeira contém os dados referentes ao raio e ao ângulo $(r, \rho)$, enquanto que na segunda matriz temos as informações referentes à elevação $(z)$ relativa a cada ponto na outra matriz. Muitas vezes, essas matrizes estão em pixels e não em

\footnotetext{
${ }^{4} \mathrm{~A}$ interseção ocorreu à frente do ponto de origem do raio de luz

${ }^{5}$ Arquivos no formato ASCII
} 
milímetros (unidade utilizada para modelagem). Neste caso, uma conversão pixel/mm se faz necessária. Para isso, o fator de calibração do topógrafo ${ }^{6}$ deve ser considerado no sistema antes da criação da malha. Unindo-se as informações de ambas as matrizes, é possível a criação de uma malha poligonal triangular que aproxima a superfície original da cónrnea examinada.

A malha poligonal é armazenada em uma lista linear em uma ordem pré-determinada para, com isso, ser possível otimizar as simulações realizadas (ver Capítulo 4). A ordem escolhida foi a radial, ou seja, os polígonos são armazenadas ângulo por ângulo, anel por anel. A figura 3.13 ilustra essa ordem de modelagem da córnea.

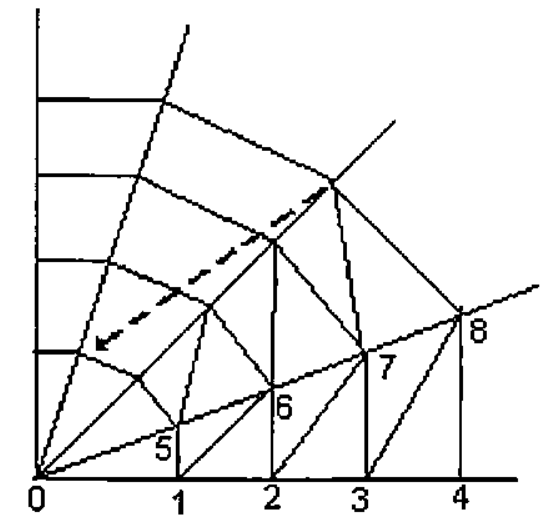

Figura 3,13: Ordenação da malha poligonal para a córnea

Após ter sido criada a malha poligonal, a próxima etapa é o cálculo da equação do plano (Eq. 3.12) que passa pelos vértices de cada triângulo. Para se determinar essa equação, utiliza-se a equação 3.13 abaixo:

$$
\begin{gathered}
A \cdot x+B \cdot y+C \cdot z+D=0 \\
A=P_{1_{y}} \cdot\left(P_{2_{z}}-P_{3_{z}}\right)+P_{2_{y}} \cdot\left(P_{3_{z}}-P_{1_{z}}\right)+P_{3_{y}} \cdot\left(P_{1_{z}}-P_{2_{z}}\right) \\
B=P_{1_{z}} \cdot\left(P_{2_{x}}-P_{3_{x}}\right)+P_{2_{z}} \cdot\left(P_{3_{x}}-P_{1_{x}}\right)+P_{3_{z}} \cdot\left(P_{1_{x}}-P_{2_{x}}\right) \\
C=P_{1_{x}} \cdot\left(P_{2_{y}}-P_{3_{y}}\right)+P_{2_{x}} \cdot\left(P_{3_{y}}-P_{1_{y}}\right)+P_{3_{z}} \cdot\left(P_{1_{y}}-P_{2_{y}}\right) \\
D=-P_{1_{x}} \cdot\left(P_{2 y} \cdot P_{3_{z}}-P_{3_{y}} \cdot P_{2_{z}}\right)-P_{2_{x}} \cdot\left(P_{3_{y}} \cdot P_{1_{z}}-P_{1_{y}} \cdot P_{3_{z}}\right)- \\
P_{3_{x}} \cdot\left(P_{1_{y}} \cdot P_{2_{z}}-P_{2_{y}} \cdot P_{1_{z}}\right)
\end{gathered}
$$

onde $\left(P_{1}, P_{2}, P_{3}\right)$ são as coordenadas dos vértices do polígono. A partir dessas informaçōes, pode-se efetuar o cálculo das intersecçōes do raio de luz com cada triângulo.

Até o presente momento, foram apresentadas as técnicas de modelagem utilizadas para os componentes do olho no modelo matemático do sistema visual humano. A partir de

\footnotetext{
${ }^{6}$ Relação pixel/mm que é fornecida pelo grupo do IFSC. Usualmente $\mathbf{0 . 0 2 4}$
} 
agora, trata-se da modelagem de outro componente que, apesar de não fazer parte do olho, foi utilizado como padrāo de testes nas simulações realizadas: os optótipos de Snellen.

\subsection{Optótipos de Snellen}

Conforme já foi apresentado no capítulo 1, os optótipos de Snellen são símbolos dispostos em linhas, em uma tabela, usados para se efetuar medições da acuidade visual de um olho de um indivíduo. Essas medições são feitas a partir de um teste que solicita que a pessoa leia (a uma distância pré-determinada) algumas linhas dessa tabela, onde cada linha apresenta optótipos com tamanhos diferentes, representando assim, diferentes graus de dificuldade na leitura. Dependendo de qual linha a pessoa consegue ler, o médico é capaz de medir sua capacidade visual?

Um optótipo é representado como uma matriz 5x5 (ver Figura 3.14) onde seu tamanho representa um ângulo visual de 5' de grau e cada $\frac{1}{5}$ representa 1' de grau (valor aceito para uma visão emétrope). Para se determinar o tamanho de um optótipo da tabela de Snellen, usa-se a fórmula 3.14, já descrita na seção 1.3.1. Foi baseado nesta equação que criou-se o modelo geométrico dos optótipos.

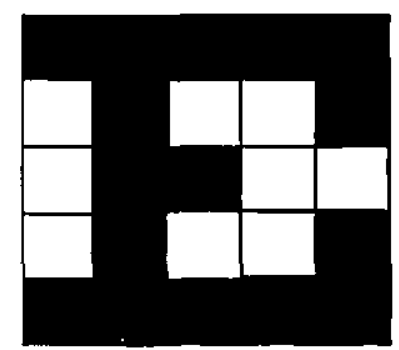

Figura 3.14: Elemento da Tabela de Snellen[Alv94]

A criação de um optótipo segue os seguinte passos:

$$
H=14,6 \cdot \frac{D}{V}
$$

1. Calcula-se o tamanho do optótipo a ser modelado (em função da distância ao observador);

2. Gera-se a matriz binária $5 \times 5$ que contém o elemento da tabela $(0=$ preto e $1=$ branco $)$;

\footnotetext{
${ }^{7}$ Cada linha da tabela de Snellen apresenta uma marcação que representa a distância máxima que a pessoa deve estar e ainda conseguir lê-la.
} 
3. Cria-se um conjunto de $5 \times 5$ polígonos quadrados para representar o optótipo (a cor de cada polígono depende do valor armazenado na matriz binária anteriormente gerada);

4. Um polígono externo (que englobe todos os demais) é criado para otimização da simulação (Bounding Box[Fol90, Hea97]).

Esse processo é ilustrado na figura 3.15 abaixo:

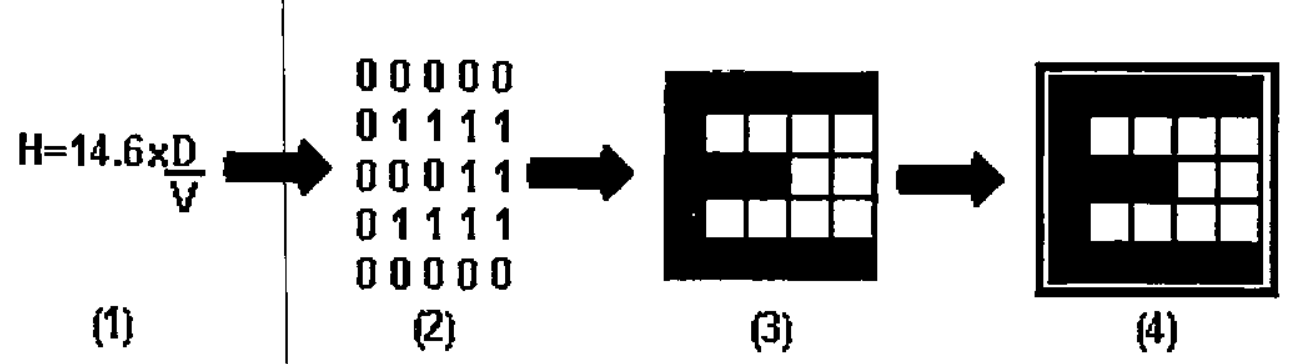

Figura 3.15: Processo de criação de um optótipo

Neste capítulo foram apresentadas as diferentes formas de modelagem para cada um dos componentes utilizados durante a simulação do sistema visual humano. No próximo capítulo, será discutido a simulaçāo ray-tracing propriamente dita, bem como os resultados obtidos. 


\section{Capítulo 4}

\section{Simulador do Sistema Visual}

Humano

Este capítulo descreve a ferramenta desenvolvida para a simulação do sistema visual humano. Essa simulação utiliza os componentes já descritos no capítulo 3. As primeiras seções discutem as diferentes alternativas de simulação (traçado de raios, modelagem, etc.) experimentadas. As seções seguintes irão mostrar os resultados obtidos nas várias simulações realizadas utilizando-se a ferramenta, bem como, uma análise desses resultados. A seguir descreve-se, separadamente, cada um dos módulos que compõem a ferramenta.

\subsection{A Simulação}

Conforme já foi adiantado nos capítulos anteriores, quando se trata de simulações da luz em ambientes tridimensionais, existem duas alternativas principais: forward ray-tracing, onde se simula o caminho da luz conforme as leis físicas da natureza, isto é, os raios de luz têm origem nas fontes de luz e são disparados em direção aos objetos presentes no ambiente. Essa alternativa, apesar de realista fisicamente, apresenta o problema de, na maioria dos casos, gerar "desperdício"de raios, ou seja, uma grande parcela dos raios de luz disparados no ambiente serão desconsiderados por não contribuirem para a geração da imagem final (mais detalhes na seção 2.3.2). A outra alternativa é a execução do traçado de raios na ordem inversa, o chamado backward ray-tracing, onde se considera o caminho inverso percorrido pelos raios desde o destino até seu ponto de partida. Essa alternativa minimiza os problemas inerentes ao desperdício de raios e, com isso, diminui o custo computacional da simulação.

Ambas as formas foram implementadas para efeito de comparação de resultados. As próximas seçōes irão tratar com maiores detalhes cada alternativa implementada.

O processo de simulação dos raios de luz através do modelo matemático do olho humano proposto nesta pesquisa se baseia no seguinte conjunto de passos:

1. Pré-processamento das informações de entrada, tais como: criação da malha poli- 
gonal a partir da|topografia da córnea, criação da malha poligonal multi-resolução da retina, etc.

2. Inicialização (pelo usuário) dos parâmetros necessários à simulação;

3: Traçado de raios no ambiente $3 \mathrm{D}$, onde estão presentes as modelagens dos componentes descritos no capítulo anterior;

4. Criação dos arquivos (formato VTK - Visualization Toolkit[Sch98]) contendo os resultados obtidos na simulação;

5. Geração das imagens resultante nesse processo.

No caso da malha da retina, o pré-processamento já foi descrito na seção 3.2. Como resultado desse processo é produzido um arquivo no formato VTK; já para a córnea, - procedimento adotad $\phi$ para a criação da malha resultante se baseia nas duas matrizes (distâncias radiais e de elevação) fornecidas pela topografia da córnea, sendo que os passos necessários são:

- Ler os valores das duas matrizes iniciais;

- Gerar uma malha inicial baseada simplesmente na ligação dos pontos fornecidos;

- Determinar as equações dos planos que passam por cada polígono, bem como o vetor normal a esse plano;

- Calcular os vetores normais em cada vértice da malha (composição das normais de todos os polígonos vizinhos);

O cálculo das normais nos vértices da malha têm a finalidade de melhorar a discretização da malha, pdis através desses valores serão interpolados vetores normais em qualquer ponto da malha original, sem a necessidade de uma discretização mais refinada (ver apêndice).

O próximo passo é definir os parâmetros necessários para o início da simulação. Esses parâmetros são nove, sendo que cinco são parâmetros de entrada e quatro de inicialização ${ }^{1}$. Os parâmetros de entradaª sāo:

Optótipos Conjunto com 5 optótipos (representando uma linha da tabela de Snellen); NumberOfRings Número de anéis utilizados no traçado de raios;

RaysPerRing Número de raios disparados para cada anel processado;

\footnotetext{
${ }^{1}$ Entende-se por parâmetro de entrada aqueles que são fornecidos pelo usuário e por parâmetro de inicialiação aqueles que são inicializados antes da compilação do programa.

${ }^{2} \mathrm{~A}$ aplicação de cada parăłmetro é apresentada nas seções seguintes.
} 
Distance Distância dos optótipos em relação ao olho (distância do exame), em milímetros $(\mathrm{mm})$;

Pupil Radius Raio da abertura pupilar (em mm).

e os parâmetros de inicjalização são:

Tipo Córnea Indica se a simulação usará o olho teórico ou o olho real ${ }^{3}$;

Marcação Marcação da tabela de Snellen (20/20, 20/30, etc.) para os optótipos já definidos;

Matriz Distância Matriz que contém as distâncias radias da topografia de córnea;

Matriz Elevação Matriz que contém as elevações (alturas) correspondente a cada ponto da matriz distância.

Com relação à abertura da pupila, um problema matemático ocorre, pois quando o olho abre a pupila significa que o ambiente está menos iluminado (por isso precisa entrar mais luz no olho); porém, o modelo criado não considera esse efeito e assim, mesmo com a pupila aberta, é disparada a mesma quantidade de luz gerando assim uma imagem ampliada (maiores detalhes nas próximas seções). Por esse motivo, a maioria das simulações realizadas se basearam em uma pupila pontual (abertura igual a 0 ).

Uma vez definidos todos os parâmetros necessários ao início da simulação, a próxima etapa é o traçado de raios. Esse processo é realizado a partir da discretização de pontos sob a superfície da córnea indicando, assim, a direção dos raios sendo simulados.

Em termos matemáticos, disparar um raio de luz significa definir dois parâmetros: ponto de origem e vetor direção do raio (equação paramétrica da reta). O cálculo desses parâmetros depende da alternativa ray-tracing que se esteja implementando: na técnica forward ray-tracing, os raios são disparado partindo dos optótipos em direção à córnea, já na backward ray-tracing, o ponto de origem está posicionado sobre a pupila e também é disparado em direção à córnea. A figura 4.1 ilustra essas alternativas de traçado de raios.

A característica comum às duas alternativas é o ponto de destino do vetor direcional do raio disparado: a superfície da córnea. Sendo assim, o processo de disparo dos raios começa com a discretização de pontos ressa estrutura. Isso é feito através da criação de "anéis virtuais"sobre a superfície, de modo a determinar o ponto de destino.

A quantidade de anés discretizados, bem como, a quantidade de pontos discretizados em cada anel é determinada pelos parâmetros de entrada NumberOfRings e RaysPerRing. Através da equação 4.1 galculam-se as coordenadas $\left(P_{x}, P_{y}, P_{z}\right)$ de um ponto em um dado anel virtual.

$$
\begin{aligned}
& P_{x}=C_{x}+\text { Radius } \cdot \cos \theta \cdot \cos \alpha \\
& P_{y}=C_{y}+\text { Radius } \cdot \sin \theta \cdot \cos \alpha \\
& P_{z}=C_{z}+\sin \alpha
\end{aligned}
$$

\footnotetext{
${ }^{3}$ São representados pelas constantes K_Cornea e K_CorneaReal respectivamente
} 
até aquele momento. Graças a essa otimização, não obrigatoriamente todos os raios solicitados pelos parâmetros de entrada sejam efetivamente processados pelo programa.

As próximas seções apresentam as formas de simulação utilizadas pela ferramenta. Inicialmente discutem-se as simulações que se basearam na técnica backward ray-tracing e, a seguir, na técnica forward ray-tracing.

\subsubsection{Backward Ray-Tracing}

O processo de simulação através da técnica backward ray-tracing se baseia nos seguintes passos:

1. Determina-se um ponto na pupila (origem dos raios disparados);

2. Determina-se (conforme descrito anteriormente), um ponto destino na direção da córnea;

3. Dispara-se um raio de luz;

4. Determina-se o ponto de intersecção do raio com a superfície da córnea;

5. Calcula-se a refração da luz nesse ponto (em relação ao vetor normal no ponto);

6. Determinam-se possíveis intersecções do raio refratado com os optótipos;

7. Caso ocorram intersecções, redispara-se (a partir da pupila) o raio inicial com sentido invertido $(\vec{V}=-\vec{V})$, em direção ao cristalino; caso contrário, descarta-se o raio e reinicia-se o processo com novo raio na pupila;

8. Calcula-se o ponto de intersecção com a face anterior do cristalino;

9. Calcula-se a refração da luz nesse ponto;

10. Calcula-se, usando o novo raio refratado, a intersecção e a refração da luz na segunda face do cristalino;

11. Determina-se a intersecção do raio com a retina;

12. Encontra-se o vértice (na malha poligonal da retina) mais próximo ao ponto de intersecção;

13. Atribui ao ponto na malha o valor 1 (cor branca) indicando que este foi iluminado;

14. Repete-se o processo até todos os anéis (na córnea) terem sido processados.

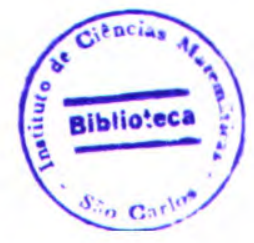


A grande vantagem dessa alternativa é a garantia automática de que todos os raios processados necessariamente passem pela pupila (condição básica para a simulação da visão). Essa característica não é garantida na técnica forward ray-tracing. Uma desvantagem percebida é que, uma vez que os raios atravessam a superfície da córnea, não há garantia que estes caminhem na direção dos optótipos (a direção do raio refratado depende uma série de fatores como o vetor normal na superfície da córnea e o índice de refração da córnea). Sendo assim, vários dos raios disparados na pupila serão descartados e não contribuirão para a formação da imagem na retina. No decorrer desta seção, serão apresentados dados estatísticos sobre o desempenho deste método quanto a utilização dos raios disparados.

Algumas particularidades na determinação de interseç̧ões do raio de luz disparado com cada componente do olho, são apresentadas no apêndice ao final desta monografia.

O processo de criaf̧ão do modelo matemático do olho ocorreu de forma gradativa, ou seja, os componentes modelados foram sendo incorporados ao modelo um a um, de maneira que fosse possível a análise quanto a sua função no sistema visual humano. A partir de agora, serão apresentados os resultados obtidos em cada etapa de implementação, ilustrando assim os diversos modelos criados durante a pesquisa, para deste modo, ser possível uma avaliação de qual modelo seria mais adequado para a solução do problema.

Inicialmente será apresentado um modelo onde os dados de todos os componentes foram obtidos a partir da bibliografia de apoio (olho teórico).

\section{Modelo do Olho Teørico}

O modelo do olho teórico é composto basicamente pelos seguintes componentes: a malha poligonal multi-resolução da retina, o modelo automático de acomodação das faces do cristalino, a pupila e a córnea modelada por equação implícita da esfera.

A intenção ao se criar este modelo era, primeiramente, avaliar a viabilidade da construção de um modelo matemático do olho humano e testar a possibilidade de simulação da luz em seus componentes. De posse dessa confirmação, a próxima motivação para o uso deste modelo era avaliar se os tipos de modelagem escolhidos eram adequados ao problema. Vale lembrar que o modelo do olho baseado em uma córnea esférica deve se comportar como um olho emétrope, ou seja, sem problemas de visão. Sendo assim, essas simulações são de grande importância no processo de entendimento do funcionamento do sistema visual humano.

Esse modelo foi o único que foi testado tanto na alternativa backward ray-tracing quanto na forward ray-tracing. Os resultados obtidos pela alternativa forward ray-tracing serão apresentados no decorrer do capítulo na seção 4.1.2.

Para efeito de simplificação na análise dos resultados obtidos, optou-se por utilizar em todas as simulações, nos diferentes modelos implementados, os mesmos optótipos (E,T,I,C,A); desta forma, simplifica-se a tarefa de avaliar e interpretar os resultados ${ }^{4}$.

\footnotetext{
${ }^{4}$ Apesar disso, a ferramenta suporta a modelagem de quaisquer sequência de optótipos
} 
Conforme já foi apressentado nas seções anteriores, uma simulação começa com a inicialização dos parâmetros desejados. Os parâmetros considerados para as simulaçōes foram: os optótipos de Snellen, a quantidade de raios a ser disparada no modelo (número de anéis $\mathrm{x}$ resolução de um anel), a distância do exame (em $\mathrm{mm}$ ), a abertura da pupila $(\mathrm{mm})$, a presença (ou não) do cristalino e o tamanho dos optótipos a serem utilizados durante a simulação (podem ser fixos ${ }^{5}$ ou variáveis conforme a distância dos optótipos ao observador).

Em função dos parâmetros de entrada número de anéis e resolução de um anel, é possível se determinar a quantidade de raios de luz que se espera disparar no sistema. Esse valor é dado pela equação $4.5^{6}$ :

$$
\text { Raios_Esperados }=(\text { Numero_Aneis }-1) \cdot \text { Resolucao_Anel }+1
$$

Porém, em decorrência da otimização realizada (de testar a ocorrência de interseções dos raios com os optótipos) o número de raios efetivamente disparados pode ser menor (ver a tabela de resultados obtidos a seguir). Em decorrência do fato de que nem todos os raios disparados atingirem os optótipos, varios deles serão descartados pelo modelo e assim, o número de raios que atingirá a retina formando a imagem pode ser ainda menor.

Os parâmetros utilizados nas simulações com o olho teórico são apresentados na tabela abaixo.

\begin{tabular}{|c|c|c|c|c|c|c|}
\hline & Optótipos & Raios & Distância & Pupila & Cristalino & Tamanho Opt. \\
\hline 01 & $\mathrm{E}, \mathrm{T}, \mathrm{I}, \mathrm{C}, \mathrm{A}$ & $850 \times 500$ & 6000.0 & 0.0 & Não & Fixo \\
\hline 02 & $\mathrm{E}, \mathrm{T}, \mathrm{I}, \mathrm{C}, \mathrm{A}$ & $850 \times 500$ & 1500.0 & 0.0 & Não & Fixo \\
\hline 03 & $\mathrm{E}, \mathrm{T}, \mathrm{I}, \mathrm{C}, \mathrm{A}$ & $850 \times 500$ & 6000.0 & 0.0 & Sim & Fixo \\
\hline 04 & $\mathrm{E}, \mathrm{T}, \mathrm{I}, \mathrm{C}, \mathrm{A}$ & $850 \times 500$ & 1500.0 & 0.0 & Sim & Fixo \\
\hline 05 & $\mathrm{E}, \mathrm{T}, \mathrm{I}, \mathrm{C}, \mathrm{A}$ & $850 \times 500$ & 6000.0 & 0.0 & Sim & Variável \\
\hline 06 & $\mathrm{E}, \mathrm{T}, \mathrm{I}, \mathrm{C}, \mathrm{A}$ & $850 \times 500$ & 1500.0 & 0.0 & Sim & Variável \\
\hline 07 & $\mathrm{E}, \mathrm{T}, \mathrm{I}, \mathrm{C}, \mathrm{A}$ & $850 \times 500$ & 6000.0 & 1.5 & Sim & Variável \\
\hline
\end{tabular}

Os resultados obtidos em cada simulação foram ${ }^{7}$ :

\begin{tabular}{|l|c|c|c|}
\hline & Raios Csperados & Raios Disparados & Raios na Retina \\
\hline 01 & 424.501 & $41.501(9.77 \%)$ & $7.650(18.43 \%)$ \\
\hline 02 & 424.501 & $407.001(95.87 \%)$ & $90.635(22.26 \%)$ \\
\hline 03 & 424.501 & $41.501(9.77 \%)$ & $7.650(18.43 \%)$ \\
\hline 04 & 424.501 & $407.001(95.87 \%)$ & $90.635(22.26 \%)$ \\
\hline 05 & 424.501 & $36.501(8.59 \%)$ & $6.648(18.21 \%)$ \\
\hline 06 & 424.501 & $37.501(8.59 \%)$ & $6.832(18.19 \%)$ \\
\hline 07 & 424.501 & $409.501(96.46 \%)$ & $86.474(21.11 \%)$ \\
\hline
\end{tabular}



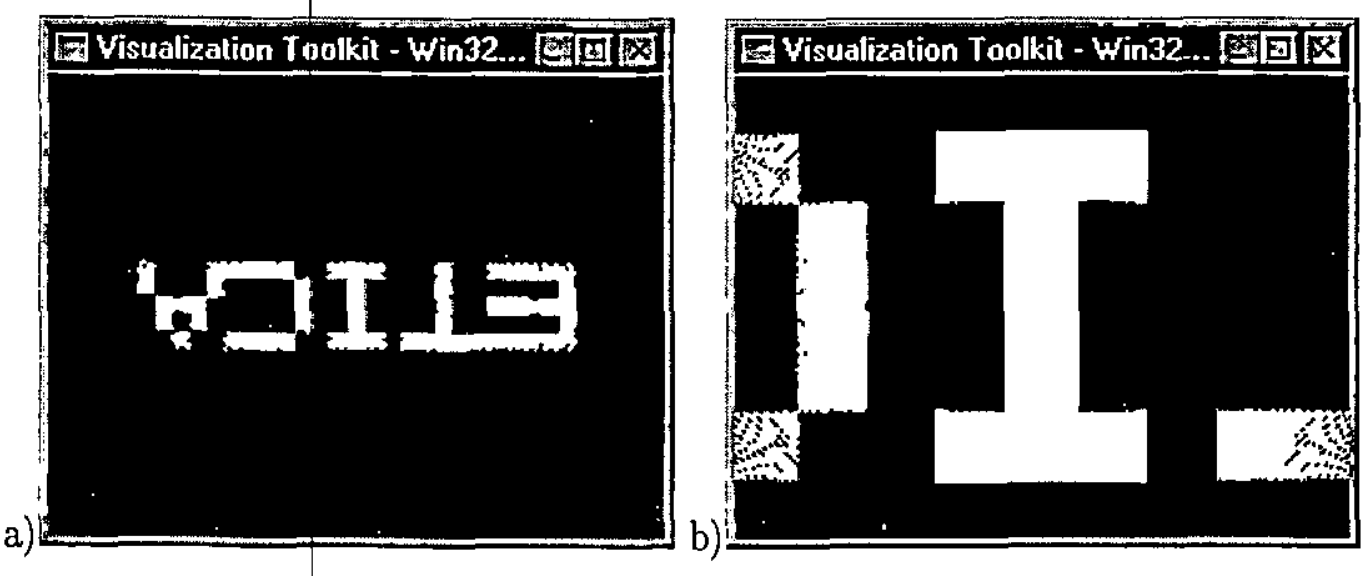

Figura 4.2: (a) Resultado da $1^{a}$ simulação (b) Resultado da $2^{a}$ simulação

a)
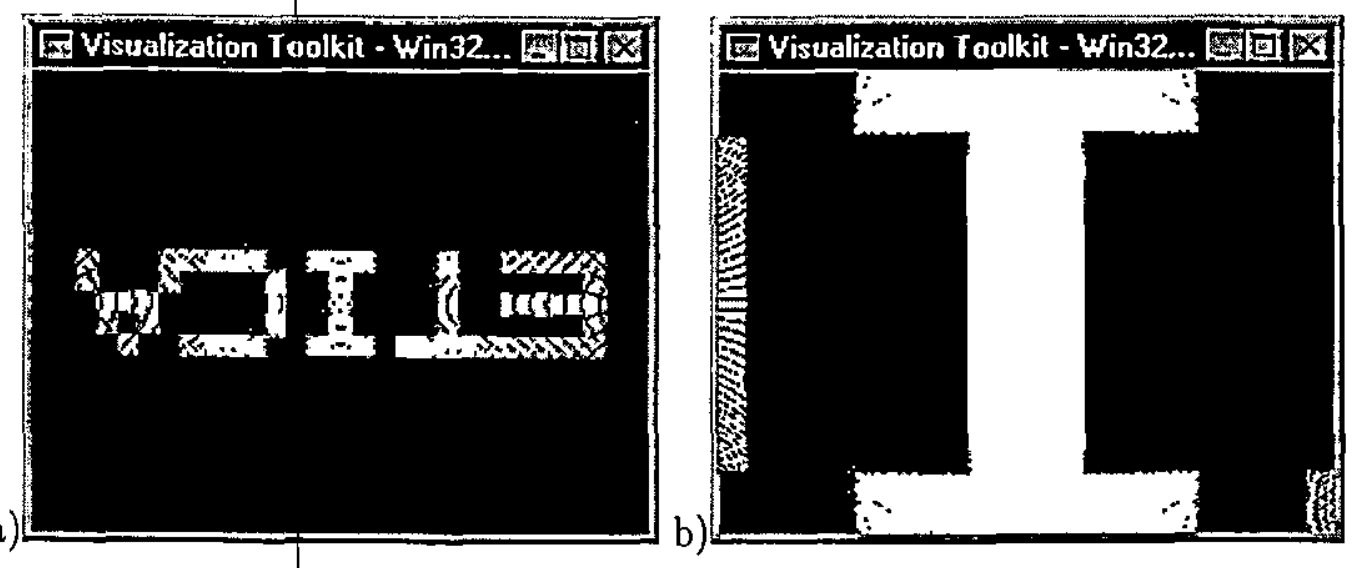

Figura 4.3: (a) Resultado da $3^{a}$ simulação (b) Resultado da $4^{a}$ simulação

Percebe-se claramente que a quantidade de raios que efetivamente formam a imagem da visão é apenas uma pequena parcela dos raios disparados e, assim mesmo, a imagem resultante apresenta uma qualidade satisfatória mantendo as propriedades esperadas para a imagem na retina (como, por exemplo, o fato da imagem aparecer invertida).

$\mathrm{Na}$ segunda simulaçăo, testou-se o efeito da variação da distância do optótipo. Esta simulação mostrou, com correção (Figura 4.2(b)), que aproximando o objeto do olho, este aparecerá maior na retina. As duas primeiras simulações mostram que o sistema é capaz de perceber corretamente as relações de perspectiva e proporção nas imagens resultantes (a qualidade das imagens resultantes é altamente dependente do refinamento da malha

\footnotetext{
${ }^{5}$ Adotou-se o valor $100.0 \mathrm{~mm}$ para os optótipos de tamanho fixo

${ }^{6} \mathrm{O}$ primeiro anel disparado é representado por um único ponto disparado sobre o ápice da córnea

${ }^{7} \mathrm{O}$ percentual apresentado na coluna raios disparados é relativo ao total de raios esperados, enquanto que, o percentual de raios na retina é relativo aos raios disparados
} 

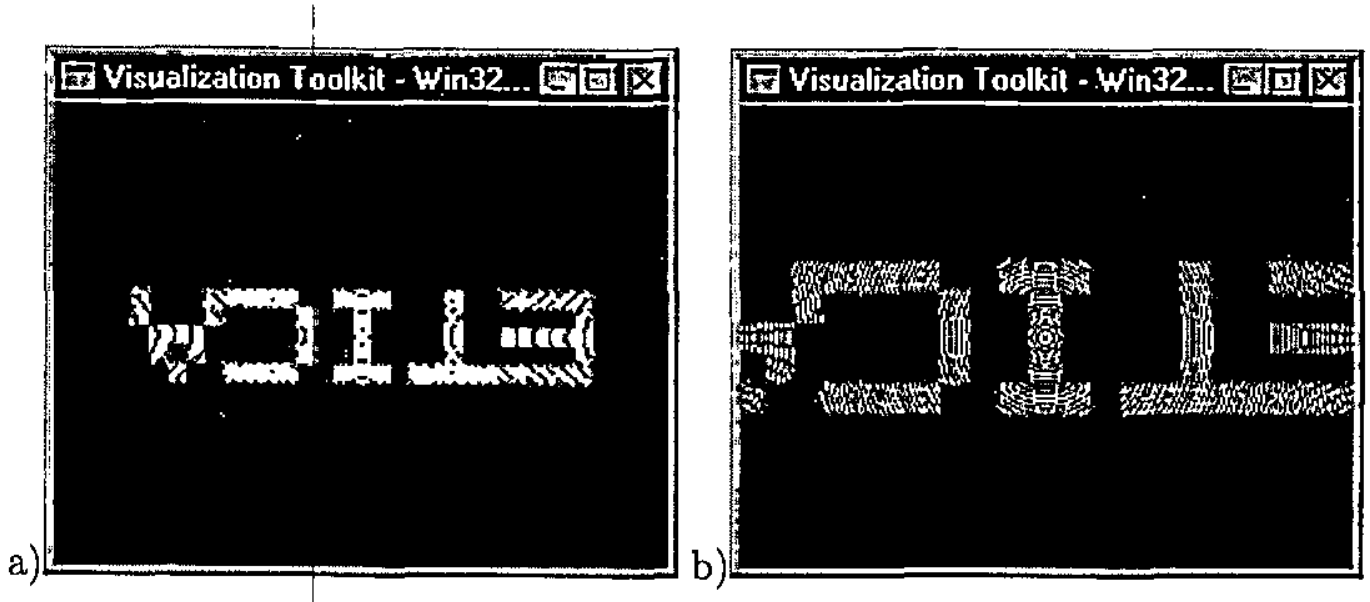

Figura 4.4: (a) Resultado da $5^{a}$ simulação (b) Resultado da $6^{a}$ simulação

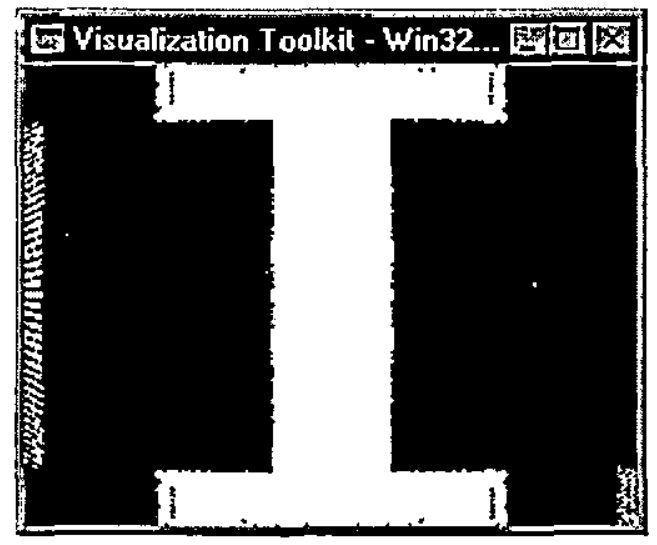

Figura 4.5: Resultado da $7^{a}$ simulação

da retina. Um refinamento melhor produziria melhores resultados).

As simulaçōes 3 e 4 testam o modelo automático de acomodação do cristalino. Através das imagens resultantes dessas simulações, percebe-se que o cristalino produz um leve aumento nas imagens (em relação às mesmas imagens sem o cristalino nas figuras 4.2(a) e (b)) melhorando a qualidade da imagem da visão. A seguir, as próximas duas simulações $\left(5^{a}\right.$ e $\left.6^{a}\right)$ se basearam na utilização do modelo de ajuste automático do tamanho dos optótipos, ou seja, o tamanho dos optótipos varia em função da distância destes com o olho. O capítulo 1 apresentou como é feito o cálculo para se determinar o tamanho de um optótipo em função da distância. Essas simulações têm a finalidade de representar os optótipos na tabela de Snellen (a variação do tamanho representa a mudança de linha na tabela).

Como os optótipos yariando com a distância têm a finalidade de representar um mesmo ângulo visual, esperava-se que as imagens resultantes fossem projetadas na retina 
com o mesmo tamanh (ou muito próximo). Apesar dos resultados apresentarem uma variação significativa com relação ao tamanho (ver Figuras 4.4 (a) e (b)), ela é pequena se comparado com os resultados obtidos nas simulações com o optótipo de tamanho fixo (ver simulações 3 e 4). Sendo assim, considerou-se os resultados aceitáveis.

O próximo componente a ser considerado nos testes realizados foi a pupila. A $7^{a}$ simulação (Figura 4.5) mostra os resultados obtidos onde a pupila foi parcialmente aberta (raio $1.5 \mathrm{~mm}$ ). Vale lembrar que, em um olho real, a abertura da pupila varia em função da quantidade de luz no ambiente. Porém, nos testes realizados, a quantidade de luz que entra no olho (número de raios disparados no ambiente) permaneceu constante, o que gera problemas nas imagens resultantes.

Como a quantidade de luz não foi considerada proporcional à abertura da pupila, ocorre o problema da ampliação da imagem resultante. A figura 4.6 ilustra o motivo para essa variação. Os raios de luz que entram no olho representam diferentes ângulos visuais com a pupila aberta e fechada.

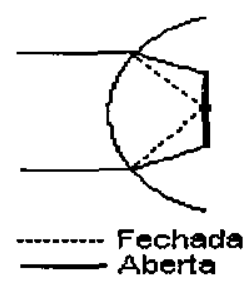

Figura 4.6: Ampliaçã indesejável da imagem resultante em simulações com a pupila aberta

Os exemplos acima citados são alguns dos testes realizados com a ferramenta para avaliação do modelo. Percebe-se que o modelo reflete a realidade sendo, porém impreciso em decorrência da resolução utilizada (principalmente na malha da retina). Aumentar porém essa resolução, aumentaria proporcionalmente o custo computacional podendo tornar o método inviável.

A próxima seção trata das simulações realizadas utilizando-se de uma topografia de córnea real para um olho emétrope, obtida através da parceria com pesquisadores do grupo de ótica oftálmica da USP/São Carlos.

\section{Modelo com dados reais de um olho emétrope}

Para as simulações com o chamado olho real, substituiu-se a córnea modelada por equação implícita pela malha poligonal triangular conforme já descrito nas seções anteriores.

O processo de simulação sofreu uma sensível redução no desempenho das simulações conforme a seção irá mostrar, mas, mesmo assim, os resultados são considerados satisfatórios pois as mesmas propriedades dos testes com o olho teórico foram preservadas. 
Para as simulações łom o olho com córnea real, utilizou-se os mesmos parâmetros dos testes realizados com ol olho teórico. Porém, conforme é ilustrado na figura 4.10(a), os resultados obtidos inicialmente foram muito abaixo do esperado.

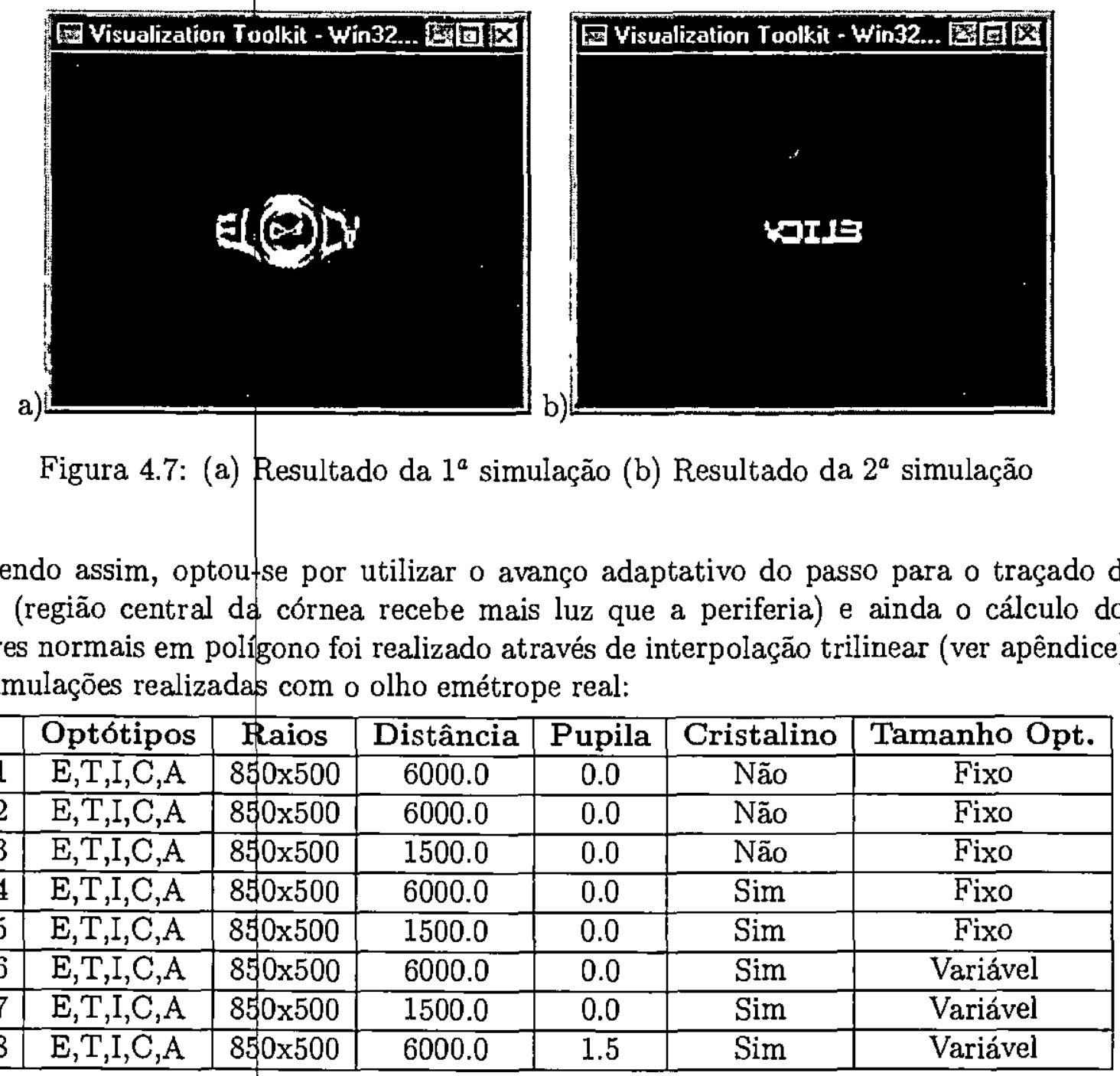

A seguir são apresentados os resultados das simulações.

\begin{tabular}{|l|c|c|c|}
\hline & Raios Esperados & Raios Disparados & Raios na Retina \\
\hline 01 & 424.501 & $22.001(5.18 \%)$ & $4.575(20.79 \%)$ \\
\hline 02 & 424.501 & $12.501(2.94 \%)$ & $2.074(16.59 \%)$ \\
\hline 03 & 424.501 & $116.001(27.32 \%)$ & $25.463(21.95 \%)$ \\
\hline 04 & 424.501 & $12.501(2.94 \%)$ & $2.074(16.59 \%)$ \\
\hline 05 & 424.501 & $116.001(27.32 \%)$ & $25.463(21.95 \%)$ \\
\hline 06 & 424.501 & $34.001(8.01 \%)$ & $6.269(18.43 \%)$ \\
\hline 07 & 424.501 & $34.001(8.01 \%)$ & $6.310(18.55 \%)$ \\
\hline 08 & 424.501 & $37.001(8.71 \%)$ & $6.115(16.52 \%)$ \\
\hline
\end{tabular}


Baseado nos resultados obtidos pelas simulações 6 e 7 é possível inferir que estes são semelhantes aos obtidos com o olho teórico. Como o tamanho dos optótipos varia para garantir que o olho visualize um objeto que represente 5' de grau, percebe-se que, com 0 auxílio da focalização proporcionada pelo cristalino, a imagem resultante na retina tende a permanecer com tamanho constante mesmo quando o objeto se afasta do observador.

Além das simulações utilizando-se dados de olhos reais emétropes, alguns teste também foram realizados para olhos que apresentavam algum tipo de ametropia. A próxima seção apresenta as simulações realizadas com essas córneas.
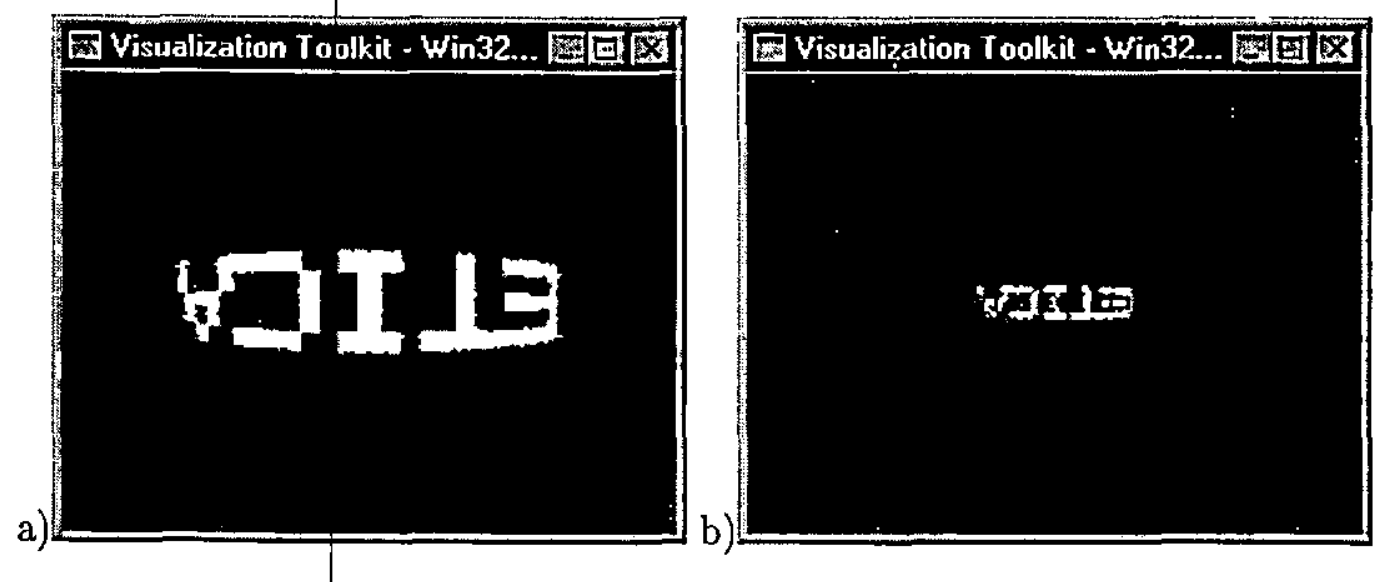

Figura 4.8: (a) Resultado da $3^{a}$ simulação (b) Resultado da $4^{a}$ simulação a)
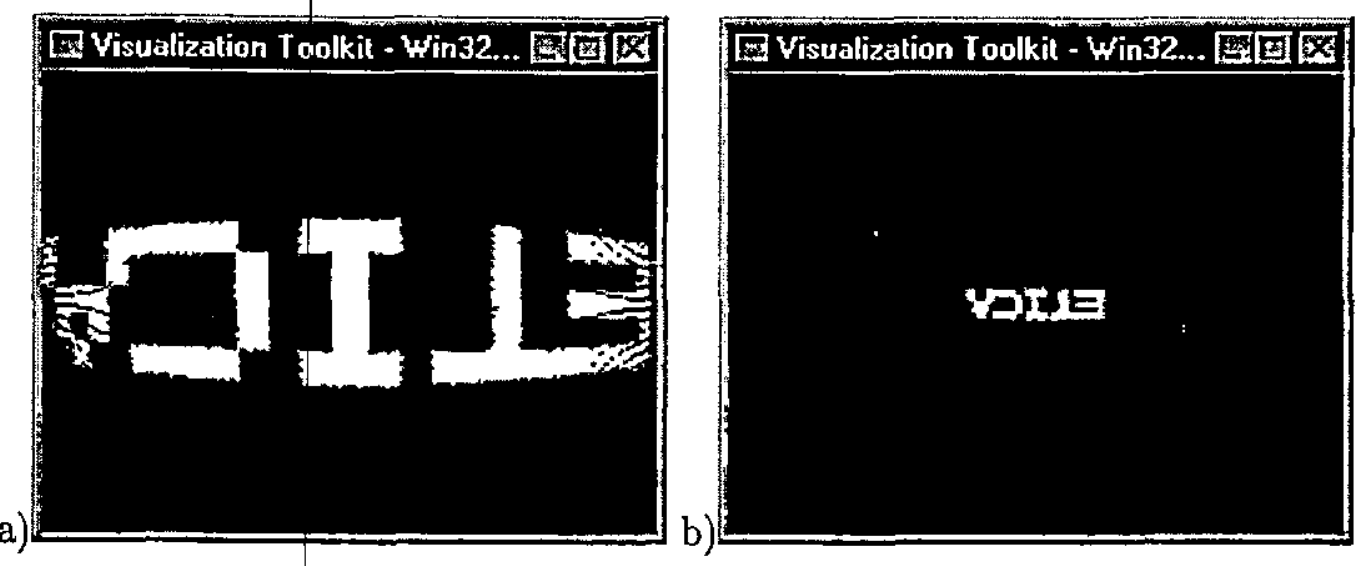

Figura 4.9: (a) Resultado da $5^{a}$ simulação (b) Resultado da $6^{a}$ simulação 

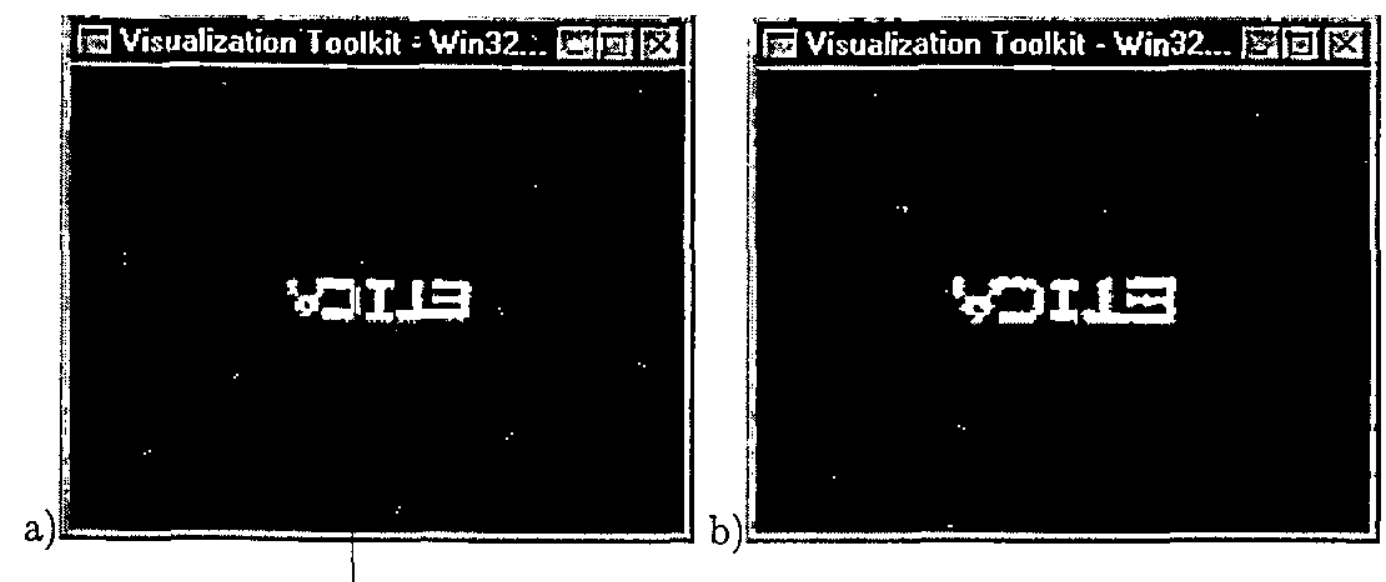

Figura 4.10: (a) Resultado da $7^{a}$ simulação (b) Resultado da $8^{a}$ simulação

Modelo com dados reais de um olho amétrope

Esta seção apresenta os resultados obtidos a partir de topografias de córneas que resultaram em ametropias dạ visāo. Serão apresentadas duas simulações: uma córnea com astigmatismo e outra com ceratocone (região com alta curvatura sobre a córnea semeIhante a uma elevação ou "calo"na superfície, conforme a figura 4.11).

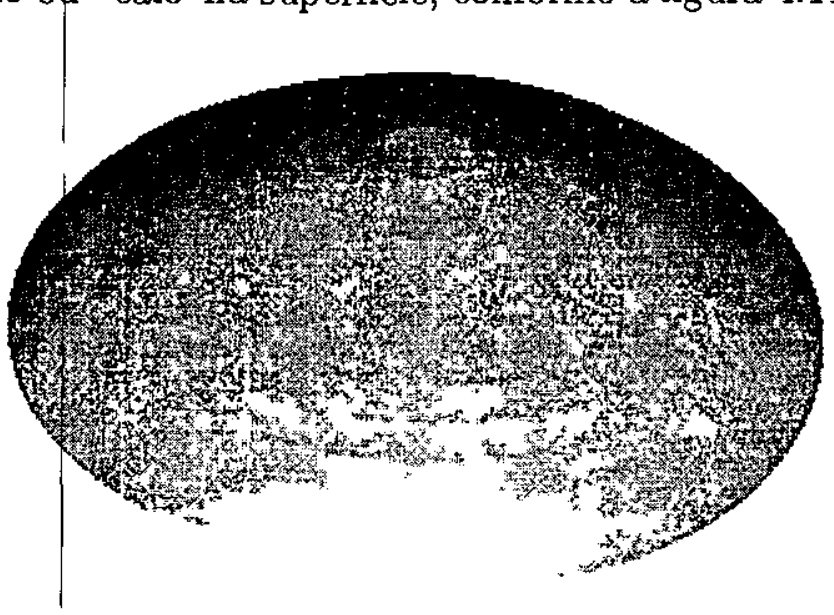

Figúra 4.11: Exemplo de córnea com ceratocone

Os parâmetros utilizados em ambas as simulaçōes foram:

\begin{tabular}{|c|c|c|c|c|c|}
\hline Optótipos & Raios & Distância & Pupila & Cristalino & Tamanho Opt. \\
\hline E,T,I,C,A & $850 \times 500$ & 6000.0 & 0.0 & Sim & Variável \\
\hline
\end{tabular}

A tabela abaixo ilustra os resultados obtidos. 


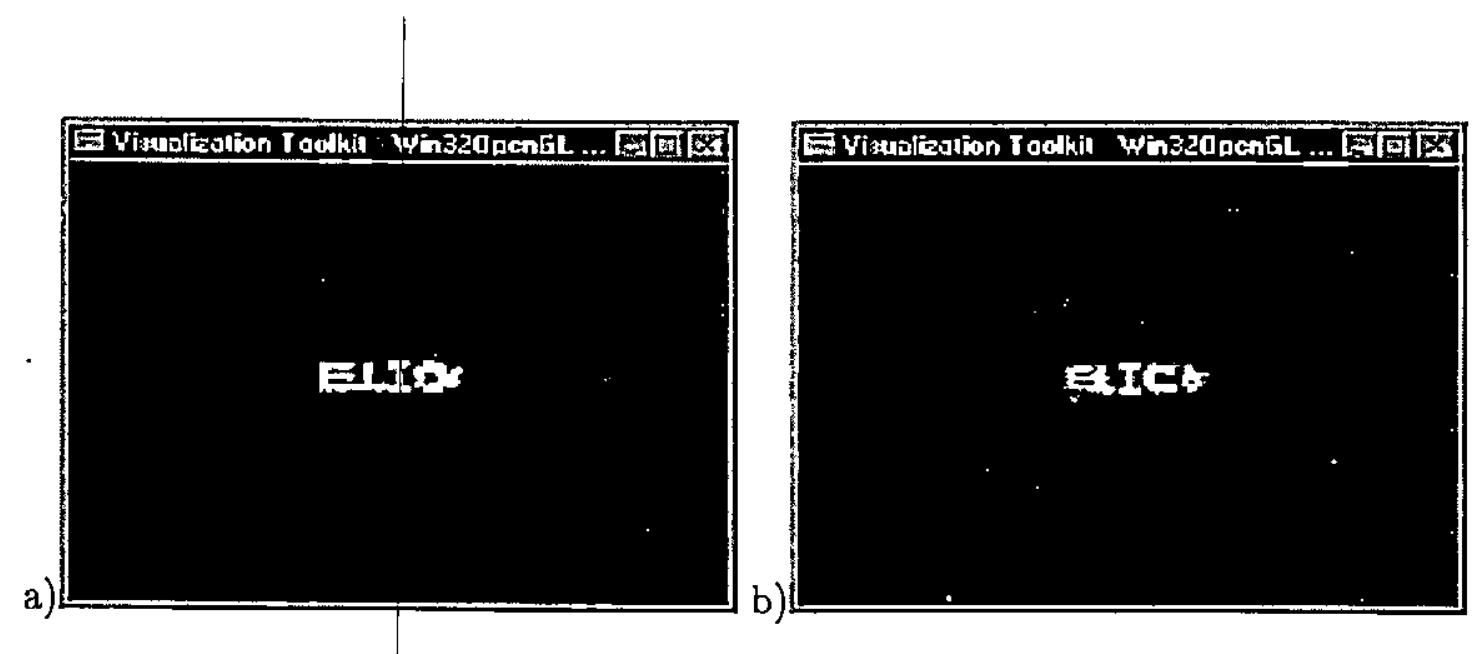

Figura 4.12: Resultados obtidos - a) Astigmatismo b) Ceratocone

\begin{tabular}{|l|c|c|c|}
\multicolumn{5}{l|}{} & \multicolumn{4}{l}{} \\
\hline & Raios Esperados & Raios Disparados & Raios na Retina \\
\hline Astigmatismo & 424.501 & $38.501(9.07 \%)$ & $4.608(11.96 \%)$ \\
\hline Ceratocone & 424.501 & $35.501(8.36 \%)$ & $5.385(15.16 \%)$ \\
\hline
\end{tabular}

Estas simulações demonstram que a ferramenta é capaz de tratar vários tipos de córneas sejam elas emétropes ou não. As simulações 4.12(a) e (b) demonstram que a ferramenta é capaz de simular ametropias, sendo os resultados dependentes de fatores como a discretização da córnea e o refinamento da malha da retina. Esses resultados podem servir como auxílio a profissionais no estudo de problemas inerentes à visão, sejam eles médicos ou estudantes de oftalmologia.

A próxima seção irá mostrar outra alternativa de simulação: forward ray-tracingque trata os raios partindo dos optótipos em direção ao olho.

\subsubsection{Forward Ray-Tracing}

A técnica forward ray-tracing apesar de ser uma representação realista do traçado de raios apresentou resultados diferentes do esperado para o problema estudado nesta pesquisa. Ela foi implementada ná tentativa de melhorar o desempenho do traçado da ferramenta, haja visto o baixo percentual de raios significativos à simulação obtidos através do método descrito anteriormente.

A idéia dessa alternativa é tratar como sendo a origem dos raios de luz disparados no ambiente, a superfície dos optótipos de Snellen. Para tal, determinou-se um círculo imaginário (Figura 4.13) que engloba a bounding box pertencente ao conjunto de optótipos, conforme já foi descrito na seção 3.6 do capítulo anterior. A função do círculo é delimitar uma região com maior probabilidade de ocorrerem raios significativos para a visão.

O processo para se determinar o círculo externo aos optótipos é:

- Determinar as coordenadas do centro da Bounding Box que engloba aos optótipos 


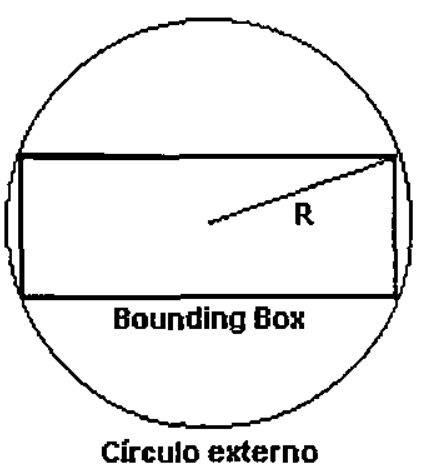

Figura 4.13: Círculo imaginário para traçado de raios a partir dos optótipos

$\left(C_{o p t}\right)$. Essas coordenadas coincidem com as coordenadas do centro do círculo externo;

- Calcular a distância entre o centro obtido e qualquer um dos quatro vértices que compõem o polígono. Esse valor representará o raio do círculo.

Um vez obtidos os parâmetros do círculo basta discretizá-lo de forma análoga ao processo já descrito para a discretização da pupila (ver seção 3.4). Essa discretização representa os pontos de origem dos raios sendo disparados no modelo. Os pontos de destino serão os mesmo discretizados pela alternativa backward ray-tracing.

Os resultados obtidos por esta técnica realmente melhoraram o aspecto do aproveitamento de raios disparados (ao contrário do suposto inicialmente, o desperdício de raios disparados diminuiu sighificativamente). O problema que se percebeu com as simulaçōes que utilizam essa alternativa, é o fato de que somente em simulaçōes com a pupila aberta se pode obter resultados satisfatórios, conforme é ilustrado na figura 4.14.

A simulação apresenta utilizou os seguintes parâmetros:

\begin{tabular}{|c|c|c|c|c|c|}
\hline Optótipos & Raios & Distância & Pupila & Cristalino & Tamanho Opt. \\
\hline E,T,I,C,A & $850 \times 500$ & 6000.0 & 4.0 & Sim & Variável \\
\hline
\end{tabular}

sendo os resultados apresentados na tabela abaixo:

\begin{tabular}{|c|c|c|}
\hline Raios Esperados & Raios Disparados & Raios na Retina \\
\hline 424.501 & 80.647 (18.99\%) & $80.641(99.99 \%)$ \\
\hline
\end{tabular}

A próxima seção discute a implementação da ferramenta e apresenta quais os módulos que a compõem. 


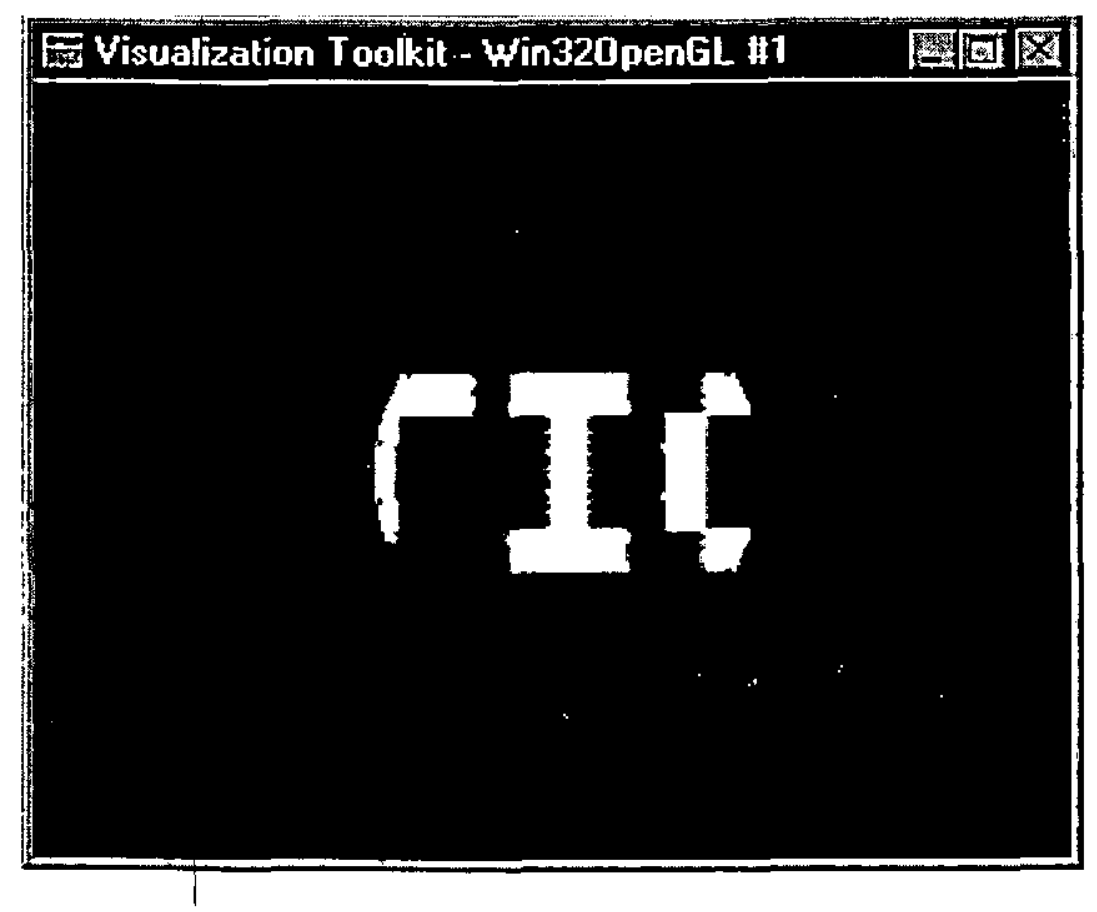

Figura 4.14: Restultado obtido por simulação usando Forward Ray-Tracing

\subsection{Os Módulos}

Este trabalho foi implementado utilizando a linguagem $\mathrm{C}++$ (Microsoft Visual Studio $\mathrm{C}++$ ) em conjunto com a biblioteca gráfica de visualização científica VTK - Visualization Toolkit[Sch98]. Esta biblioteca é de dominio público e implementa as principais técnicas de visualização científica e computação gráfica. Seu código é aberto, isto significa que é possivel se ter acesso a sua implementação e, assim, promover alterações e inclusões no mesmo, se necessário.

A ferramenta desenvolvida durante esta pesquisa é composta por 9 diferentes módulos: mainfile.cpp, EyeModel.cpp, Eye.cpp, CCrystalline.cpp, CCornea.cpp, Optotype.cpp, CMatrix.cpp, CLists.cpp e Defs.cpp.

O módulo mainfile. $c p p$, como o próprio nome sugere, é o módulo principal do programa. É nele que estão definidas todas as inicializações e solicitação de parâmetros de entrada ao usuário (ver seção 4.1).

O módulo que implementa a simulação propriamente dita é o EyeModel.cpp. código-fonte da definição da classe CEyeModel é descrito na figura 4.15.

O método CEyeModel::Simulate() é responsável pela realização da simulação descrita nas seções anteriores. Já o método CEyeModel::Visualize() utiliza a biblioteca VTK para exibir os resultados da simulação. Os demais métodos são responsáveis pela inicialização da classe. 


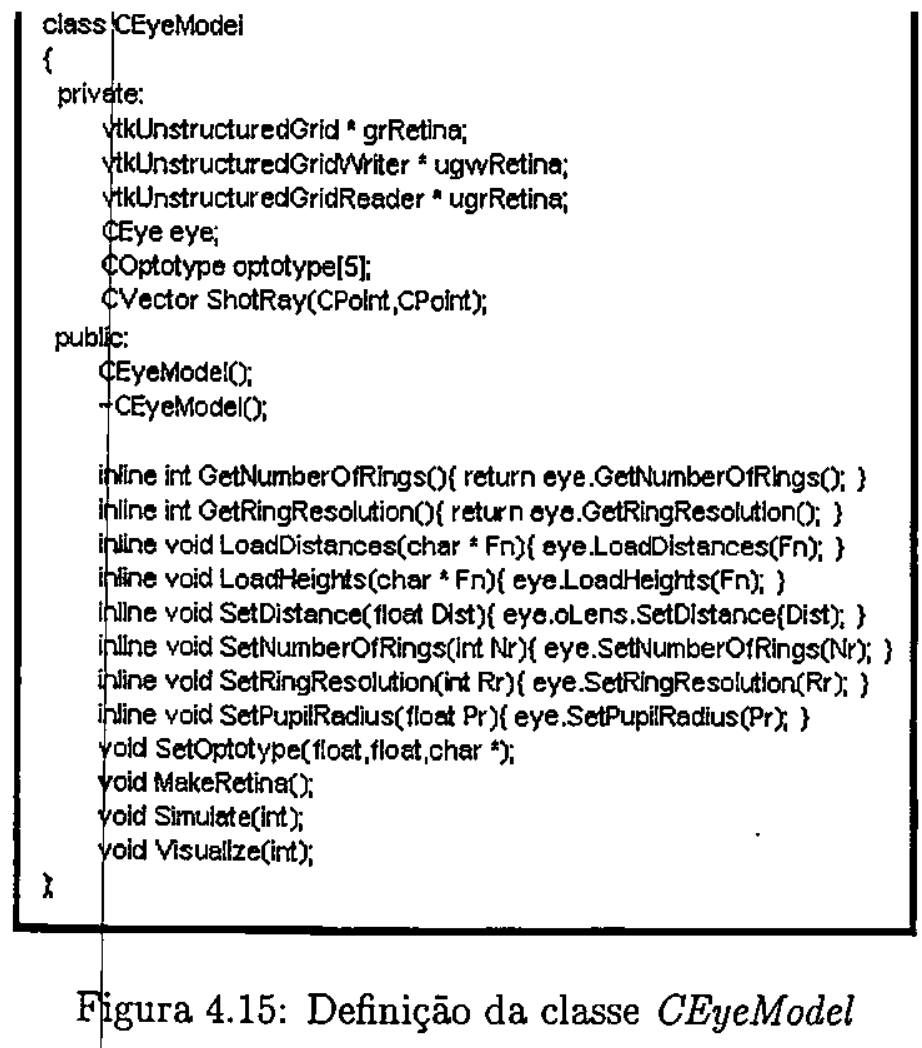

O módulo Eye.cpp implementa as rotinas referentes aos componentes do olho, cálculos de interseções de raios de luz com diferentes superfícies, de vetores normais às superfícies, entre outros. É neste módulo que são tratados a pupila e a córnea teórica (simulação feitas a partir da semi-esfera).

Como o cristalino é uma estrutura ocular que requeriu uma modelagem específica, foi criado o módulo CCrystalline.cpp. Este módulo trata das interações dos raios de luz com cada uma das superfícies do cristalino. É através do método CCrystalline::SetDistance() que a classe é capaz de adaptar automaticamente os valores dos raios e centros de curvatura de cada face do cristalino em função da distância, conforme já foi descrito na seção 3.3.

Outro módulo que foi criado para tratar um componente do olho em particular, foi o CCornea.cpp. Quando o simulador utiliza dados de topografias de córneas para, com isso, simular cóneas reais no sistema, a classe CCornea é ativada. Os métodos principais dessa classe são: CCornea::GetPoints() cuja função é (a partir dos valores lidos pela classe $C M a t r i x)$ gerar a malha poligonal que aproxima a superfície da córnea; CCornea::MakeGrid() que gera um vtkUnstructuredGrid ${ }^{8}$ para posterior visualização usando VTK (ver Figura 4.16); CCornea::SmoothGrid() que é o método responsável pela sua-

\footnotetext{
${ }^{8}$ Estrutura de malha poligonal do VTK
} 
vização da malha original (este processo é feito através do cálculo de sucessivas médias entre vértics vizinhos na malha) e ainda os métodos CCornea::LoadDistances() e CCornea::LoadHeights() cuja função é simplesmente enviar uma mensagem para a classe CMatrix ler as matrizes de distâncias e elevação para uma córnea. A figura 4.11 mostrou um exemplo de uma córnea gerada por esta classe.

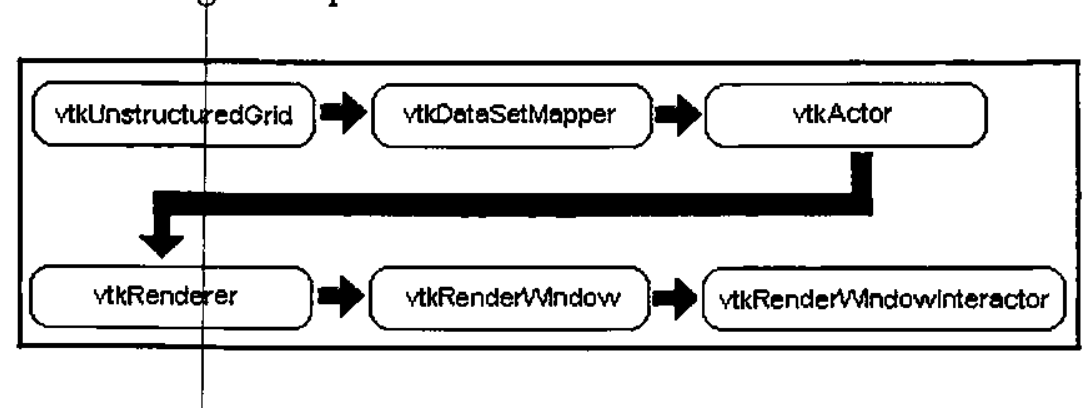

Figura 4.16: Pipeline de visualização usando biblioteca VTK

O próximo módulo a ser estudado é o Optotype.cpp o qual é bastante simples: sua função é a de criar e armazenar uma lista contendo os 5 optótipos utilizados na simulação. O principal método desta classe é o COptotype::SetPosition() responsável pela criação e posicionamento dos optốtipos em relação à distância dos mesmos ao observador.

O programa inclui aínda três módulos auxiliares: CMatrix.cpp que é responsável pela leitura dos dados armazenados no arquivo ASCII e sua posterior conversão numérica. O módulo CLists.cpp implementa uma estrutura de dados do tipo lista encadeada e serve para armazenar os vértices, arestas e polígonos das malhas utilizadas pelo sistema ${ }^{9}$. O último módulo do sistema (Defs.cpp) é tão somente um módulo para definição das constantes e tipos utilizados, bem como, de funções auxiliares como por exemplo, a função Norm Vector que é respqnsável pela normalização de vetores.

O ponto chave do processo de simulação usando ray-tracing está no cálculo das interseções dos raios de luz com os diversos componentes do olho. O cálculo utilizado em cada uma das estruturas é descrito, em maiores detalhes, no apêndice.

O próximo capítulo apresenta as conclusões da pesquisa, bem como sugestões de aperfeiçoamento e implementação de novas funcionalidades na ferramenta.

\footnotetext{
${ }^{9}$ Esta classe foi implementada baseada numa estrutura template (lista encadeada genérica) 


\section{Capítulo 5}

\section{Conclusões e Trabalhos Futuros}

Baseado nos resultados apresentados, conclui-se que simular o funcionamento ótico do sistema visual humano é uma tarefa extremamente complexa. Existem diversos fatores que influenciam nos resultados finais, como problemas inerentes ao conhecimento médico com relação ao olho (não há dados seguros sobre vários aspectos aqui considerados na pesquisa, tais como, a forma e dimensões reais do cristalino, assim, utilizou-se um modelo aceito entre oftalmologistas).

Apesar das dificuldades encontradas, várias conclusōes preliminares podem ser obtidas. A primeira e mais importante é que considera-se que o objetivo inicial desta pesquisa foi atingido. Provou-se que é possível criar um modelo matemático do olho humano e, a partir dele, simular seu funcionamento ótico. E ainda, de posse de aparelhos capazes de efetuar aferições de tamanho e forma dos componentes do olho, seria possível criar um modelo baseado em dados reais de olhos humanos, o que permitiria tornar a ferramenta de simulação, uma ferramenta de auxílio a médicos e estudantes de oftalmologia.

Considera-se que este trabalho tenha sido um importante ponto de partida para que se possa simular o funciфnamento do sistema visual humano de maneira completa e precisa. A aplicação de técnicas de traçado dos raios de luz em ambientes tridimensionais permitiria o desenvolvimento de uma grande quantidade de aplicações relacionadas à oftalmologia, tais como a simulação de lentes corretivas para ametropias (Figura 5.1). O médico poderia, através de uma ferramenta de simulação do sistema visual, analisar vantagens e desvantagens do uso de uma lente específica para a correção da ametropia aferida, aumentando assim a precisão e confiabilidade de diagnósticos. Outra aplicação seria a simulação de cirurgias em córneas para se analisar os reais ganhos da intervenção, na melhoria da qualidade da visão do paciente.

Outras sugestões para possíveis melhoramentos do trabalho realizado seria a modelagem da superfície da córnea por superfícies splines [Fol90, Hea97], o que permitiria (em teoria) aumentar a qualidade da imagem simulada devido ao fato de estar-se trabalhando com uma superfície "contínua" ao invés de uma discretizada. Outra melhoria prevista com o uso dessa modelagem seria no desempenho da ferramenta (é mais rápido tratar a interação da luz com uma equação implícita do que com uma malha poligonal). Ainda como 


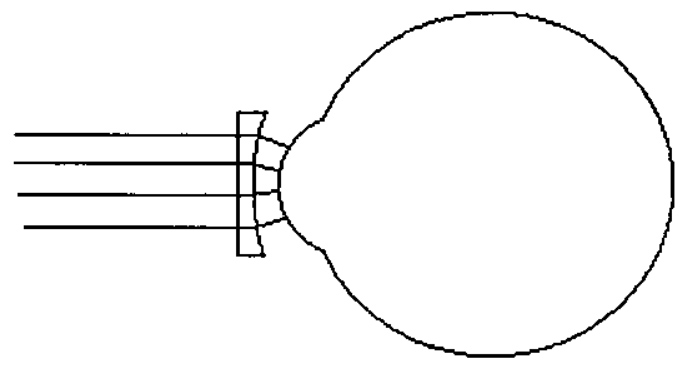

Figura 5.1: Simulações de lentes corretivas

sugestão de melhoramentio, temos o estudo de um modelo de iluminação mais realista que considere a abertura da pupila e consiga determinar a quantidade de luz necessária para a simulação, permitindo com isso, produzir resultados ainda mais precisos.

Permitir ao olho visualizar imagens coloridas poderia ser um importante passo para a criaçāo de uma ferramenta de auxílio a pesquisadores (médicos ou estudantes).

Acredita-se que os resultados tenham sido promissores, sendo assim, espera-se que este trabalho sirva de incentiyo para novas pesquisas na área, dada a importância do tema. 


\section{Apêndice A}

O cálculo das interseções se diferencia de estrutura para estrutura e apesar de já terem sido descritos nos capítulos anteriores, existem peculiaridades de cada uma. Serão essas peculiaridades que serão descritas aqui.

A primeira estrutura a receber a luz (segundo a estratégia utilizada na simulação e descrita na seção 4.1.1) é a córnea. A córnea foi modelada de duas formas distintas: equação implícita e malha poligonal. Através de equação implícita, o cálculo de possíveis interseç̧ões é exclusivamente algébrico e já foi descrito na seção 2.3.2. Com relação ao cálculo de interseç̧ões na malha poligonal, o processo é mais complexo.

A estratégia para definir se uma malha poligonal foi interseptada por um certo raio de luz é um processo custoso computacionalmente. É necessário que se percorram todas as faces da lista original, efetuando-se a verificação de intersecção em cada polígono separadamente $^{1}$, até que se encontre uma intersecção ou se tenha percorrido a lista por completo, indicando assim, a ausência de intersecções. Para que fosse possível alguma otimização nesse processo, optou-se por ordenar a lista de polígonos conforme já foi descrito na seção 3.5. Essa ordenação permitiu que, ao invés de ser necessária a verificação de todos os polígonos, apenas alguns poucos seriam verificados, diminuindo significativamente o tempo de processamento.

Como os polígonos săo armazenados segundo uma ordem polar (coordenadas polares), a idéia é processar apenas os polígonos que estejam em uma região da malha (fatia) próxima ao ângulo de disparo do raio de luz ${ }^{2}$. Essa região é definida pelos polígonos que dado um certo ângulo $\theta$ estejam na região $\left[\theta-1^{\circ} . . \theta+1^{\circ}\right]$, conforme a figura A.1.

Utilizando-se essa alternativa pode-se determinar o ganho de tempo de busca como sendo a diferença no número de polígonos a serem processados. Na primeira alternativa (busca em toda a lista), temos $360^{\circ}$ com 16 anéis por raio mais os 360 polígonos que completam a região central da malha, o que resulta em $16 \cdot 360+360=6120$ polígonos a serem testados. Enquanto que, ao utilizarmos a ordenação de lista e busca por fatia, a procura se resume a 3 graus (ao invés dos $360^{\circ}$ do método anterior) e sabendo-se que cada raio possui 2 polígonos temos $16 \cdot 2 \cdot 3=96$ polígonos.

\footnotetext{
${ }^{1} \mathrm{O}$ cálculo de intersecção raio/polígono é descrito em detalhes no capítulo 2

${ }^{2}$ Esse ângulo é obtido enquanto se discretizam pontos na superfície da pupila (ver seção 3.4)
} 


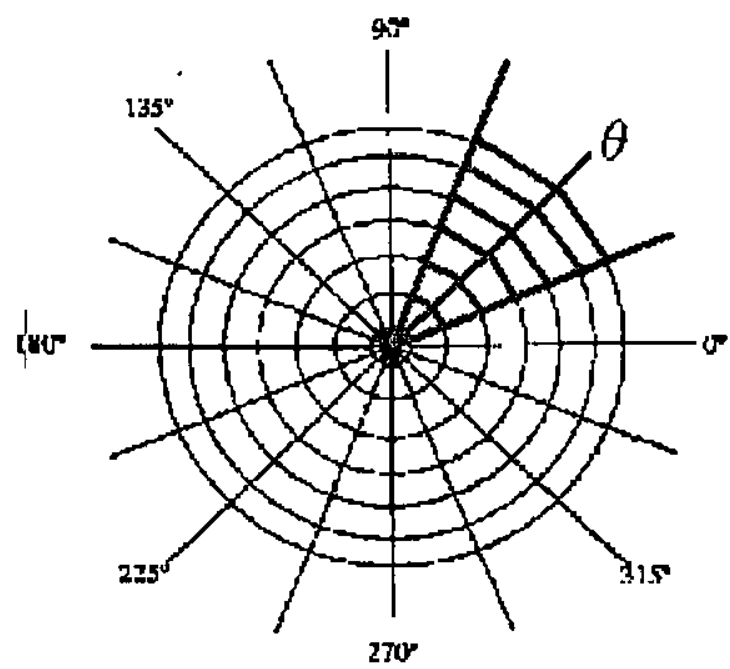

Figura A.1: Cálcuıło otimizado de intersecções da luz com uma malha poligonal

Para se determinar quais polígonos devem ser testados para um certo valor de $\theta$, utilizase a equação A.1 abaixo (buscam-se os polígonos que estejam entre $[$ Inicio, Fim $])^{3}$ :

$$
\begin{aligned}
& \text { Angulo_Cart }=\frac{0 \cdot 360}{2 \pi} \\
& \text { Angulo_Cart }=\text { Angulo_Cart }==0 ? 360: \text { Angulo_Cart } \\
& \text { Prev }=(\text { Angulo_Cart }-1)>0 ? \text { Angulo_Cart }-1: 360 \\
& \text { Next }=(\text { Angulo_Cart }+1)<360 ? \text { Angulo_Cart }+1: 1 \\
& \text { Inicio }=(\text { Prev-1) } 31+1 \\
& \text { Fim }=\text { Next } \cdot 31
\end{aligned}
$$

Uma vez determinado o ponto de intersecção da reta com um dos polígonos da malha, a próxima etapa é determinar o vetor normal ao ponto. Foram implementadas duas técnicas para essa finalidade: a primeira considera todos os pontos de um polígono como tendo o mesmo vetor normal (Figura A.2(a)). A outra alternativa suaviza significativamente a imagem resultante pois executa uma interpolação trilinear nas coordenadas do vetor normal, em função das normais calculada para os vértices dos polígonos (Figura A.2(b)).

Para se determinar a normal a um vértice, faz-se a composição (média) entre todas as faces que compartilham o vértice. Para se determinar a normal a um ponto arbitrário $(P)$ sobre o polígono (Figura A.3), utilizam-se as coordenadas baricêntricas do triângulo que diz que um ponto pode ser escrito como uma combinação linear dos vértices $(A, B, C)$ do triângulo conforme a equação A.2.

\footnotetext{
${ }^{3}$ Código-fonte em $\mathrm{C}++$
}

$$
P=\alpha \cdot A+\beta \cdot B+\gamma \cdot C
$$




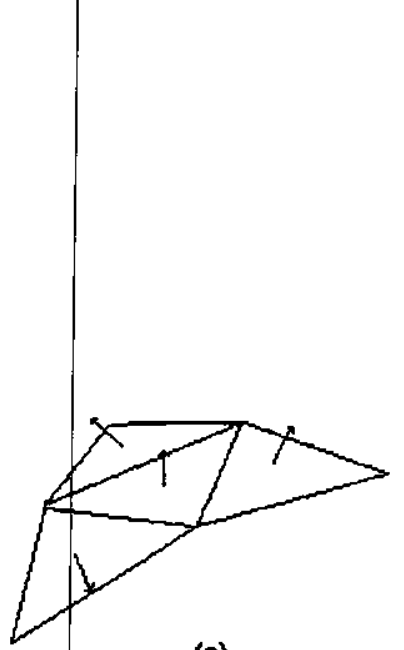

(a)

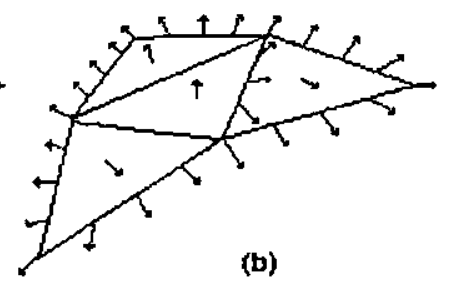

(b)

Figura A.2: Interpolação trilinear das normais em um polígono

onde:

e ainda:

$$
\begin{gathered}
\alpha+\beta+\gamma=1 \\
\alpha=\frac{\text { Area } P B C}{\text { Area }_{A B C}} \\
\beta=\frac{\text { Arrea } A P C}{\text { Area }_{A B C}} \\
\gamma=\frac{\text { Area } A B P}{\text { Area }_{A B C}}
\end{gathered}
$$

onde $A r e a_{A B C}$ representa a área do triângulo formado pelos vértices $A, B, C$. Para se determinar a área de um triângulo, inicialmente definem-se dois vetores $\left(\vec{V}_{1}, \vec{V}_{2}\right)$ a partir de um dos vértices (em direção aos outros dois vértices) e, então, através da equação A.5 determina-se seu valor.

$$
\operatorname{Area}_{A B C}=\frac{1}{2} \cdot\left|\vec{V}_{1} \times \vec{V}_{2}\right|
$$

Figura A.3: Coordenadas baricêntricas de um ponto em um triângulo

Outro componente da simulação que apresenta particularidades no cálculo das interseç̧ões é o optótipo. Para determinar se um optótipo foi interseptado por um raio é necessário realizar dois passos:

1. Verificar se houve intersecção do raio com o bounding box (polígono externo que engloba todos os demais);

2. Verificar se o mesmo raio intercepta pelo menos um polígono interno preto (valor 0 na matriz binária gerada). 
Para definir quais poligonos internos devem ser testados, utiliza-se a matriz binária que armazena o optótipo. Todos os elementos cujo valor seja preto (0) deverão ser testados, os demais podem ser desconsiderados. Se o raio interceptar um polígono, todos os demais podem ser desconsiderados e o processo é encerrado sendo o optótipo considerado interceptado.

Analogamente ao processo de cálculo de intersecção para a córnea teórica temos o cálculo para o cristalino e a retina, onde o processo é realizado algebricamente. A única particularidade é que no caso do cristalino, o processo é realizado duas vezes (uma para cada face). 


\section{Referênciąs Bibliográficas}

[Alv94] Alves, Aderbal de Albuquerque, "Biblioteca Brasileira de Oftalmologia - Refração", cap. 17, pág. 109 a 122, Editora Cultura Médica, 2a. Ed., 416 p., 1994.

[Ass99] Assis, Jesus de Paula, "Revista Superinteressante", Ano 13, N. 11, pg. 60-66, Novembro, Editora Abril, 1999.

[Bro92] Brodlie, K.W, Carpenter, L.A., Earnshaw, R.A., Gallop, J.R., Hubbold, R.J., Mumford, A.M., Osland, C.D. e Quarendon, P. (eds.), "Scientific Visualization - Tecniques and Applications", Springer-Verlag, 284 p., 1992.

[Car96] Carvalho, Luis A V. de, "Desenvolvimento de um Instrumento Computadoriza. do para Medida da Curvatura da Córnea Durante o Ato Cirúrgico", Dissertação de Mestrado apresentada ao IFSC/USP, São Carlos, 115 p., 1996.

[Ces95] César, Carlos N.L., "Um Módulo para a Visualização eficiente de Sólidos BRep", Dissertação de Mestrado apresentada ao ICMC/USP, São Carlos, 98 p., 1995.

[Fer77] Ferreira, A. B. H., "Minidicionário A urélio". Ed. Nova Fronteira, 506 p., 1977.

[Fil99] Filho, Ogê M. e Neto, Hugo V., "Processamento Digital de Imagens", Brasport Ed., 406 p., 1999.

[Fol90] Foley, James D., van Dam, Andries, Feiner, Steven K. e Hughes, John F., "Computer Graphics - Principles and Practice", Addison-Wesley, 1174 p., 1990.

[Gal95] Gallagher, Richard S. (ed.), "Computer Visualization", CRC Press, 312 p.,1995.

[Gla91] Glassner, Andrew S. (ed.), "An Introduction to Ray Tracing", Academic Press, 329 p., 1991.

[Gon93] Gonzalez, R.C. e Woods, R.E. "Digital Image Processing", Addison-Wesley, 716 p., 1993. 
[Gra80] Le Grand Y.le El Hage, S.G. "Physiological Optics", Springer Series in Optical Sciences, Sptinger-Verlag, vol. 13, 335 p., 1980.

[Har92] Haralick, Robert M. e Shapiro, Linda G., "Computer and Robot Vision", Addison-Wesley, vol. I, 672p., 1992.

[Hea97] Hearn, Donald e Baker, Pauline M., "Computer Graphics", Prentice Hall, 652 p., 1997.

[Hoh96] Höhne, Karl Heinz e Kikinis, Ron (eds.), "Visualization in biomedical computing :4th International Conference - VBC '96", vol. 1131, Hamburgo, Alemanha, Setembfo 22-25, Proceedings, 610 p., Springer-Verlag, 1996.

[Lim90] Lim, Jae S., "Two-Dimensional Signal and Image Processing", Prentice Hall, 694 p., 1990.

[Min97] Minghim, R. e Oliveira, M.C.F., "Uma Introdução à Visualização Computacional", XVł Jornada de Atualização em Informática - XVII Congresso da Sociedade Brasileira de Computação, pg. 85 a 127, 1997.

[Ned99] Nedel, Luciana Porcher, Freitas, Carla Maria dal Sasso e Manssour, Isabel Harb. "Computação Gráfica e Medicina". XII Simpósio Brasileiro de Computação Gráfica e Processamento de Imagens - Minicursos. Campinas-SP, Brasil, 1999.

[Ped87] Pedrotti, Frank L. e Pedrotti, Leno S., "Introduction to Optics", cap. 9, pág. 192 a 213, Prentice Hall, 551 p., 1987.

[Rog85] Rogers, David F., "Procedural Elements for Computer Graphics", McGraw Hill, 433 p., 1985.

[San93] Sanders, Donald R. e Koch, Douglas D. (eds.), "An Atlas of Corneal Topography", Slack Ed., 209 p., 1993.

[Sch98] Schroeder, W. J., Martin, K. e Lorensen, B. "The Visualization Toolkit - An Object-Oriented Approach to $3 D$ Graphics", 2 Edição, Prentice Hall, 826 p., 1998.

[Tay99] Taylor, Chris e Colchester, Alan (eds.). "Medical Image Computing and Computer-Assisted Intervation - MICCAI'gg", Second International Conference, Proceedings, Springer Ed., vol. 1679, 1240 p., Cambridge-UK, Setembro, 1999.

[Tha90] Thalmann, Daniel (ed.), "Scientific Visualization and Graphics Simulation", Wiley Ed., 264 p., 1990. 
[Udu91] Udupa, J.K.|e Herman, G.T. "3D Imaging in Medicine", 'CRC_Press,_347.p., 1991.

[Ven94] Ventura, Liliane, Sousa, Júlio de F. e Castro, Jarbas C., "Desenvolvimento de um Sistema para Diagnóstico de Erros Refrativos Oculares", Revista de Física Aplicada e Instrumentação, vol. 9, N. 2, pg. 55-60, Junho, 1994.

[Ven96] Ventura, Liliane, Sousa, Sidney J.F., Masili, Mauro, Santos, Luis E.R., Vieira, Luis A.C e Castro, Jarbas C., "Desenvolvimento de um 'software' para a determinação dutomatizada de miopia, hipermetropia e astigmatismo oculares", Revista de Fłsica Aplicada e Instrumentação, vol. 11, N. 2, pg. 77-83, Junho, 1996.

[Weg92] Wegner, T., "Image Lab", Berkeley, 423 p., 1992.

[Wel93] Wells, D., Young, C e Farmer, D., "Criaçôes em Ray Tracing", Berkeley, 558 p., 1993. 